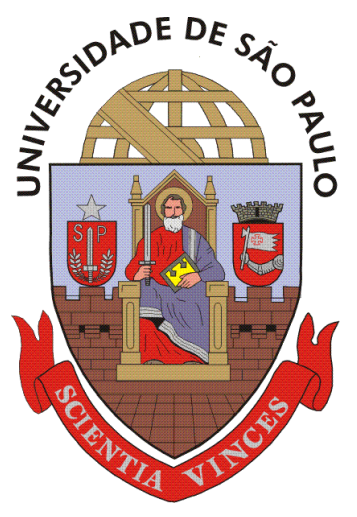

Universidade de São Paulo - USP

Escola de Engenharia de São Carlos - EESC

Departamento de Engenharia Elétrica

Programa de Pós-Graduação em Engenharia Elétrica

\title{
Estudos de sistemas OFDM para Comunicações Ópticas
}

\section{Willian Câmara Corrêa}

São Carlos, SP 



\section{Willian Câmara Corrêa}

\section{Estudos de sistemas OFDM para Comunicações Ópticas}

Dissertação de mestrado apresentada à Escola de Engenharia de São Carlos da Universidade de São Paulo, como parte dos requisitos para obtenção do título de Mestre em Ciências Programa de Engenharia Elétrica. Área de Concentração - Telecomunicações.

Orientador: Prof. Dr. Amílcar Careli César

São Carlos

2012

Trata-se da versão corrigida da dissertação. A versão original se encontra disponível na EESC/USP que aloja o Programa de Pós-Graduação de Engenharia Elétrica. 
Autorizo a reprodução e divulgação total ou parcial deste trabalho, por qualquer meio convencional ou eletrônico, para fins de estudo e pesquisa, desde que citada a fonte.

Ficha catalográfica preparada pela Seção de Tratamento

da Informação do Serviço de Biblioteca - EESC/USP

Corrêa, Willian Câmara

C824e $\quad$ Estudos de sistemas OFDM para comunicações ópticas. / William Câmara Corrêa ; orientador Amílcar Careli César. -- São Carlos, 2012 .

Dissertação (Mestrado - Programa de Pós-Graduação em Engenharia Elétrica e Área de Concentração em Telecomunicações) -- Escola de Engenharia de São Carlos da Universidade de São Paulo, 2012.

1. OFDM óptico. 2. QAM. 3. Detecção direta. 4. Detecção coerente. 5. Rede óptica de acesso. I. Título 


\section{FOLHA DE JULGAMENTO}

\section{Candidato: Bacharel WILLIAN CÂMARA CORRÊA.}

Titulo da dissertação: "Estudos de sistemas OFDM para comunicações ópticas",

Data da defesa: 03/10/2012

\section{Comissão Julgadora:}

Prof. Titular Amílcar Careli César (Orientador)

(Escola de Engenharia de São Carlos/EESC)

Profa. Dra. Mônica de Lacerda Rocha

(Escola de Engenharia de São Carlos/EESC)

Prof. Dr. Carlos Alberto de Francisco

(Universidade Federal de São Carlos/UFSCar)
Resultado:

$\triangle P R O V \triangle D O$

APRONADO

AAROVADO

Coordenador do Programa de Pós-Graduação em Engenharia Elétrica e Presidente da Comissão de Pós-Graduação:

Prof. Titular Denis Vinicius Coury 



\section{Dedicatória}

Dedico este trabalho aos meus pais Julio de Oliveira Corrêa e Antônia Gerônimo Câmara Corrêa. Meu amor por vocês não cabe em palavras. 



\section{Agradecimentos}

Agradeço inicialmente a Deus pela saúde e paz para desenvolver este trabalho. Todas as dificuldades, sem exceção, contribuíram para meu engrandecimento.

Ao professor Dr. Amílcar Careli Cesar, pela orientação, confiança e paciência ao longo desses anos, meu muito obrigado.

À professora $\mathrm{Dr}^{\mathrm{a}}$ Mônica de Lacerda Rocha pelos ensinamentos de comunicações ópticas e incentivo ao trabalho desenvolvido.

Ao Dr. Helvécio Moreira de Almeida Neto pela visão das aplicações práticas deste trabalho.

Ao professor Dr. Emerson Carlos Pedrino pelos ensinamentos técnicos, profissionais e amizade.

À minha namorada Larissa Bueno, pela compreensão e carinho ao longo dos últimos meses.

A todos meus colegas do departamento de computação da UFSCar, pela amizade e incentivo.

Aos meus amigos Evelton Cardoso, Augusto Cesar e Paulo César (Paulinho) pelos momentos de descontração e informação no DC/UFSCar.

Aos funcionários do Departamento de Engenharia Elétrica da EESC/USP, pelo suporte e aos demais pertecentes à instituição.

Aos colegas e amigo(a)s do Departamento de Engenharia Elétrica, Arturo, Larissa, Mariana, Nereida, Rafael e Thiago pelos conhecimentos transmitidos, amizade e bom humor.

Aos meus amigos do prédio, Sérgio Toledo, Jorge e Gabriel pelos momentos de descontração e informação.

À minha amiga Débora Scopim pela revisão final desta dissertação.

À Juliana Vidal da biblioteca EESC-USP, pelas informações técnicas de formatação do texto. A todos que contribuíram direta e indiretamente para a realização deste trabalho.

Meus Sinceros Agradecimentos. 



\section{Sumário}

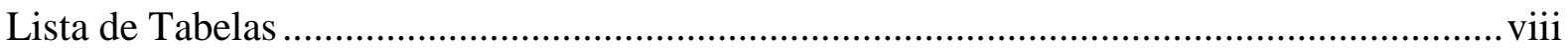

Lista de Abreviaturas, Siglas e Acrônimos ................................................................................. ix

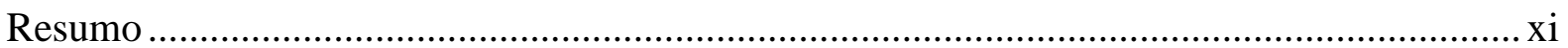

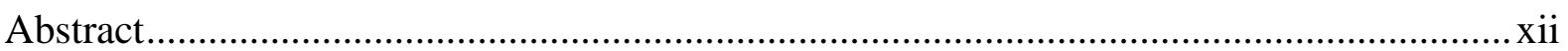

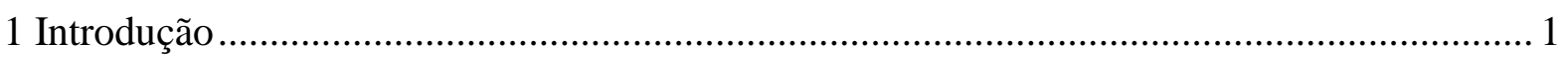

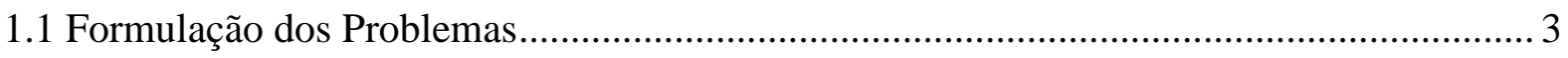

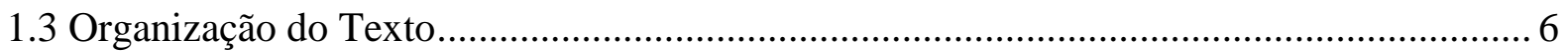

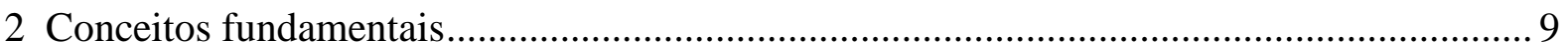

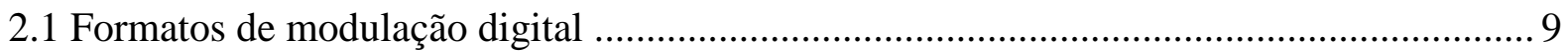

2.2 Modulação de amplitude em quadratura (QAM - quadratura amplitude modulation) ..... 12

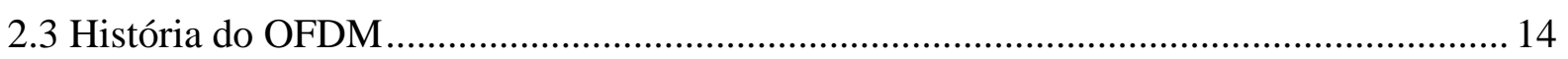

2.4 Multiplexação por divisão de frequência (FDM) …...................................................... 15

2.5 Multiplexação por divisão de frequências ortogonais (OFDM) ....................................... 16

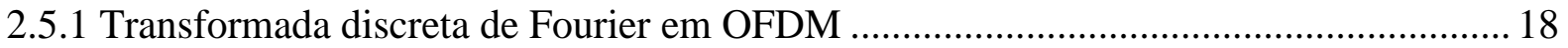

2.6 Componentes da arquitetura OFDM-QAM no Optisystem........................................... 19

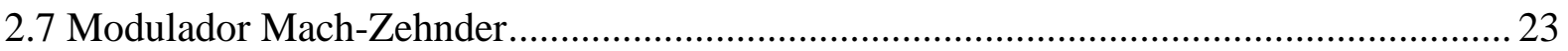

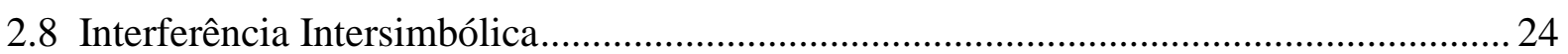

2.9 Prefixo Cíclico (CP - cyclic prefix) e equalização adaptativa ......................................... 26

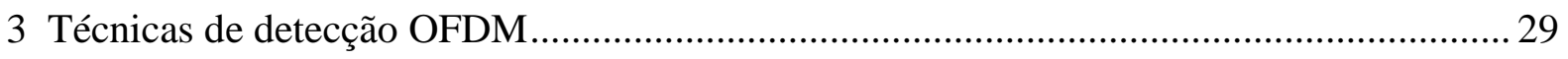

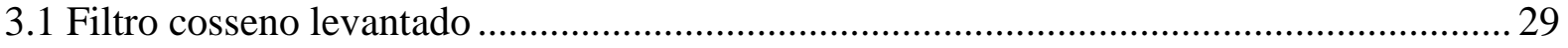

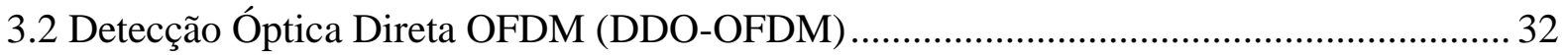

3.2.1 Detecção óptica direta linearmente mapeada ................................................................... 34

3.2.2 Detecção óptica direta mapeada de forma não linear ..................................................... 39

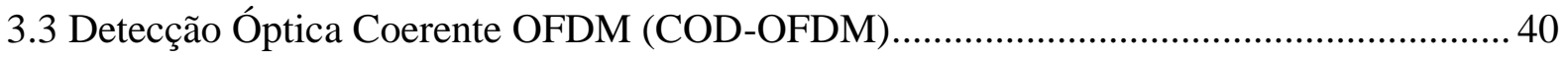

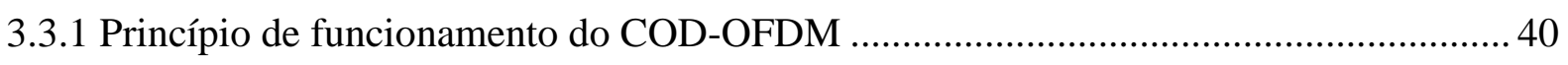

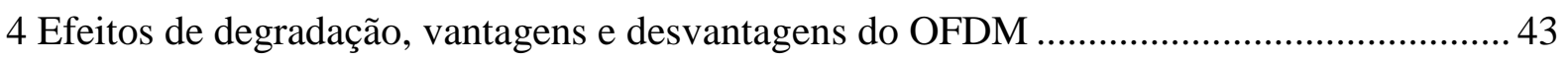

4.1 Principais efeitos de degradação do sinal ......................................................................... 43

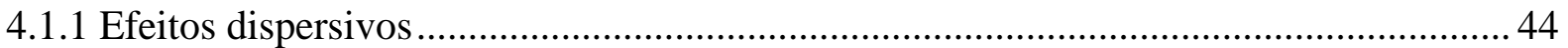

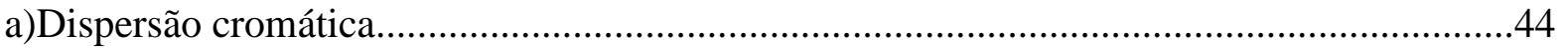

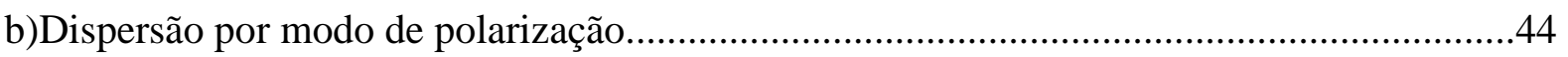




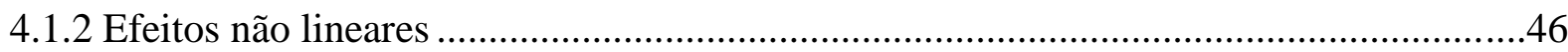

a) Automodulação de fase (SPM - Self-phase modulation)...............................................46

b) Modulação de fase cruzada (XPM - cross-phase modulation) .........................................47

c) Mistura de quatro ondas (FWM - four-wave mixing) .............................................47

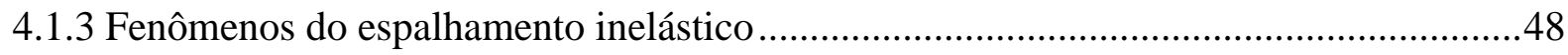

a)Espalhamento estimulado Brillouin (SBS - Stimulated Brillouin-scattering) ......................48

b)Espalhamento estimulado Raman (SRS Stimulated Raman-scattering).............................48

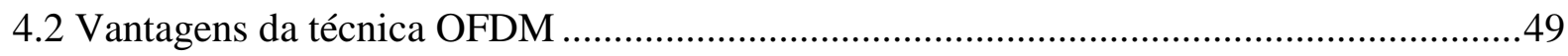

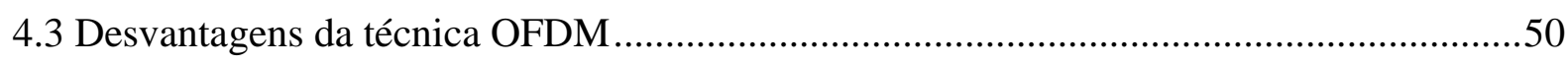

5 Simulações computacionais de sistemas OFDM nas arquiteturas de detecção direta e

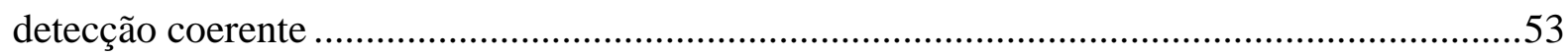

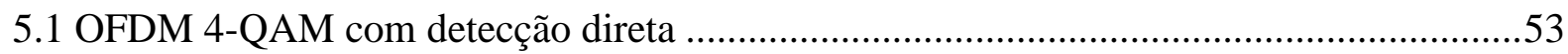

5.1.1 Simulações do OFDM 4-QAM com detecção direta .....................................................53

5.2 OFDM 4-QAM e 16-QAM com detecção coerente........................................................58

5.2.1 Simulações OFDM 4-QAM e 16-QAM com detecção coerente ....................................58

5.3 WDM-OFDM-PON com detecção coerente................................................................66

5.3.1 Importância e simulações da arquitetura WDM-OFDM-PON com detecção coerente..66

5.4 OFDM 4-QAM de dupla polarização com detecção coerente ...........................................71

5.4.1 Características e simulações da arquitetura OFDM 4-QAM de dupla polarização com

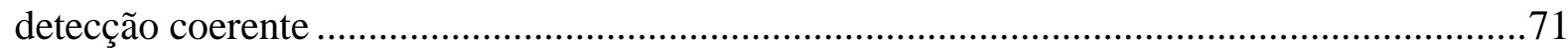

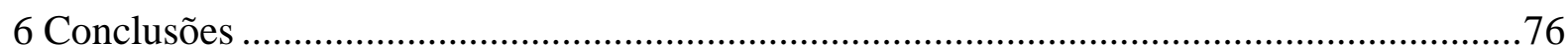

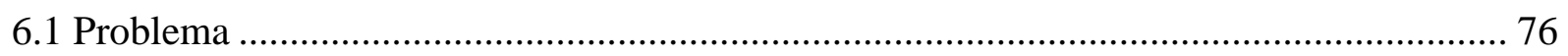

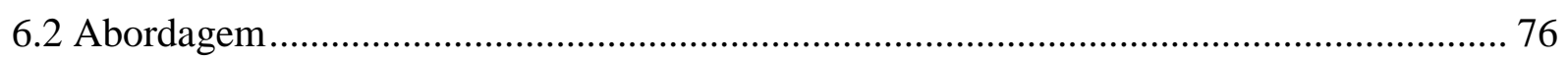

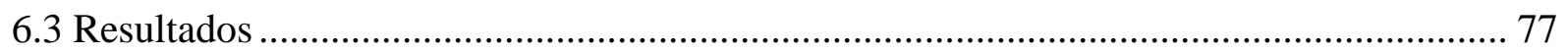

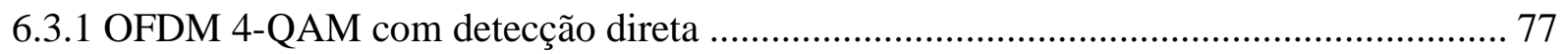

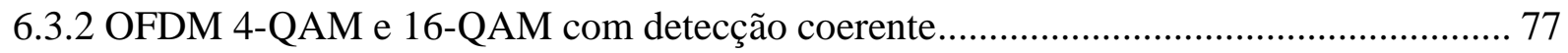

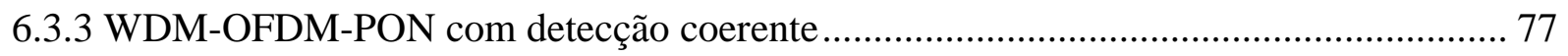

6.3.4 OFDM 4-QAM de dupla polarização com detecção coerente ...................................... 78

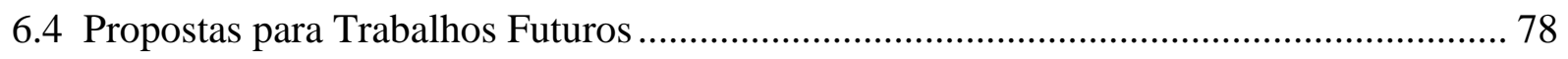

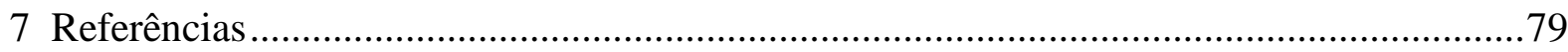




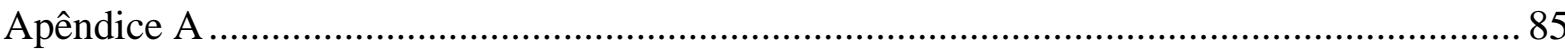

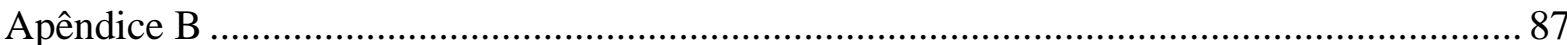




\section{Lista de Figuras}

Figura 1.1: Rede óptica passiva, adaptada de [8]............................................................. 3

Figura 1.2: Fluxograma para direcionamento do trabalho desenvolvido............................... 8

Figura 2.1: Sinais digitais - (a) Unipolar NRZ, (b) polar NRZ e (c) Unipolar RZ [22]........ 10

Figura 2.2: Classificação de importantes formatos de modulação [26]................................ 11

Figura 2.3: (a) Constelação quadrada $M=16$ e k =4, 16-QAM, simulada no Matlab 2010a... 13

Figura 2.4: Constelação cruzada $\mathrm{M}=32$ e k=5, 32-QAM, simulada no Matlab 2010a [22] ... 13

Figura 2.5: Desenvolvimento histórico da tecnologia OFDM [6]. 15

Figura 2.6: Espectro do FDM, multiplexação sem sobreposição das subportadoras [37]...... 16

Figura 2.7: Diagrama conceitual para um sistema de multiplexação multiportadora. Os termos $c_{1} \ldots c_{k i}$ representam os símbolos de número i da subportadora $\mathrm{k}$ antes da multiplexação e $c^{\prime}{ }_{1 \ldots} \ldots c^{\prime}{ }_{k i}$ após a demultiplexação [6]. 17

Figura 2.8: Subportadoras OFDM no domínio da frequência. 18

Figura 2.9: Layout introdutório para os bits gerados e o formato de modulação e multiplexação adotado; no caso QAM e o OFDM.

Figura 2.10: (a) Transformada rápida inversa de Fourier, (b) Transformada rápida de Fourier simulados no Matlab 2010a [22].

Figura 2.11: Modulador simétrico de Mach-Zehnder, utilizado em modulação externa [6]... 23

Figura 2.12: (a) Diagrama de olho de um sistema com baixa interferência intersimbólica, (b) sistema com interferência intersimbólica severa, simulados no Optisystem 9.0.

Figura 2.13: Constelações 4-QAM obtidas no VPI player 8.7. Em (a) sem equalização e em (b) com equalização [13].

Figura 2.14: Representação do prefixo cíclico [42]. 28

Figura 3.1: Representação da função sinc(2Wt), simulado no Matlab 2010a [22], na qual 2Wt está em radianos. 
Figura 3.2: Perfil da função cosseno levantado para diferentes graus de suavidade, simulados no Matlab 2010a.

Figura 3.3: Localização dos analisadores de espectro para a obtenção dos resultados obtidos no Optisystem 9.0.

Figura 3.4: (a) Espectro da banda base (domínio elétrico) e (b) espectro do sinal (em banda lateral dupla) no domínio óptico (sem filtragem), simulados no Optisystem 9.0.

Figura 3.5: (a) Espectro antes do MZM simétrico, (b) espectro óptico na saída do filtro, localizado após o MZM simétrico. Espectros simulados no Optisystem 9.0.

Figura 3.6: (a) Espectro com bandas laterais muito próximas dificultando a filtragem da banda lateral, (b) banda lateral sem supressão (filtragem incompleta da banda lateral)...... 38

Figura 3.7: (a) Espectro óptico em LM-DDO-OFDM, (b) Espectro óptico em NLM-DDOOFDM, simulados no Optisystem 9.0.

Figura 3.8: Esquema básico da arquitetura COD-OFDM com conversão direta [6].

Figura 3.9: Esquema básico da arquitetura COD-OFDM com frequência intermediária [6] ... 42

Figura 4.1: Relação dos principais efeitos de degradação do sinal em fibras ópticas [24]. .43

Figura 4.2: Espectro de um pulso sob ação de dispersão cromática, a) saída do transmissor, b) espectro óptico após enlace de $10 \mathrm{~km}$. Dados do pulso de entrada: pulso gaussiano, potência de pico de $0 \mathrm{dBm}$, comprimento de onda $1552 \mathrm{~nm}$. Características do enlace: parâmetros da Tabela 5.2, pág. 54, com coeficiente não linear da fibra igual a zero. Simulação no Optisystem 9.0. Layout do sistema na Figura B.5.

Figura 4.3: (a) Fibra ideal com simetria circular, (b) fibra real assimétrica [55]. 45

Figura 4.4: Efeito da birrefringência em cada modo de polarização [55].

Figura 4.5: Espectro de um pulso sob a ação do SPM, a) Pulso transmitido, b) espectro óptico após enlace de $10 \mathrm{~km}$. Dados do pulso transmitido: gaussiano com 1552nm, potência do laser $30 \mathrm{dBm}$. Dados da fibra: valores da tabela 5.2, pág. 54. Simulado no Optisystem 9.0. Layout do sistema em B.6. .46

Figura 4.6: Espectro de dois pulsos sob a ação de XPM, modulação de fase cruzada, a) Dois pulsos em WDM, b) espectro óptico, após enlace de $20 \mathrm{~m}$. Dados do pulso: dois pulsos gaussianos com $62 \mathrm{dBm}$. Dados da fibra: valores padrão da tabela 5.2, pág. 54. Simulados no Optisystem 9.0. Layout do sistema em B.7.

Figura 4.7: Desvanecimento plano e desvanecimento seletivo [37]. 
Figura 4.8: a) Espectro de potência do sinal na saída do transmissor, b) espectro de potência do sinal que chega ao receptor. Simulados no Optisystem 9.0.

Figura 5.1: Enlaces de fibra óptica, (a) passivo e (b) ativo [60]. 55

Figura 5.2: Constelação DD-OFDM 4-QAM, após o sinal percorrer diferentes distâncias.... 56

Figura 5.3: BER em função OSNR para os parâmetros das Tabelas 1 e 3. 61

Figura 5.4: Constelações obtidas na recepção do sistema OFDM ao longo do enlace. 62

Figura 5.5: Constelações obtidas na recepção do sistema OFDM, ao longo do enlace com efeitos de propagação e ruído de fase do laser nulo. 64

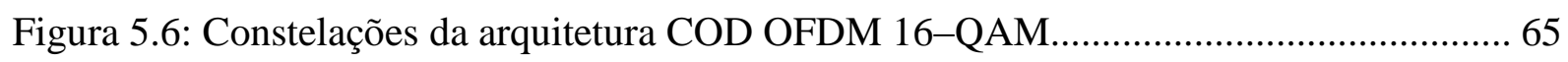

Figura 5.7: Constelação do canal 1 da arquitetura WDM-OFDM-PON. 69

Figura 5.8: BER em função do comprimento do enlace para a arquitetura WDM-OFDM-PON com os parâmetros das Tabelas 5.5 e 5.6.

Figura 5.9: Representação de uma transmissão de polarizações ortogonais, multiplexadas e moduladas pelas técnicas OFDM-4QAM. Em (a) sinal elétrico transmitido, (b) mistura de polarização com resultante em X, (c) mistura de polarização com resultante em Y, (d) e (e) componentes de polarização sem mistura, obtidas no processo de demultiplexação [67]. ..... 72

Figura 5.10: BER em função do comprimento do enlace para a arquitetura de OFDM 4-QAM de dupla polarização com detecção coerente, com os parâmetros da Tabela 5.7 e da Tabela 5.8 .

Figura 5.11: Constelações em: (a) Constelação back to back, (b) enlace com $15 \mathrm{~km}$, (c) $80 \mathrm{~km}$ e (d) $180 \mathrm{~km}$. 75

Figura B.1: Layout da arquitetura OFDM 4-QAM com detecção direta, simulado no Optisystem 9.0 [30]...... 88

Figura B.2: Layout do sistema OFDM 4-QAM com detecção coerente, simulado no Optisystem 9.0 [30]......

Figura B.3: Layout do sistema WDM-OFDM-PON com detecção coerente, no Optisystem 10.0 [30]. 90

Figura B.4: Layout do sistema 100 Gb/s COD-OFDM com dupla polarização, simulado no Optisystem 10.0 [30]. 
Figura B.5: Layout do sistema para o efeito de dispersão cromática. .................................. 92

Figura B.6: Layout do sistema para o efeito de automodulação de fase. ............................... 92

Figura B.7: Layout do sistema para o efeito de modulação de fase cruzada............................93 


\section{Lista de Tabelas}

Tabela 2.1: Componentes utilizados na montagem do sistema OFDM-QAM.

Tabela 5.1: Parâmetros de simulação DD-OFDM [15]. 54

Tabela 5.2: Características do enlace utilizado na simulação para DD-OFDM [12].............. 55

Tabela 5.3: Parâmetros de simulação COD-OFDM [16] ..................................................... 59

Tabela 5.4: Características do enlace utilizado na simulação COD-OFDM [12].................... 60

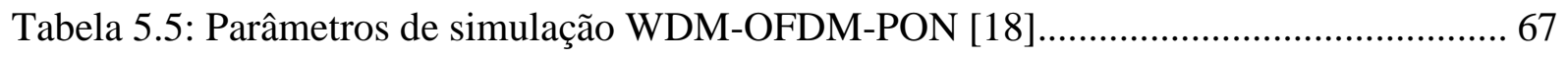

Tabela 5.6: Características do enlace utilizado na simulação WDM-OFDM-PON [12]......... 68

Tabela 5.7: Parâmetros da simulação DP-OFDM [20] ......................................................... 73

Tabela 5.8: Características do enlace utilizado na simulação [12] ....................................... 74 
Lista de Abreviaturas, Siglas e Acrônimos

\begin{tabular}{|c|c|}
\hline $\mathrm{ADC}$ & analog to digital converter \\
\hline $\mathrm{ADC}$ & analog to digital converter \\
\hline$A P K$ & amplitude phase keying \\
\hline ASE & amplified spontaneous emission \\
\hline ASK & amplitude shift keying \\
\hline BER & bit error rate \\
\hline BO-SSB & baseband optical single sideband \\
\hline BPSK & binary phase shift keying \\
\hline CAD & computer aided design \\
\hline CATV & community antenna television \\
\hline $\mathrm{CO}$ & central office \\
\hline$C O D$ & coherent optical detection \\
\hline $\mathrm{CP}$ & cyclic prefix \\
\hline DAC & digital to analog converter \\
\hline DDO & direct detection optical \\
\hline DFT & discrete Fourier transform \\
\hline DGD & differential group velocity \\
\hline DSP & digital signal processor \\
\hline DWDM & $\begin{array}{l}\text { dense wavelength division } \\
\text { multiplexing }\end{array}$ \\
\hline FDM & frequency division multiplexing \\
\hline FEC & forward error correction \\
\hline FTTH & fiber to the home \\
\hline ICI & intercarrier interference \\
\hline IDFT & inverse discrete Fourier transform \\
\hline IFFT & inverse fast Fourier transform \\
\hline ISDB-T & $\begin{array}{lcc}\text { integrated } & \text { service } & \text { digital } \\
\text { broadcasting } & \text { - terrestrial } & \end{array}$ \\
\hline ISI & intersymbol interference \\
\hline LANs & local area networks \\
\hline LM & linearly mapped \\
\hline
\end{tabular}




\begin{tabular}{|l|l|}
\hline MANs & metro area networks \\
\hline MZM & Mach-Zehnder modulator \\
\hline NLM & nonlinearly mapped \\
\hline NRZ & no return to zero \\
\hline OBM & orthogonal band multiplexed \\
\hline OFDM & $\begin{array}{l}\text { orthogonal frequency division } \\
\text { multiplexing }\end{array}$ \\
\hline OLT & optical line terminal \\
\hline ONU & optical network unit \\
\hline OSNR & optical signal to noise ratio \\
\hline OSSB & offset single sideband \\
\hline OTN & optical transport network \\
\hline PAM & pulse amplitude modulation \\
\hline PAPR & peak to average power ratio \\
\hline PBCS & polarization beam combiner/splitter \\
\hline PMD & polarization mode dispersion \\
\hline PON & passive optical network \\
\hline PRBS & pseudo random binary sequence \\
\hline QAM & quadrature amplitude modulation \\
\hline QPSK & quadrature phase shift keying \\
\hline RF & radio frequency \\
\hline RF-TA & radio frequency tone-assisted \\
\hline RZ & return to zero \\
\hline SMF & single mode optical fiber \\
\hline SNR & signal-to-noise ratio \\
\hline SSB & single sideband \\
\hline TDM & time division multiplexing \\
\hline WDM & wavelength division multiplexing \\
\hline Wi-MAX & worldwide interowave access \\
\hline
\end{tabular}




\section{Resumo}

Corrêa, W. C., "Estudos de sistemas OFDM para comunicações ópticas", 2012. Dissertação (mestrado) - Escola de Engenharia de São Carlos, Universidade de São Paulo.

A utilização, em sistemas de comunicações ópticas, de formatos de modulação digitais é vista, atualmente, como uma forma promissora de aumentar a eficiência espectral, frente aos diversos efeitos de degradação do sinal em fibra óptica, sem alterar a infraestrutura já implantada. É neste contexto que surge a técnica OFDM (orthogonal frequency division multiplexing) que estabelece sobreposição espectral das subportadoras e, desta forma, permite a transmissão dos dados em forma multiplexada com grande eficiência espectral. No presente trabalho, foi proposta a simulação da técnica OFDM com modulação QAM (quadrature amplitude modulation) no software Optisystem, versões 9.0 e 10.0. O objetivo principal da pesquisa é estudar algumas configurações de sistemas OFDM óptico, com detecção direta e coerente, visando avaliar seu desempenho sistêmico frente a efeitos de propagação. Usando as figuras de mérito BER e diagrama de constelação para estabelecer a meta de ótimo desempenho, analisamos a técnica OFDM com detecção coerente em configurações aplicáveis, principalmente, para redes ópticas de acesso com alcance estendido.

Para validação dos resultados, são apresentados também estudos que relacionam as degradações do sinal em fibra óptica e a técnica OFDM. Estes resultados foram comparados com os existentes na literatura, apresentando boa concordância.

Palavras chave: OFDM óptico, QAM, detecção direta, detecção coerente, rede óptica de acesso. 


\begin{abstract}
Correa, W. C., "Studies OFDM systems for optical communications", 2012. Dissertation (master's degree) - School of Engineering of São Carlos, University of São Paulo.
\end{abstract}

The development of digital modulation formats in optical communications systems is considered to be a promising way to increase the spectral efficiency and to combat the effects of signal degradation in optical fiber without changing the infrastructure already deployed. In this context, the technique called OFDM (orthogonal frequency division multiplexing) establishes a particular spectral overlap of the subcarriers, which allows data transmission to be multiplexed with high spectral efficiency. The main objective of the research is to study some configurations of optical OFDM systems with direct detection and coherent in order to evaluate their performance against propagation effects. Using the figures of merit BER and constellation diagram to establish the goal of optimal performance, we analyze the OFDM technique with coherent detection in configurations more applicable for optical access networks with extended reach.

To validate the results we also present some studies that relate the degradation of the signal in an optical fiber and the OFDM technique. These results were compared with those described in literature, showing good agreement.

Keywords: Optical OFDM, QAM, direct detection, coherent detection, optical access network. 


\section{Introdução}

Atualmente, as fibras ópticas são de fundamental importância para as telecomunicações. Seu emprego alterou a transmissão dos sinais do domínio elétrico (fios de cobre) para o domínio fotônico e essa alteração agregou aos sistemas de comunicação, entre diversas vantagens, elevada largura de banda e imunidade a interferências eletromagnéticas, viabilizando as tecnologias de informação e comunicação (TICs) atuais. O prêmio Nobel de Física em 2009, concedido a Charles K. Kao [1], por seu trabalho no desenvolvimento de fibras com atenuação reduzida, foi uma forma de reconhecimento da importância das pesquisas em comunicações ópticas.

Apesar dos avanços tecnológicos já alcançados pelos sistemas mais modernos, a crescente demanda pelo aumento da capacidade de transmissão nas fibras motivou os estudos de formatos de modulação e multiplexação de sinais. O formato de modulação usado durante muitos anos foi o OOK (on/off keying) com codificação NRZ (no return to zero) sem retorno ao zero e RZ (return to zero) com retorno ao zero. Entretanto, o formato OOK com apenas um bit por símbolo não atende, atualmente, às necessidades dos sistemas de comunicação óptica para operar com taxas de transmissão elevadas (superiores a $100 \mathrm{~Gb} / \mathrm{s}$ ). Nestas taxas o consequente impacto de efeitos de degradação de sinais nas fibras motivou a investigação de técnicas de multiplexação e de modulação alternativos, chamados, atualmente, de "avançadas" [2].

É neste contexto que surge a técnica OFDM (orthogonal frequency division multiplexing), a qual permite o envio de subportadoras multiplexadas em frequência, explorando a característica especial imposta pela técnica: a ortogonalidade.

A técnica tem sido utilizada tanto em comunicações ópticas como em comunicações sem fio, com destaque para WiMAX (worldwide interoperability for microwave access), padrões de TV digital como DVB-T (digital video broadcasting - terrestrial) e ISDB-T (integrated service digital broadcasting - terrestrial) [3],[4].

A superposição do espectro de sinais na técnica OFDM permite um aumento da eficiência espectral $(\mathrm{J})$ do sistema, que é definida como a razão entre a taxa de bit $\left(\mathrm{R}_{\mathrm{b}}\right)$ transmitida e a largura de banda (W) utilizada [5].

Apesar da excelente eficiência espectral e da ótima compatibilidade da técnica com formatos de modulação avançados, o OFDM requer uma alta relação entre as potências de pico e média (PAPR - peak to average power ratio). Esse problema reduz significativamente 
a eficiência dos amplificadores de potência do enlace, o que torna a técnica alvo de diversas críticas [6]. Essa desvantagem, como será mostrada ao longo da dissertação, é um dos fatores limitantes para que os sinais transmitidos não ultrapassem distâncias superiores a 200 km, caso não haja processamento digital de sinal.

Esta limitação despertou o interesse de pesquisadores para aplicações do OFDM em redes ópticas de acesso [7], já que estas redes geralmente se estendem a distâncias menores que $100 \mathrm{~km}$ das redes locais.

As redes ópticas de acesso são responsáveis pela conexão da central provedora de serviço (Central Office - $\mathrm{CO}$ ) aos assinantes residenciais ou empresariais (localizados nas redes locais), constituindo esta a última etapa do fluxo de informação, comumente chamada de última milha [8]. Tradicionalmente, essas redes operam em taxas de até $100 \mathrm{Mb} / \mathrm{s}$, porém em redes mais modernas, esta taxa pode alcançar os $10 \mathrm{~Gb} / \mathrm{s}$. Ou seja, a taxa de transmissão vai depender de quanto o usuário está disposto a pagar [9].

As redes ópticas passivas ( $\mathrm{PON}$ - passive optical network) são arquiteturas de redes de acesso que possibilitam uma infraestrutura de rede com ótima razão custo-benefício. Tais redes utilizam, em princípio, apenas divisores de sinal óptico (splitters) para que vários usuários sejam atendidos por uma mesma fibra óptica. Assim, nessas redes não há componentes elétricos no campo, como switches Ethernet, amplificadores e regeneradores ópticos, permitindo que gastos operacionais sejam reduzidos.

É apresentada na Figura 1.1, uma rede local, como um condomínio residencial, e uma rede de acesso a dezenas de quilômetros do condomínio. Na rede de acesso está a central provedora de serviços, onde fica localizado o terminal de linha óptica (OLT - optical line terminal) [9]. 


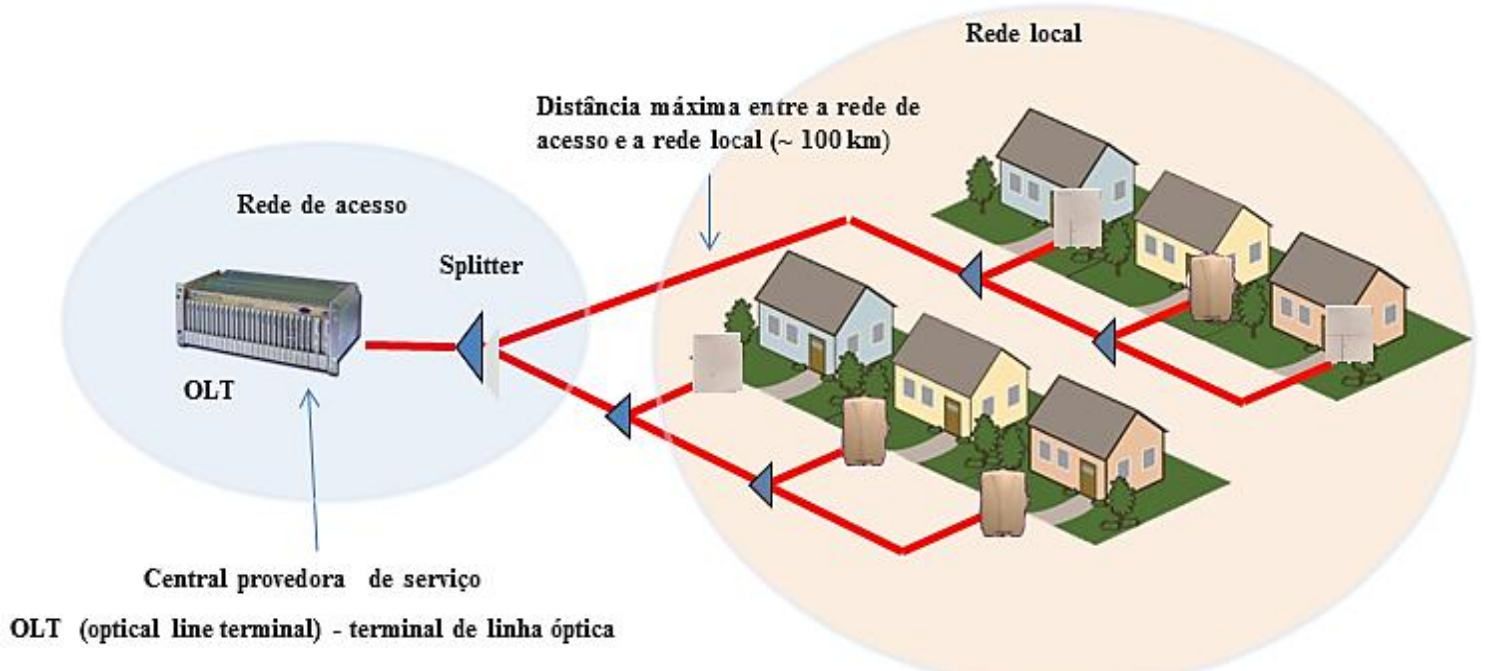

Figura 1.1: Rede óptica passiva, adaptada de [8].

No contexto de redes ópticas de acesso, os formatos de "modulação avançada" e OFDM são uma ótima alternativa para aumentar a eficiência espectral em fibras ópticas, principalmente, nas instalações até o cliente (FTTH - fiber to the home). As instalações FTTH ligam as centrais provedoras de serviço ao usuário residencial, e são muito promissoras. Pesquisas revelam que até 2015 mais de 100 milhões de residências em todo mundo tenham acesso a uma conexão direta com fibra óptica [10].

\subsection{Formulação dos Problemas}

Atualmente, as redes de comunicações ópticas têm condições de oferecer largura de banda e confiabilidade capazes de atender a um tráfego dinâmico e diversificado formado por voz, dados e vídeo. Neste contexto, as técnicas OFDM, modulação de amplitude em quadratura (QAM- quadrature amplitude modulation) e detecção coerente, são tidas como o estado da arte para prover uma melhor eficiência dos sistemas de comunicações ópticas, pois aumentam a capacidade de transmissão nas fibras [6]. É importante, dessa forma, um estudo com o objetivo de reunir as vantagens, desvantagens e limitações destas técnicas.

Em relação ao OFDM tradicional, conforme já citado, a PAPR é um dos maiores problemas. Para resolvê-lo, alguns pesquisadores utilizam algoritmos de alocação de potência como o water filling [11], no qual o usuário tem a possibilidade de alocar maior nível de potência em faixas de frequências menos ruidosas, permitindo, assim, maximizar a razão 
sinal-ruído óptica (OSNR - optical signal to noise ratio) nessas faixas de transmissão. Entretanto, este algoritmo não está, atualmente, disponível em transmissores OFDM comerciais [12].

Outro problema nos sistemas OFDM e QAM são as altas taxas de erro de bit (BERbit error rate). Estas taxas estão situadas entre $10^{-1}$ a $10^{-5}$ e são altas devido à ausência de um processador digital de sinal no receptor (DSP - digital signal processor) que atua juntamente com códigos corretores de erro. A inserção deste componente em um sistema de comunicação óptica permite que distâncias maiores que $200 \mathrm{~km}$ sejam alcançadas com menores taxas de erro de bit [6].

Apesar das vantagens, em utilizar o processador digital de sinal e os algoritmos de alocação de potências, ambos não foram utilizados, pois não são recursos disponíveis até o momento no simulador Optisystem, versões 9.0 e 10.0 [12].

\subsection{Trabalhos Relacionados e Objetivos}

A partir de 2005 começaram a se intensificar, na literatura, trabalhos relacionados à OFDM em comunicações ópticas. Com base nestes, foram simuladas e estudadas quatro arquiteturas típicas de OFDM com modulação QAM: uma com a técnica de detecção direta (DDO - direct detection optical) e três com a técnica de detecção coerente (COD - coherent optical detection).

Os resultados da pesquisa foram obtidos a partir de simuladores comerciais para sistemas de comunicação óptica, são eles: Optisystem e VPI Transmission Maker ${ }^{\text {TM }}$ Optical Systems [13], softwares do tipo CAD (computer aided design).

As principais ideias relacionadas à técnica OFDM foram extraídas dos artigos mencionados abaixo:

1. análise da arquitetura OFDM-QAM com detecção direta. São apresentados nos artigos vários parâmetros do transmissor, receptor e enlace óptico, facilitando a reprodução do experimento em software comercial [14], [15].

2. proposta da arquitetura OFDM-QAM com detecção coerente para mitigar ruídos de fase do laser [16].

3. redes de acesso utilizando a técnica WDM-OFDM-PON [17]. 
4. análise do custo-benefício da técnica WDM-OFDM-PON [18].

5. proposta da técnica de dupla polarização com modulações QPSK e QAM [19], [20].

6. OFDM para comunicações ópticas [21],[6],[3].

A partir da análise desses artigos, observou-se que a maioria era formada por trabalhos experimentais, mas como o simulador Optisystem (Seção 2.6) possui uma vasta biblioteca de componentes para comunicações ópticas, nos propusermos a simular e estudar estas arquiteturas de comunicação óptica OFDM.

Assim, a partir do estudo acima, pode-se afirmar que os objetivos deste trabalho foram:

1. estudo do formato de modulação digital QAM e da técnica de multiplexação OFDM, no domínio elétrico e posterior modulação no domínio óptico;

2. estudo das arquiteturas de detecção direta e coerente com OFDM, por meio de simulações nos softwares comerciais de comunicações ópticas, já citados, e por meio do software Matlab 2010a [22];

3. estudo da técnica WDM-OFDM-PON com detecção coerente;

4. estudo da técnica de dupla polarização-OFDM com detecção coerente;

5. especificação de parâmetros do sistema de transmissão, recepção e enlace a fim de minimizar a taxa de erro de bit (BER), na ausência do processador digital de sinal no receptor;

6. contextualização de qual topologia de rede óptica as simulações OFDM podem ser aplicadas;

7. compreensão de quais fatores de degradação em fibras ópticas afetam os sistemas OFDM. 


\subsection{Organização do Texto}

Para a organização e entendimento desta dissertação foram utilizadas duas definições: arquitetura OFDM e técnica OFDM. A arquitetura OFDM consiste no sistema de comunicação óptico completo formado por transmissor, enlace e receptor. Já a técnica OFDM é o conjunto de métodos utilizados no transmissor para alcançar a multiplexação.

Com relação aos capítulos da dissertação, estes foram organizados da seguinte maneira.

Capítulo 1: Introdução. Neste capítulo é introduzido o conceito de redes ópticas passivas e são formulados os principais problemas a serem estudados nesta pesquisa. São apresentados no capítulo alguns artigos relacionados com a simulação desta pesquisa e como a dissertação está organizada.

Capítulo 2: Conceitos fundamentais. Exploração de características importantes como a formulação matemática de um sinal OFDM, a modulação QAM, a interferência intersimbólica, o modulador Mach-Zehnder, o prefixo cíclico e uma apresentação sucinta do simulador Optisystem. Dessa forma, o capítulo descreve as bases teóricas e conceituais para entendimento dos demais capítulos.

Capítulo 3: Sistemas de detecção OFDM. Neste capítulo é mostrada a importância dos filtros nos sistemas de comunicação óptica OFDM. São apresentadas as principais características da detecção direta e coerente OFDM.

Capítulo 4: Efeitos de degradação, vantagens e desvantagens do OFDM. Neste capítulo são apresentados os principais fatores de degradação de sinal em comunicações ópticas, efeitos dispersivos, efeitos não lineares e fenômenos de espalhamento inelástico. São abordadas também as principais vantagens e desvantagens do OFDM em comunicações ópticas.

Capítulo 5: Simulações computacionais de sistemas OFDM nas arquiteturas de detecção direta e detecção coerente. Neste capítulo são apresentadas quatro arquiteturas 
OFDM, sendo uma com detecção direta e três com detecção coerente. São analisados gráficos de BER, em função do comprimento da fibra e as constelações de sinais no receptor.

Capítulo 6: Conclusões. Resume os principais resultados desta dissertação e propõe em linhas gerais, trabalhos futuros.

Para um direcionamento mais claro e objetivo deste trabalho, segue demonstração de um fluxograma esquematizando o desenvolvimento do estudo, de acordo com a Figura 1.2. 


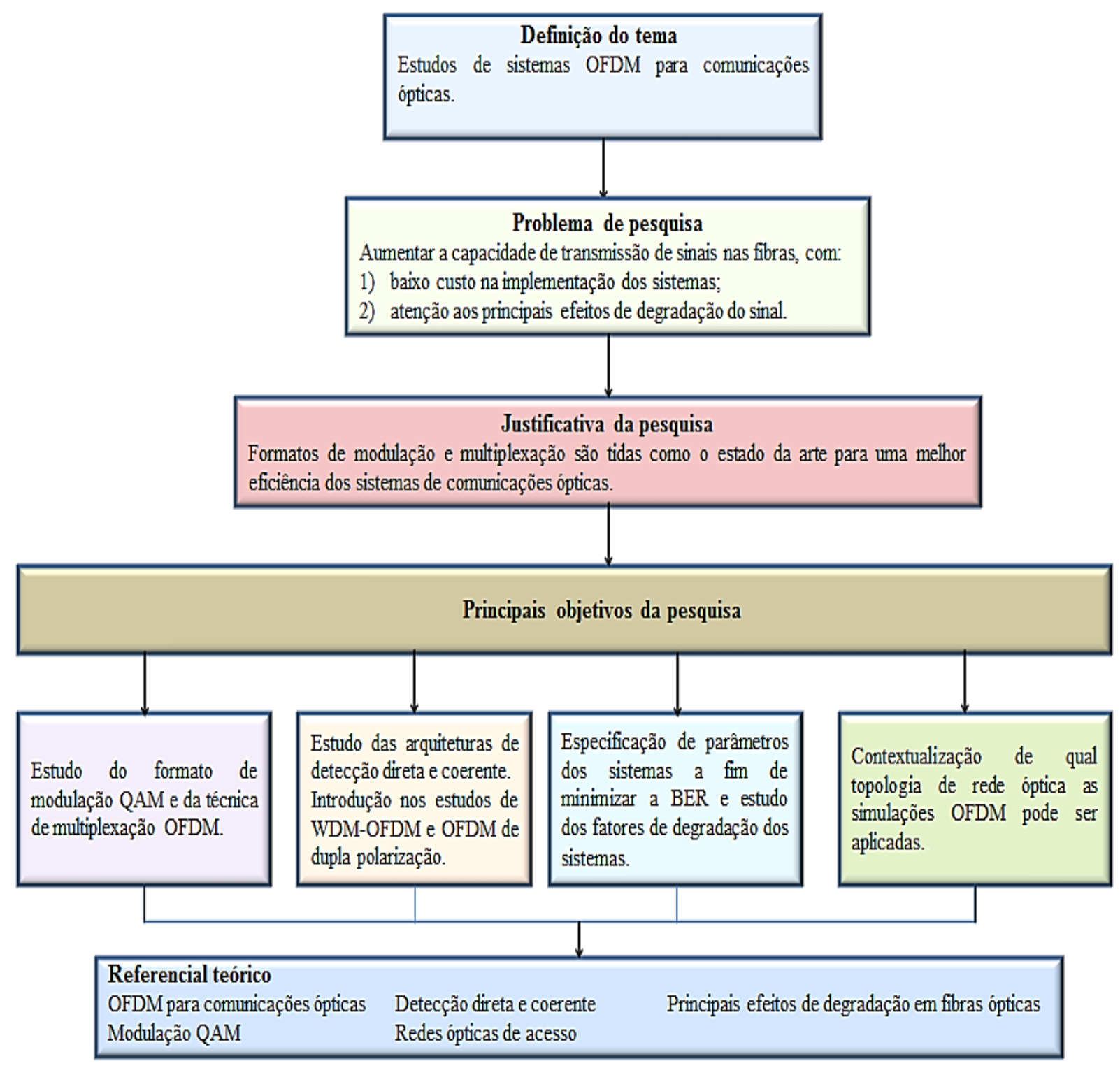

Figura 1.2: Fluxograma para direcionamento do trabalho desenvolvido. 


\section{Conceitos fundamentais}

Existem meios de transmissão que, devido sua natureza física, não apresentam condições para que os sinais elétricos possam se propagar e, neste caso, os símbolos digitais devem ser representados de forma adequada a estes meios. São exemplos destes meios a fibra óptica e a atmosfera terrestre, sendo que, em ambos os casos, a transmissão deve acontecer por meio de ondas eletromagnéticas. Dessa forma, a informação digital é transmitida mediante a codificação de parâmetros de uma portadora, variando-se a sua amplitude, fase ou frequência, ou seja, a partir de um processo chamado modulação digital. Assim, a modulação digital é a variação de um parâmetro de uma onda por um sinal modulante [23].

Há dois tipos de modulação: a modulação direta que permite ajuste da corrente injetada no próprio laser, alterando, assim, a potência óptica gerada e, consequentemente, modulando a amplitude; e a modulação externa, a qual utiliza um dispositivo externo ao laser para a modulação da luz.

A multiplexação, por outro lado, é a transmissão simultânea de dois ou mais sinais, utilizando o mesmo canal de transmissão. Define-se, assim, como canal, o meio de transmissão entre o transmissor e o receptor óptico.

Assim, são apresentados neste capítulo, conceitos fundamentais sobre a técnica de modulação QAM e a técnica de multiplexação OFDM, técnicas fundamentais no desenvolvimento desta pesquisa.

\subsection{Formatos de modulação digital}

Quando a transmissão de símbolos digitais ocorre por meio de pulsos de tensão ou corrente, os sinais são transmitidos em sua banda de frequência original, ou seja, sua banda base. Em geral, os sinais em banda base podem ser classificados segundo sua polaridade e a largura de pulso, podendo ser NRZ ou RZ.

O sinal é dito NRZ quando o pulso ocupa todo o intervalo de tempo destinado ao símbolo (não retorna ao zero), e RZ, quando o pulso ocupa apenas parte do intervalo de tempo (retorna ao zero).

Um sinal pulsado é considerado unipolar quando representa um dos símbolos por um pulso, que pode ser de polaridade positiva ou negativa, e o outro símbolo por ausência de 
pulso, assim, surge a denominação de chaveamento por liga/desliga (OOK - on/off keying). Já os pulsos polares possuem um pulso de polaridade positiva para representar um símbolo binário. Enquanto o pulso de polaridade negativa representa o outro símbolo [23].

São mostrados na Figura 2.1, alguns sinais digitais NRZ e RZ, simulados no MATLAB 2010a [22].

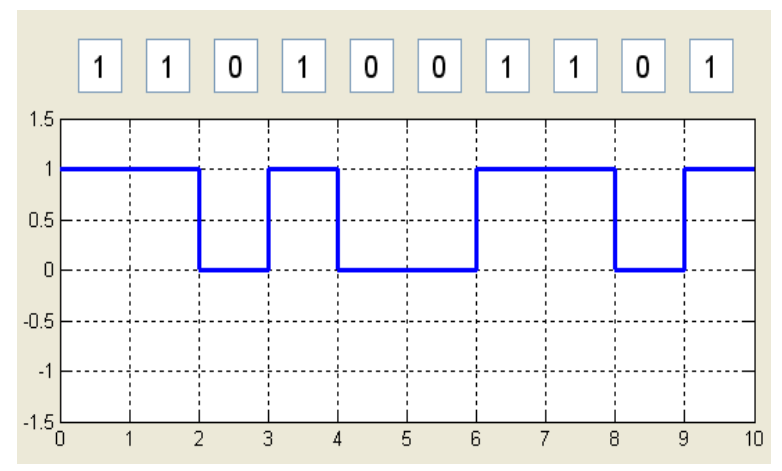

(a) Unipolar NRZ

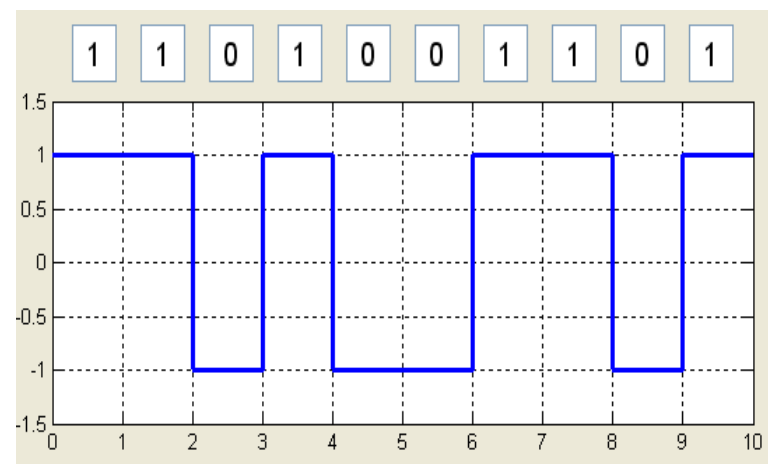

(b) Polar NRZ

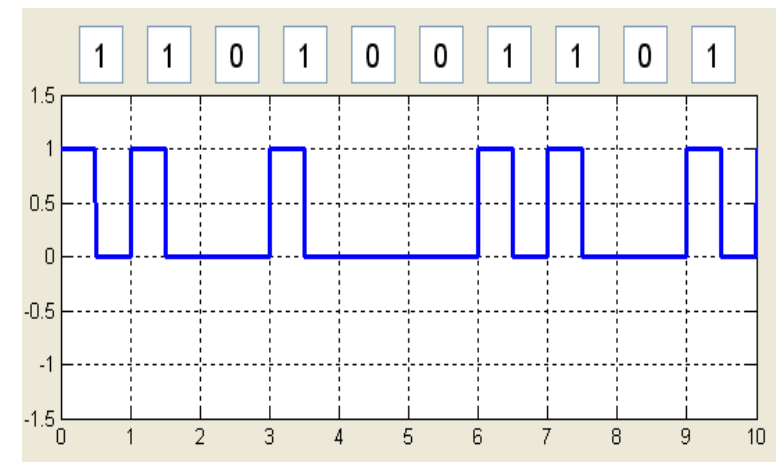

(c) Unipolar RZ

Figura 2.1: Sinais digitais - (a) Unipolar NRZ, (b) polar NRZ e (c) Unipolar RZ [22].

Os sinais NRZ e RZ são de fundamental importância para a modulação das portadoras em comunicações ópticas. Por exemplo, o método mais simples de modulação por intensidade é o chaveamento em amplitude (ASK- amplitude shift keying), que pode ter sua portadora óptica modulada por um sinal NRZ.

Existe uma variedade de formatos de modulação de intensidade que podem ser binários ou multinível, com ou sem chirp (mudança da frequência do sinal com o tempo). A desvantagem da modulação por amplitude é requerer, pelo menos, um ciclo da portadora para enviar um único bit, a não ser que um esquema de modulação híbrido seja utilizado [26].

A modulação por chaveamento de fase também pode ser classificada como binária ou multinível, com o chaveamento por deslocamento de fase binário (BPSK - binary phase shift 
keying) ou o chaveamento por deslocamento de fase em quadratura (QPSK - quadrature phase shift keying), este último classificado como multinível. Os formatos BPSK e QPSK são formatos de modulação disponíveis nos simuladores Optisystem 9.0 e 10.0, para serem utilizados na multiplexação OFDM.

A modulação por chaveamento de amplitude e fase (APK - amplitude phase keying) ocorre quando há mudanças tanto na amplitude como na fase de uma portadora. Uma forma especial desta modulação é a QAM, sendo o terceiro formato compatível com a técnica OFDM, nos simuladores Optisystem 9.0 e 10.0.

São apresentados, na Figura 2.2, alguns importantes formatos de modulação digital de amplitude e fase.

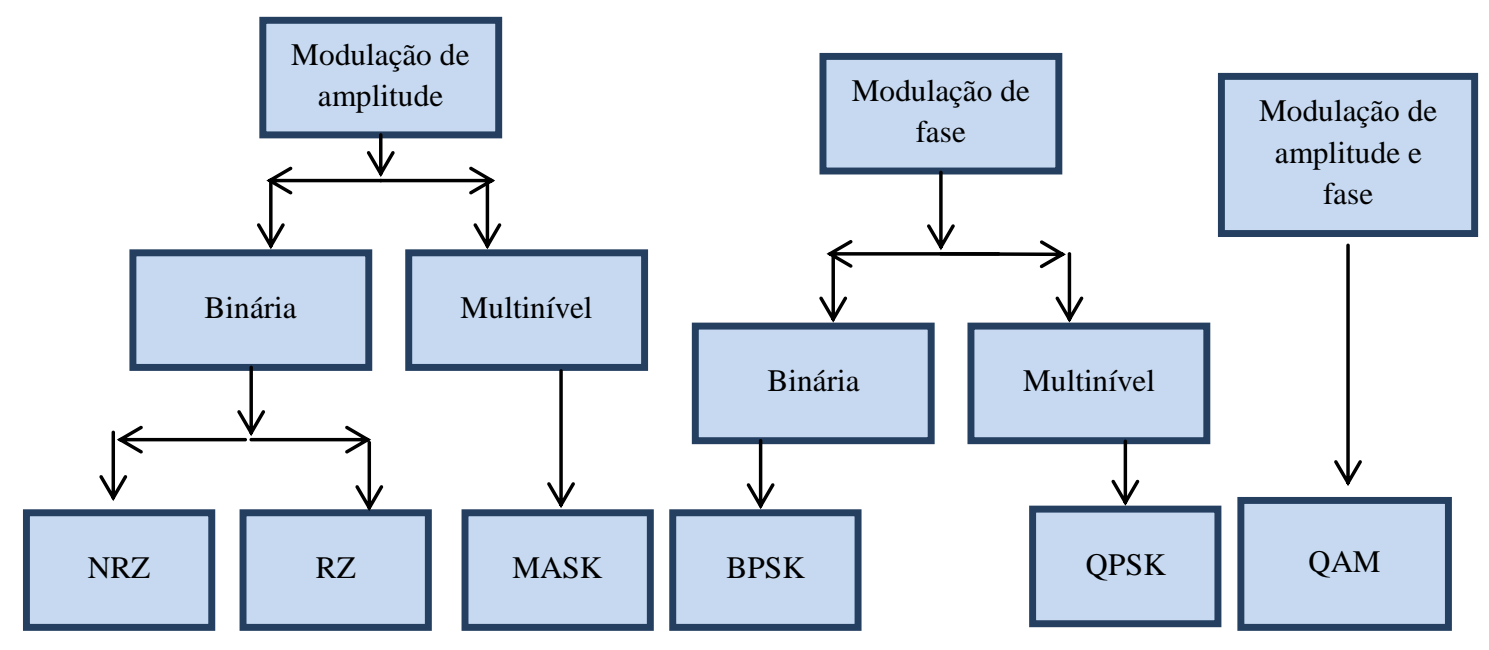

NRZ: No-return to zero

RZ: Return to zero

MASK: Multilevel amplitude shift keying

BPSK: Binary phase shift keying

QPSK: Quadrature phase shift keying

QAM: Quadrature amplitude modulation

Figura 2.2: Classificação de importantes formatos de modulação [26].

Formatos de modulação com grande número de bits por símbolo, também chamados de modulação de alta ordem, proporcionam alta taxa de transmissão de dados. O uso da largura de banda é mais eficiente nesses formatos [2]. Entretanto, tais formatos possuem eficiência reduzida em enlaces de longa distância (superiores a $100 \mathrm{~km}$ ), pois requerem alta OSNR, inviabilizando sua utilização [24], [6]. 
Entre os três tipos de modulação BPSK, QPSK e QAM; o QAM é único formato que permite o controle de fase e amplitude do sinal concomitantemente. Isso significa que os problemas provocados por ruídos associados aos deslocamentos de amplitude podem ser minimizados por meio da escolha adequada da fase de um sistema QAM [25]. Por esse motivo, o OFDM-QAM é a técnica normalmente adotada e será o foco principal deste trabalho.

É importante destacar que a modulação por polarização tem recebido pouca atenção em comunicações ópticas devido à necessidade de um complexo gerenciamento da polarização no receptor. Este gerenciamento envolve a utilização de vários receptores coerentes, um para cada polarização, já que ocorrem mudanças aleatórias da polarização da luz na fibra óptica [26].

\subsection{Modulação de amplitude em quadratura (QAM - quadratura amplitude modulation)}

Um sinal QAM - M-ário é definido por

$s_{k}(t)=\sqrt{\frac{2 E_{O}}{T}} a_{k} \cos \left(2 \pi f_{c} t\right)-\sqrt{\frac{2 E_{O}}{T}} b_{k} \operatorname{sen}\left(2 \pi f_{c} t\right) d t \quad 0 \leq t \leq T ; k=0, \pm 1, \pm 2, \ldots$

no qual, $\mathrm{E}_{0}$ é a energia do sinal, no estado de menor amplitude, $\mathrm{T}$ é o intervalo do símbolo, $\mathrm{f}_{\mathrm{c}}$ é a frequência da portadora, $a_{k}$ e $b_{k}$ são números inteiros com k=1,2...M.

$\mathrm{O}$ sinal $\mathrm{s}_{\mathrm{k}}(\mathrm{t})$ consiste em duas portadoras moduladas em fase e em quadratura, sendo cada uma delas modulada por um conjunto de amplitudes discretas. Dependendo do número M de símbolos possíveis na modulação QAM, existem duas constelações de sinais distintas: quadrada, para as quais o número de bits por símbolo é par, e a cruzada para as quais o número de bits por símbolo é ímpar [27].

A constelação de sinais é uma representação vetorial, na qual são enfatizadas as posições relativas dos sinais modulados. Nesta representação não há visualização da evolução do sinal com o tempo, diferentemente da representação fasorial.

A expressão que relaciona o número de bits por símbolo $\mathrm{k}$ e o número $\mathrm{M}$ de símbolos é expressa por 


$$
M=2^{k}
$$

na qual $\mathrm{k}=1,2,3 \ldots$

É apresentado na Figura 2.3, um exemplo de constelação quadrada.

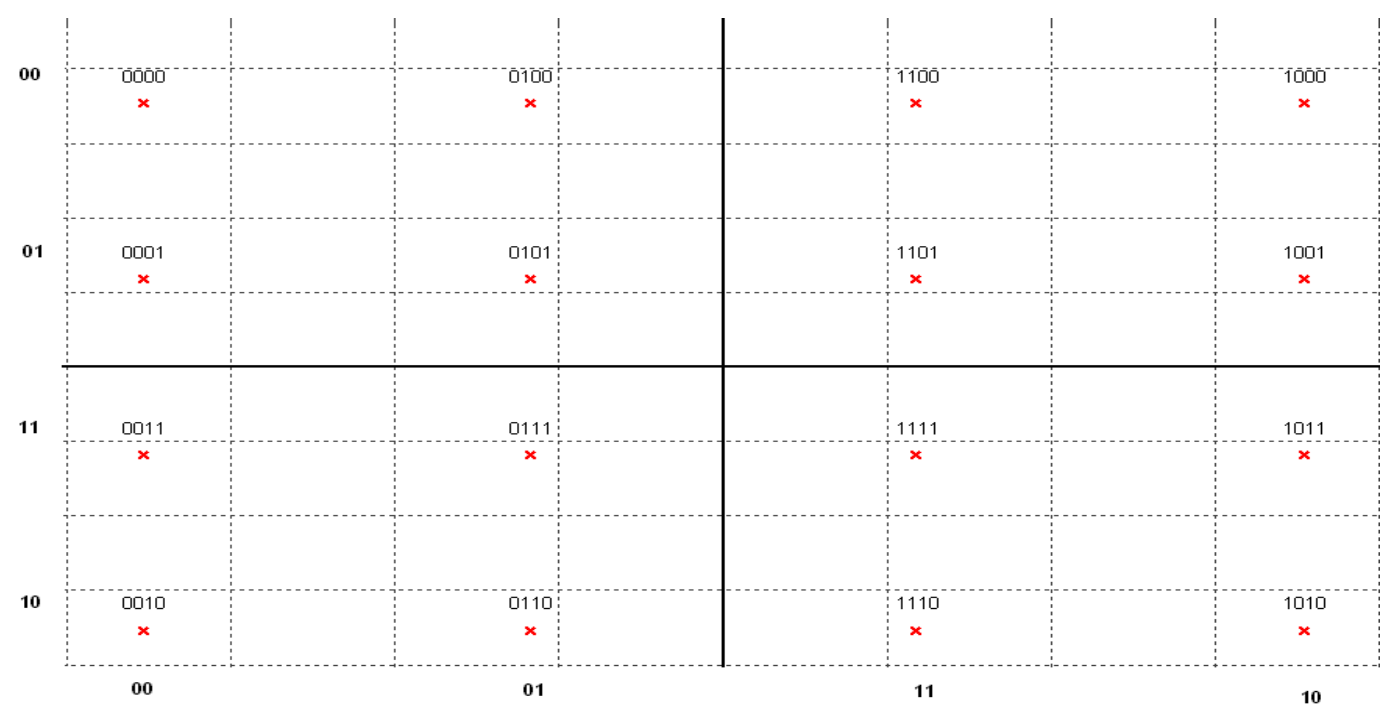

Figura 2.3: (a) Constelação quadrada $\mathrm{M}=16$ e k =4, 16-QAM, simulada no Matlab 2010a.

A fim de compreender a codificação dos pontos da constelação exibidos na Figura 2.3, observa-se que os dois bits à esquerda estão especificados na abscissa do espaço de sinais, começando e seguindo a ordem: 00, 01, 11 e 10 . Os dois bits à direita estão especificados na ordenada do espaço de sinais, começando e seguindo de baixo para cima a ordem: 10, 11, 01 e 00. Na Figura 2.4 é apresentada uma constelação cruzada.

\begin{tabular}{|c|c|c|c|c|c|}
\hline & $\begin{array}{l}00000 \\
\times\end{array}$ & $\begin{array}{l}00001 \\
\times\end{array}$ & $\underset{\times}{10001}$ & $\underset{\times}{10000}$ & \\
\hline$\underset{\times}{00100}$ & $\begin{array}{l}01100 \\
\times\end{array}$ & $\begin{array}{l}01000 \\
\times\end{array}$ & $\underset{\times}{11000}$ & $\underset{\times}{11100}$ & $\underset{\times}{10100}$ \\
\hline$\underset{\times}{00101}$ & $\underset{\times}{01101}$ & $\begin{array}{l}01001 \\
\times\end{array}$ & $\underset{\times}{11001}$ & $\underset{\times}{11101}$ & $\begin{array}{l}10101 \\
\times\end{array}$ \\
\hline$\underset{\times}{001111} \times$ & $\underset{\times}{01111}$ & $\begin{array}{l}01011 \\
\times\end{array}$ & $\underset{\times}{11011}$ & $\underset{\times}{11111}$ & $\begin{array}{l}10111 \\
\times\end{array}$ \\
\hline \multirow[t]{2}{*}{$\underset{\times}{00110}$} & $\begin{array}{l}01110 \\
\times\end{array}$ & $\begin{array}{l}01010 \\
\times\end{array}$ & $\begin{array}{c}11010 \\
\times\end{array}$ & $\underset{\times}{11110}$ & $\underset{\times}{10110}$ \\
\hline & $\underset{\times}{00010}$ & $\begin{array}{l}00011 \\
\times\end{array}$ & $\underset{\times}{10011}$ & $\underset{\times}{10010}$ & \\
\hline
\end{tabular}

Figura 2.4: Constelação cruzada M=32 e k=5, 32-QAM, simulada no Matlab 2010a [22]. 
A constelação apresentada na Figura 2.4, em forma de cruz, não permite a utilização da codificação Gray perfeita como no caso das constelações quadradas. Além disso, uma constelação cruzada não pode ser gerada por duas modulações de amplitude de pulso (PAMpulse amplitude modulation) iguais. Esse deve ser o motivo para que o simulador Optisystem realize apenas a simulação de constelações quadradas, que são geradas com um número de símbolos par, maior ou igual a $4(\mathrm{M} \geq 4)[28]$.

\subsection{História do OFDM}

É ilustrada, na Figura 2.5, a linha do tempo da técnica OFDM [6]. A primeira proposta da técnica é apresentada, em 1966, por Robert W. Chang e patenteada, em 1970, pelo Bell Labs [22]. Em 1969, surge a proposta para gerar sinais multiplexados, usando a transformada inversa de Fourier (IFFT - inverse fast Fourier transform) [29], permitindo que os sinais fossem processados com maior velocidade computacional.

Em 1980, é proposto um importante aspecto da técnica OFDM, o prefixo cíclico (CP), o qual será discutido adiante. Durante a década de 80, mais precisamente em 1985, os Laboratórios Bell publicam pesquisas de OFDM em comunicações móveis [30]. Dois anos depois, Lassalle e Alard [31] aplicaram a técnica em radiodifusão e notaram a importância de combinar técnica de correção de erro (FEC - forward error correction) com OFDM.

Em 1995, Telatar e Foschini [32], [33] publicam trabalhos sobre a possibilidade da técnica OFDM ser usada em sistemas com múltiplas entradas e múltiplas saídas (MIMO multiple input multiple output), o que melhoraria, posteriormente, o desempenho das comunicações móveis com o uso de várias antenas de transmissão e recepção. A partir de 2001, a técnica OFDM começa a ser implementada em redes locais sem fio (WLAN wireless local area networks) [34]. Entretanto, os estudos de OFDM em comunicações ópticas têm ocorrido, mais recentemente, a partir de 2005, com o objetivo principal de aumentar a eficiência espectral dos sistemas de comunicações ópticas. 


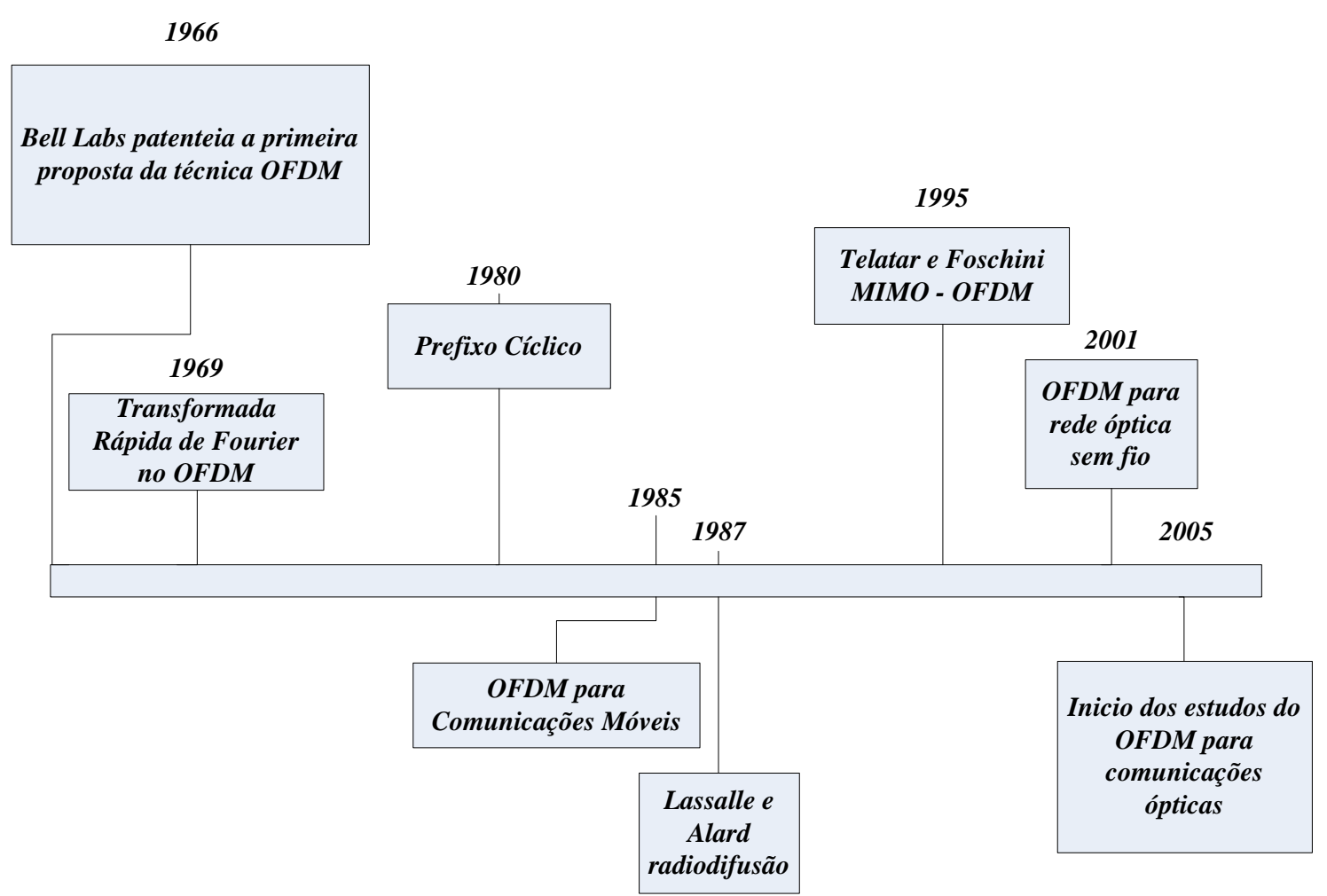

Figura 2.5: Desenvolvimento histórico da tecnologia OFDM [6].

\subsection{Multiplexação por divisão de frequência (FDM)}

Quando várias subportadoras são separadas por banda de guarda, de maneira que elas não se interfiram mutuamente, chamamos a técnica de multiplexação por divisão de frequência (FDM - frequency division multiplexing). A multiplexação por divisão de frequência é uma importante operação na transmissão de sinais, na qual vários sinais independentes podem ser combinados em um único canal.

O primeiro teste desta técnica foi realizado em 1910 [35], quando uma linha telefônica foi utilizada para transmitir dois sinais de voz simultaneamente. Entretanto, somente em 1918, foi executada a primeira aplicação comercial de sistemas FDM. Neste sistema, os espaçamentos entre as subportadoras permitem que a recepção ocorra de maneira adequada. $\mathrm{O}$ FDM é classificado como uma técnica sem sobreposição multiportadora, que apresenta como principal desvantagem a separação dos sinais que, apesar de pequena, provoca desperdício no uso do espectro. É ilustrado, na Figura 2.6, o espectro do FDM. Em comunicações ópticas 
esse espectro está situado em torno de $200 \mathrm{GHz}$, com espaçamento de $20 \mathrm{GHz}$ entre cada subportadora [36].

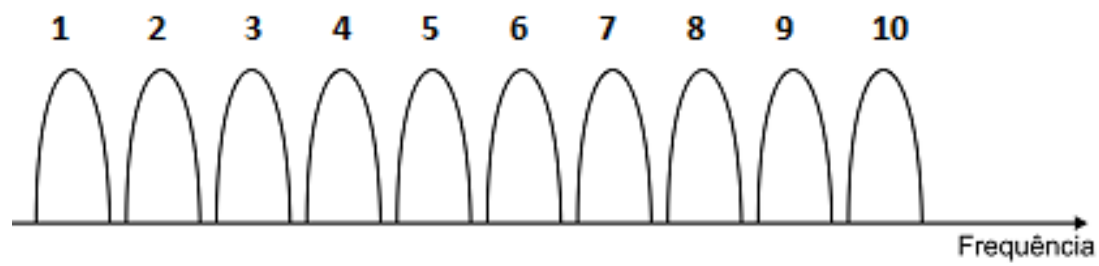

Figura 2.6: Espectro do FDM, multiplexação sem sobreposição das subportadoras [37].

\subsection{Multiplexação por divisão de frequências ortogonais (OFDM)}

OFDM é uma classe especial de multiplexação multiportadora, e seus sinais no domínio temporal s(t) são representados por [6]:

$$
\begin{gathered}
s(t)=\sum_{i=-\infty}^{+\infty} \sum_{k=1}^{N_{s c}} c_{k i} s_{k}\left(t-i T_{S}\right) \\
s_{k}(t)=\pi(t) e^{j 2 \pi f_{k} t} \\
\pi(t)=\left\{\begin{array}{l}
1,\left(0<t \leq T_{S}\right) \\
0,\left(t \leq 0, t>T_{S}\right)
\end{array}\right\}
\end{gathered}
$$

nas quais, $c_{k i}$ é o $i$-ésimo símbolo da subportadora $k, s_{k}$ é a forma de onda para a $k$-ésima subportadora, $N_{s c}$ é o número de subportadoras, $f_{k}$ é a frequência da subportadora, $T_{s}$ é o período do símbolo e $\pi(t)$ é uma função de modelagem de pulso (pulse shaping function). É ilustrado, na Figura 2.7, um diagrama conceitual para um sistema de multiplexação multiportadora. 


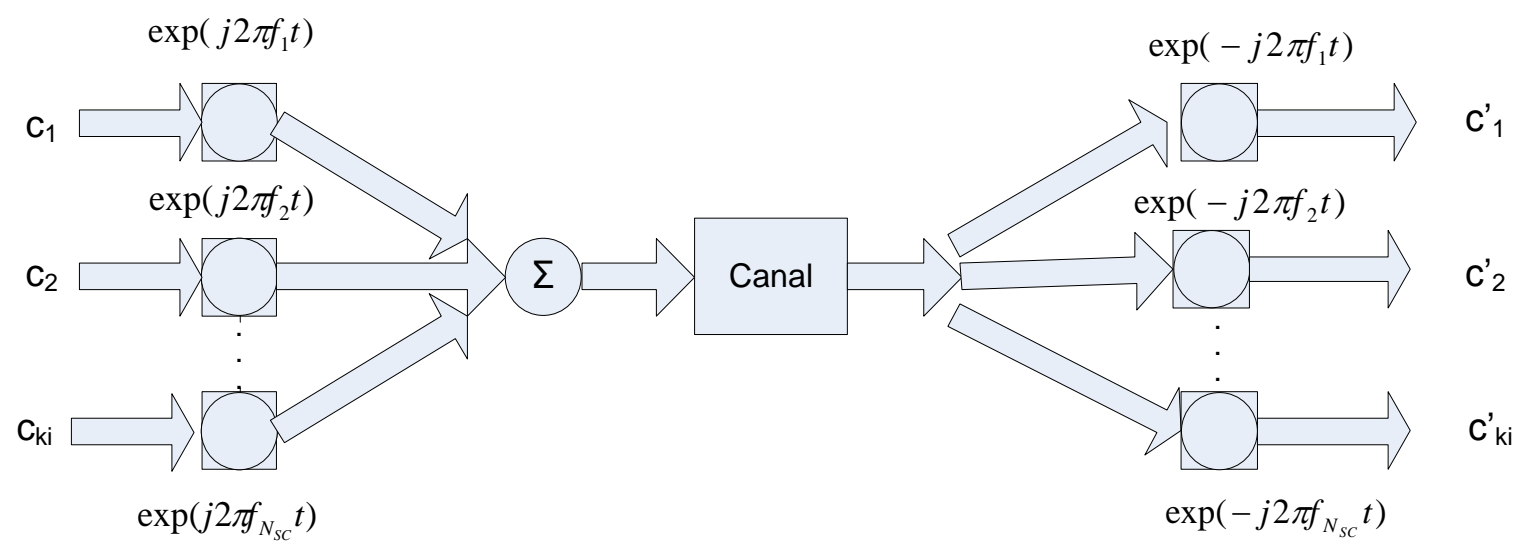

Figura 2.7: Diagrama conceitual para um sistema de multiplexação multiportadora. Os termos $c_{1} \ldots c_{k i}$ representam os símbolos de número i da subportadora $\mathrm{k}$ antes da multiplexação e $c^{\prime}{ }_{1} \ldots c^{\prime}{ }_{k i}$ após a demultiplexação [6].

A informação do símbolo $c_{i k}$ é obtida no processo de demultiplexação é expressa por

$$
c_{k i}^{\prime}=\frac{1}{T_{S}} \int_{0}^{T_{S}} r\left(t-i T_{S}\right) s_{k}^{*} d t=\frac{1}{T_{S}} \int_{0}^{T_{S}} r\left(t-i T_{S}\right) e^{-j 2 \pi f f_{k} t} d t
$$

na qual a sequência temporal $r\left(t-i T_{s}\right)$ é multiplicada pelo complexo conjugado de $s_{k}$ e integrada no período do símbolo da subportadora k para determinar o símbolo $c^{\prime}{ }_{k i}$. A sequência $r\left(t-i T_{s}\right)$ representa a parte temporal do sinal, já no domínio de recepção. Para evitar que as subportadoras da técnica OFDM produzam interferências interportadoras (ICI - intercarrier interference), as subportadoras devem ser ortogonais entre si. Logo,

$$
\int_{0}^{T} \cos \left(\omega_{i} t\right) \cos \left(\omega_{k} t\right) d t=0
$$

para qualquer $i, k$ e $i \neq k$, na qual T é o tempo de sinalização de cada subportadora [38].

São apresentadas na Figura 2.8, três subportadoras OFDM no domínio da frequência. Nota-se que a técnica oferece excelente eficiência espectral, pois graças a mutua ortogonalidade entre subportadoras, estas podem ser alocadas com sobreposição entre si. 


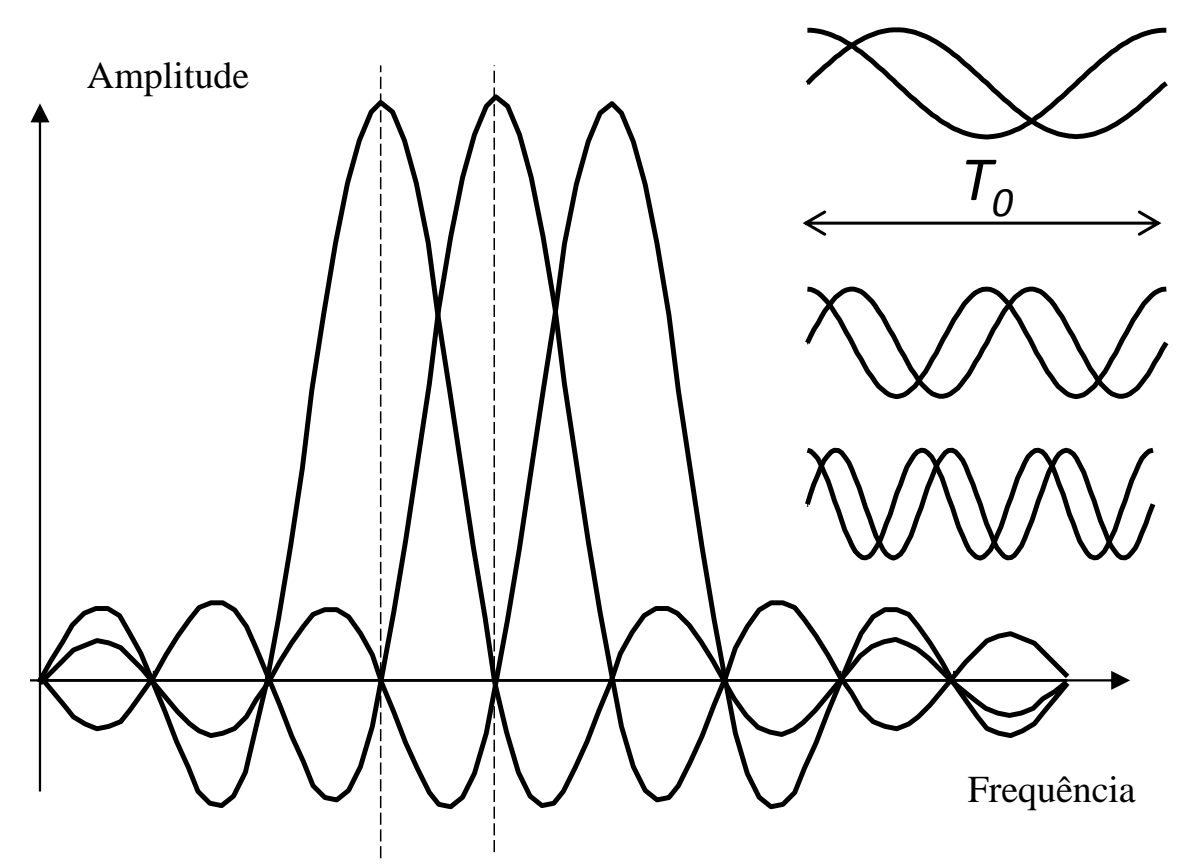

Figura 2.8: Subportadoras OFDM no domínio da frequência.

A transmissão paralela de dados pelas subportadoras, em taxas mais baixas, permite que o OFDM seja robusto a efeitos de degradação, como a interferência intersimbólica (Seção 2.8).

\subsubsection{Transformada discreta de Fourier em OFDM}

No início dos estudos em OFDM, o grande número de subportadoras no sinal tornava complexa sua multiplexação. Isso ocorria por causa do elevado número de osciladores e filtros utilizados, tanto na detecção, quanto na transmissão do sinal. Weinsten e Ebert [3] revelaram que a multiplexação/demultiplexação OFDM podia ser processada utilizando a transformada inversa discreta de Fourier (IDFT - inverse discrete Fourier transform) e a transformada discreta de Fourier (DFT - discrete Fourier transform) [3], o que reduziria a complexidade do sistema, pois haveria uma migração de um sistema analógico para um digital.

Da Equação (2.3) de multiplexação e da (2.6) de demultiplexação, ao omitir o índice i e renomear os índices $\mathrm{N}_{\mathrm{sc}}$ por $\mathrm{N}$ e $\mathrm{T}_{\mathrm{s}}$ por $\mathrm{T}_{\mathrm{s}} / \mathrm{N}$ em (2.3), apenas um símbolo passa a ser analisado. O símbolo de índice $\mathrm{m}$, da amostra s(t) é então representado por 


$$
s_{m}=\sum_{k=1}^{N} c_{k} \cdot e^{j 2 \pi f_{k} \frac{(m-1) T_{S}}{N}}
$$

Sendo $f_{k}$ uma convenção para a frequência da subportadora $k$ em função do período do símbolo $\mathrm{T}_{\mathrm{s}}$, de acordo com [6]:

$$
f_{k}=\frac{k-1}{T_{S}}
$$

substituindo (2.9) em (2.8) temos:

$$
s_{m}=\sum_{k=1}^{N} c_{k} \cdot e^{j 2 \pi f_{k} \frac{(m-1) T_{S}}{N}}=\sum_{k=1}^{N} c_{k} \cdot e^{j 2 \pi \frac{(m-1)(k-1)}{N}}=\mathfrak{I}^{-1}\left\{c_{k}\right\}
$$

na qual $\mathfrak{J}^{-1}$ é a transformada inversa de Fourier e $m \in[1, \mathrm{~N}]$. Assim, o símbolo após o processo de demultiplexação pode ser obtido por

$$
c^{\prime} k=\mathfrak{J}\left\{r_{m}\right\}
$$

na qual $r_{m}$ é a amostra de sinal recebido em cada intervalo de tempo $\mathrm{T}_{s} / \mathrm{N}$ [6].

\subsection{Componentes da arquitetura OFDM-QAM no Optisystem}

O software Optisystem é uma ferramenta CAD (computer aided design), que permite a realização de simulações de sistemas de comunicações ópticas. O software dispõe de diversos componentes que permitem aos usuários planejar, testar e simular enlaces ópticos na camada de transmissão de redes ópticas. A biblioteca de componentes do software possui mais de 250 componentes ativos e passivos, nos domínios elétrico e óptico, em sua versão 9.0 [12]. Além dos componentes ativos e passivos, o software possui ferramentas de visualização gráfica que permitem analisar o desempenho do sistema, sendo as principais: analisadores de BER e diagrama de olho, medidores de potência, osciloscópios e analisadores de espectro.

São apresentados, na Tabela 2.1, os componentes utilizados na montagem dos sistemas OFDM desta dissertação. 
Tabela 2.1: Componentes utilizados na montagem do sistema OFDM-QAM.

\begin{tabular}{|c|c|c|}
\hline (a) PRis Generdor & (b) NRZ-Reference & $\begin{array}{l}\text { (a) (PRBS - pseudo random binary sequence) } \\
\text { gera uma sequência aleatória de bits. } \\
\text { (b) Gera um sinal de não retorno ao zero para } \\
\text { calibração do analisador de BER. }\end{array}$ \\
\hline $\begin{array}{l}\text { (c) } 0 \text { OFDM Modulator } \\
\text { (c) }\end{array}$ & OFDM Demodulator & $\begin{array}{l}\text { (c) Esse componente multiplexa um sinal digital } \\
\text { em múltiplas subportadoras ortogonais. } \\
\text { (d) Esse componente demultiplexa um sinal } \\
\text { OFDM em um sinal digital. }\end{array}$ \\
\hline $\begin{array}{l}\text { DAM } \\
\text { (e) OAM Sequence Generator }\end{array}$ & 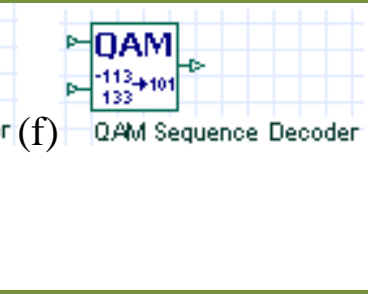 & $\begin{array}{l}\text { (e) Gera duas sequências de símbolos paralelos } \\
\text { a partir de sinais binários, usando a modulação } \\
\text { de amplitude em quadratura. } \\
\text { (f) Decodifica duas sequências de símbolos } \\
\text { paralelos QAM em um sinal binário. }\end{array}$ \\
\hline (g) & (h) Quadrature Demodulator & $\begin{array}{l}\text { (g) Modula um sinal em amplitude e fase } \\
\text { (quadratura). } \\
\text { (h) O sinal em quadratura é demodulado. }\end{array}$ \\
\hline (i) LiNb MQ Modulator & Photodetector PIN & $\begin{array}{l}\text { (i) Simula o modulador Mach-Zehnder, } \\
\text { utilizando um modelo analítico. } \\
\text { (j) Fotodetector PIN (semicondutor PN } \\
\text { polarizado inversamente). }\end{array}$ \\
\hline (k) Constellation Msualizer & (1) BER Analyzer & $\begin{array}{l}\text { (k) Exibe a constelação de um sinal elétrico. } \\
\text { (l) Calcula a taxa de erro de bits e aplica código } \\
\text { corretor de erro. Mostra o fator de qualidade do } \\
\text { sistema e exibe o diagrama de olho. }\end{array}$ \\
\hline 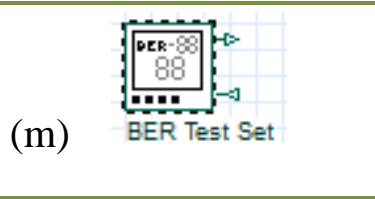 & 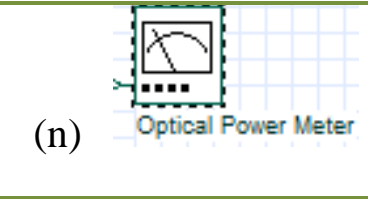 & $\begin{array}{l}\text { (m) Compara bits recebidos com relação aos } \\
\text { enviados (contagem direta de erro). } \\
\text { (n) Calcula a potência óptica no ponto inserido. }\end{array}$ \\
\hline (o) LP Cosine Roll Off Fitter & (p) $\frac{\text { Optical Filter }}{s}$ & $\begin{array}{l}\text { (o) Filtro cosseno levantado (domínio elétrico). } \\
\text { (p) Filtro passa faixa (domínio óptico). }\end{array}$ \\
\hline Bectrical Amplifier & (r) Optical Amplifier & $\begin{array}{l}\text { (q) Amplificador elétrico. } \\
\text { (r) Amplificador óptico de semicondutor. }\end{array}$ \\
\hline (s) & 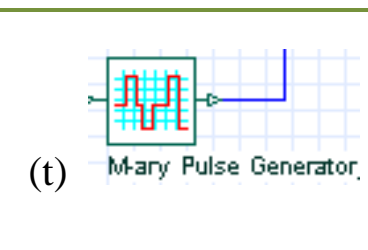 & $\begin{array}{l}\text { (s) Permite criar subsistemas gerando, assim, } \\
\text { um layout mais limpo. } \\
\text { (t) Gerador de pulso elétrico utilizado no } \\
\text { visualizador de constelação. }\end{array}$ \\
\hline
\end{tabular}




\begin{tabular}{|l|l|}
\hline (u) & $\begin{array}{l}\text { (u) Adiciona atenuação óptica ao sistema. } \\
\text { (v) Exibe o espectro elétrico. }\end{array}$ \\
\hline
\end{tabular}

Na Figura 2.9 são apresentados os componentes iniciais para o processo de modulação e multiplexação OFDM - QAM no Optisystem 9.0.

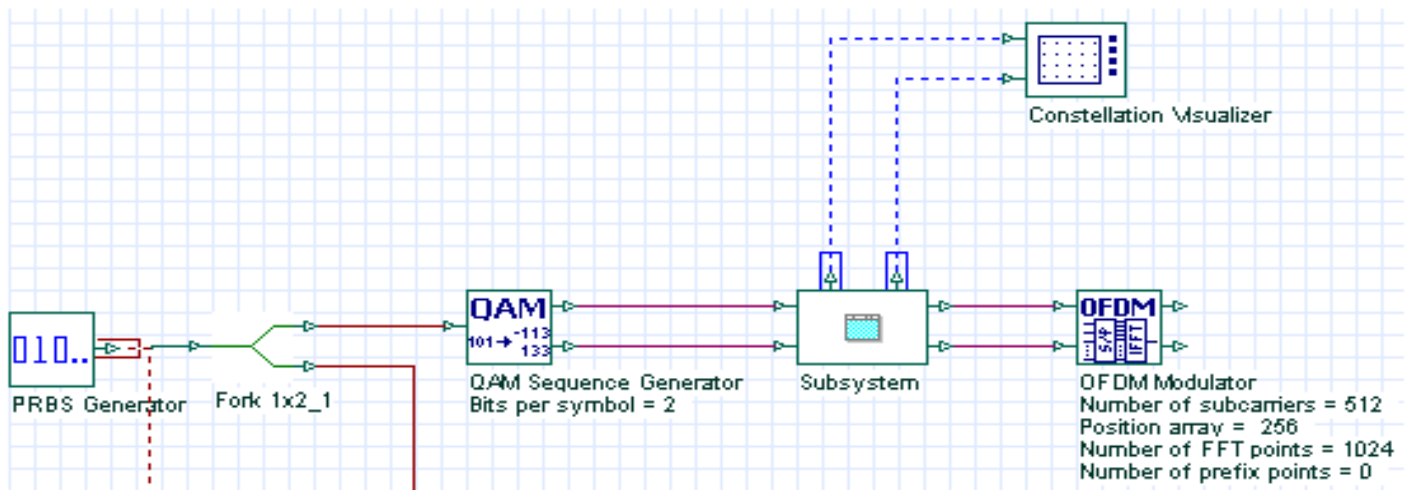

Figura 2.9: Layout introdutório para os bits gerados e o formato de modulação e multiplexação adotado; no caso QAM e o OFDM.

Os componentes PRBS e $Q A M$ sequence generator executam, essencialmente, as funções apresentadas na Tabela 2.1. No componente OFDM, entretanto, o usuário pode alterar diversas propriedades. Pode-se especificar, inicialmente, o número de subportadoras utilizadas na multiplexação, adicionar prefixo cíclico $(C P$ - ciclic prefix) e escolher qual o melhor tipo de interpolação para a informação digital. Neste componente também é realizada a conversão digital-analógico (DAC - digital to analog converter) das informações 
processadas na modulação. O componente OFDM também possui um parâmetro que permite escolher o intervalo de atuação da IDFT.

A IDFT realiza um processamento de sinal que permite obter sequências temporais a partir das sequências em frequência. O processamento pode ser otimizado, caso seja utilizada a transformada rápida inversa de Fourier IFFT (inverse fast Fourier transform). A IDFT é realizada no transmissor e a DFT é realizada no receptor. Desta forma, o receptor realiza a conversão analógico-digital (ADC - analog to digital converter) da informação.

É mostrada na Figura 2.10 a conversão do domínio da frequência para o domínio temporal realizada pela IFFT e do domínio temporal para o domínio da frequência realizada pela FFT.
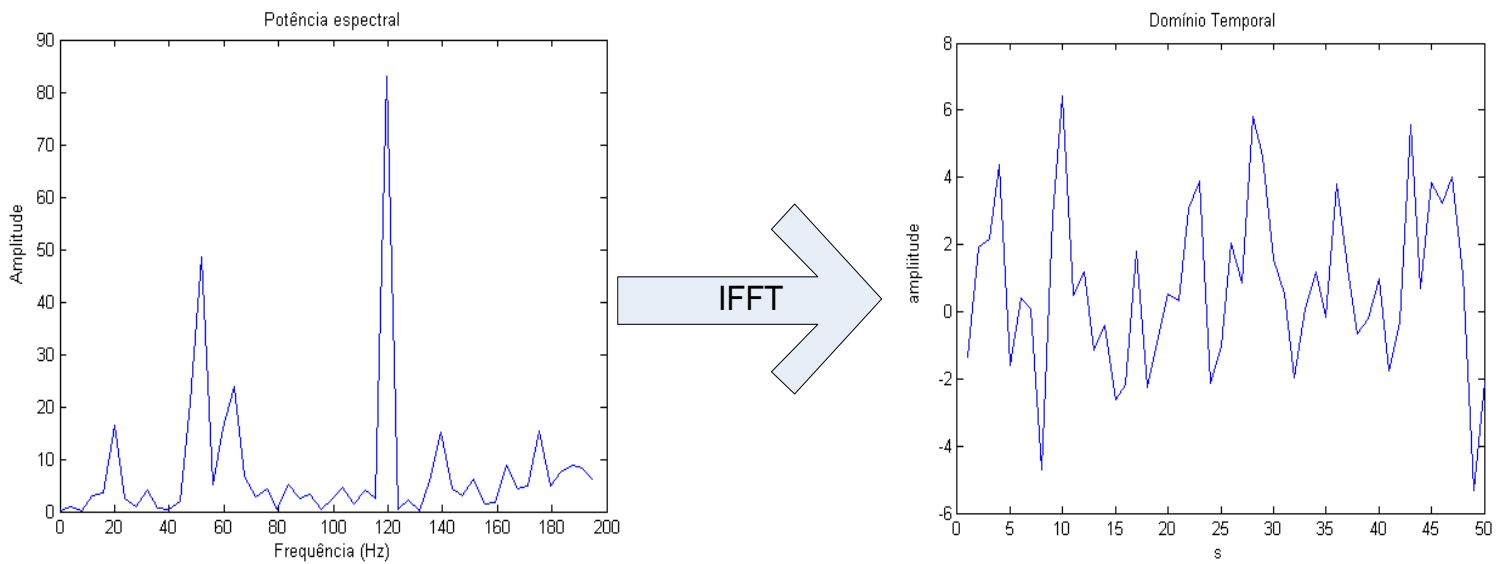

(a)
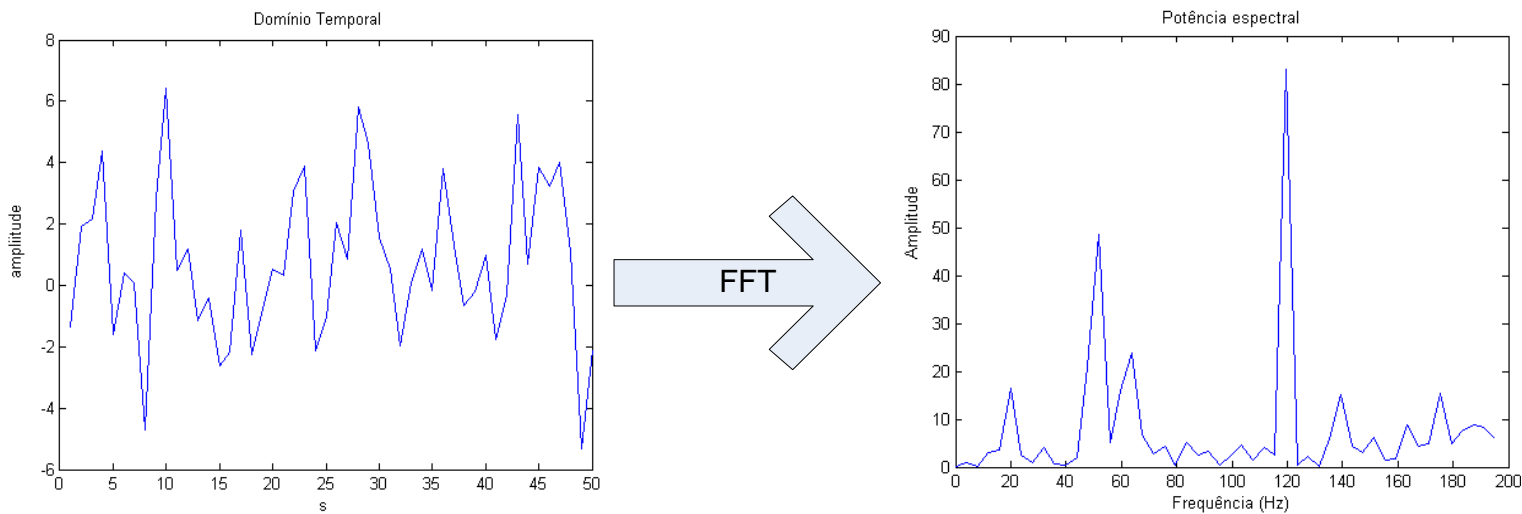

(b)

Figura 2.10: (a) Transformada rápida inversa de Fourier, (b) Transformada rápida de Fourier simulados no Matlab 2010a [22]. 
Desta forma, após a IDFT, o sinal está pronto para receber o prefixo cíclico. O prefixo cíclico é discutido na Seção 2.9.

\subsection{Modulador Mach-Zehnder}

Para transmissão com taxas iguais ou superiores a $10 \mathrm{~Gb} / \mathrm{s}$ e transmissão em longa distância, a modulação direta torna-se difícil e, caso seja necessário o uso de formatos de modulação que exigem maior velocidade de chaveamento nos sinais, as modulações externas são preferencialmente escolhidas. É ilustrado, na Figura 2.11, o modulador simétrico de Mach-Zehnder (MZM - Mach-Zehnder modulator), comumente empregado.

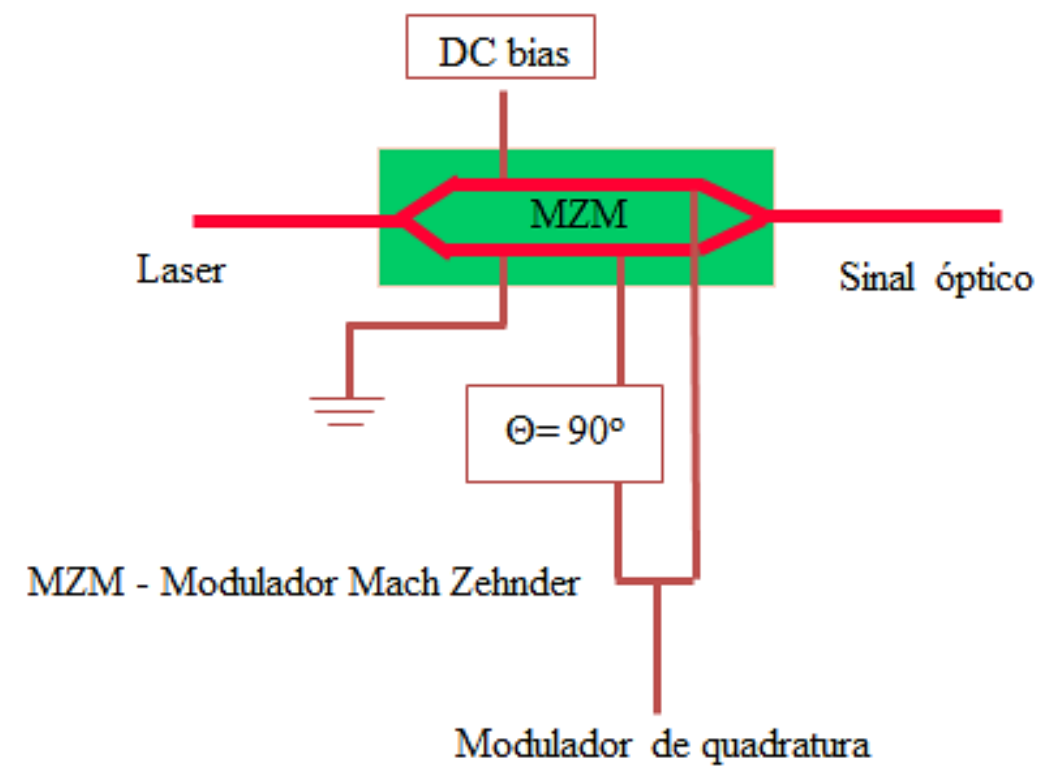

Figura 2.11: Modulador simétrico de Mach-Zehnder, utilizado em modulação externa [6].

O MZM é, basicamente, um interferômetro de Mach-Zehnder. Quando uma tensão elétrica é aplicada nos braços do modulador, o sinal óptico é modulado em fase. Combinando os sinais dos dois percursos ópticos, com diferentes valores de fase, é obtido na saída do modulador um sinal modulado em intensidade. O valor desta intensidade vai depender, exclusivamente, se houve interferência destrutiva ou construtiva dos sinais.

O modulador de quadratura, como apresentado na Figura 2.11, é o responsável pela inserção da tensão elétrica e da diferença de fase entre os braços do modulador Mach-Zehnder. 


\subsection{Interferência Intersimbólica}

A interferência intersimbólica (ISI - intersymbol interference) é uma forma de distorção de um sinal em que um símbolo interfere com símbolos adjacentes. A presença de ISI no sistema introduz erros na recepção do sinal, tornando a transmissão menos confiável. Além disto, esta interferência é muito prejudicial, caso o canal seja muito seletivo em frequência, levando a ocorrência de desvanecimento seletivo, que será discutido no Capítulo 4.

Se o canal não apresenta resposta em frequência plana em toda a faixa de frequências, é inevitável a utilização de equalização em frequência, sendo esta diferente da equalização adaptativa da constelação, a ser discutida na Seção 2.9. A equalização em frequência compensa as distorções em frequência causadas pelo canal, apresentando uma resposta em frequência inversa à resposta do canal.

O efeito qualitativo da ISI pode ser visualizado construindo-se o diagrama de olho. Este diagrama é obtido seccionando a sequência de sinais na saída do canal de transmissão em segmentos de $\mathrm{T}$ segundos, e superpondo cada segmento no intervalo [0,T]. A formação do diagrama de olho é ilustrada na Figura 2.12, a partir de uma simulação no Optisystem 9.0.

É ilustrado, na Figura 2.12, um diagrama de olho praticamente livre de ISI em (a) e com forte presença de ISI em (b). 


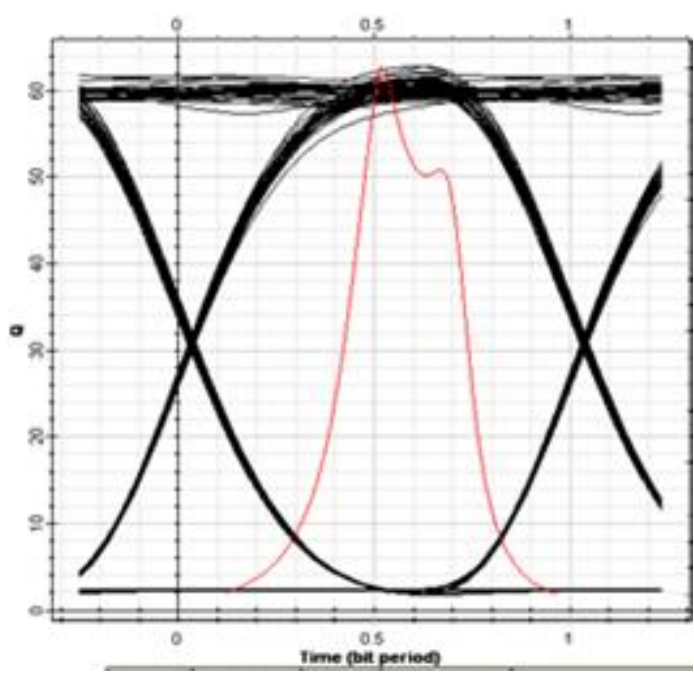

(a)

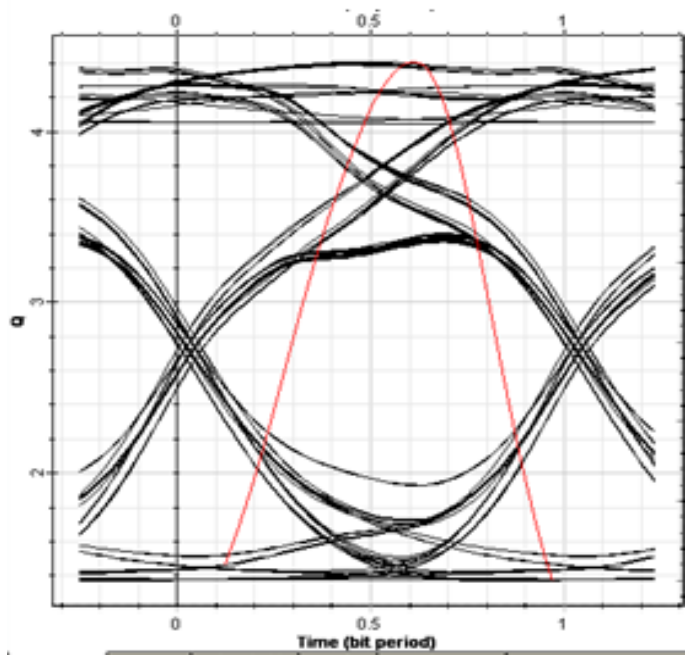

(b)

Figura 2.12: (a) Diagrama de olho de um sistema com baixa interferência intersimbólica, (b) sistema com interferência intersimbólica severa, simulados no Optisystem 9.0.

O diagrama de olho pode ser observado em um osciloscópio, com taxa de varredura horizontal igual a 1/T. Uma ISI severa, como a da Figura 2.12 (b), provoca o fechamento do olho e reduz a robustez da transmissão. A curva com destaque em vermelho no diagrama de olho é o fator de mérito do sistema (também chamado de fator de qualidade). Por definição, o fator de qualidade é o múltiplo $2 \pi$ da razão entre a máxima energia armazenada pelo circuito, $\mathrm{W}_{\text {máx, }}$ e a energia por ele dissipada em um ciclo do sinal $\mathrm{W}_{\mathrm{d}}$,

$$
Q=2 \pi \frac{w_{\text {máx }}}{w_{d}}
$$

Em um sistema de comunicação óptica com uma única subportadora, a taxa de símbolos produzidos no transmissor é

$$
R_{\text {Simbolos }}=\frac{R_{\text {Bits }}}{m}
$$

na qual $m$ é o número de bits por símbolo e $R_{B i t s}$ é a quantidade de bits na transmissão.

Para o formato de modulação 4-QAM, por exemplo, $m=2$ e a expressão que define a ordem de modulação é

$$
S_{\text {símbolos }}=2^{m}
$$


No sistema OFDM com $\mathrm{N}$ subportadoras, a taxa de símbolos por subportadora $\mathrm{R}_{\mathrm{S}, \mathrm{P}} \mathrm{e}$

$$
R_{S, P}=\frac{R_{B I T S}}{m \cdot N}
$$

Logo, a quantidade de símbolos por subportadora é $\mathrm{N}$ vezes inferior a de um sistema que não utiliza a técnica OFDM. Uma taxa de símbolos baixa torna o sistema robusto à interferência intersimbólica [39].

\subsection{Prefixo Cíclico (CP - cyclic prefix) e equalização adaptativa}

Os sistemas de transmissão OFDM são concebidos para operar com dois tipos de proteção contra as degradações na resposta impulsiva de um canal de comunicação. A primeira proteção é realizada no domínio temporal, sendo denominada de prefixo cíclico. A segunda é uma proteção no domínio da frequência empregando a técnica de equalização adaptativa [40].

O prefixo cíclico é uma cópia da parte final de um símbolo OFDM que é concatenado a ele em sua parte inicial. É uma das características mais importantes dos sistemas OFDM, já que sua função é diminuir a interferência intersimbólica.

Em sistemas de recepção que permitem a inserção de subportadoras piloto, a equalização do canal de transmissão é efetuada por ajustes de fase e amplitude do sinal. Este ajuste aumenta a eficiência dos equalizadores em canais dispersivos. As subportadoras pilotos não transportam informação e são inseridas e removidas dinamicamente na transmissão em posições e frequências específicas, de acordo com o sincronismo transmissor/receptor.

O equalizador consiste em um dispositivo de decisão que determina qual símbolo da constelação, na saída do receptor, é o mais próximo à constelação transmitida.

Um aspecto do funcionamento dos equalizadores é baseado na forma de adaptação; assim, os equalizadores são classificados em supervisionados e autodidatas. No caso da equalização supervisionada, há necessidade do envio da sequência de treinamento, previamente conhecida no receptor, para que o equalizador possa ajustar seus coeficientes e enviar uma decisão adequada da constelação. No caso da equalização autodidata, o sinal de treinamento é substituído por um aprendizado permanente, com base em algoritmos estatísticos [41]. 
É apresentada, na Figura 2.13 (a), uma constelação 4-QAM sem equalização, obtida após a passagem do sinal por um canal dispersivo. Na Figura 2.13 (b) é apresentada a mesma constelação após o processo de equalização adaptativa autodidata.

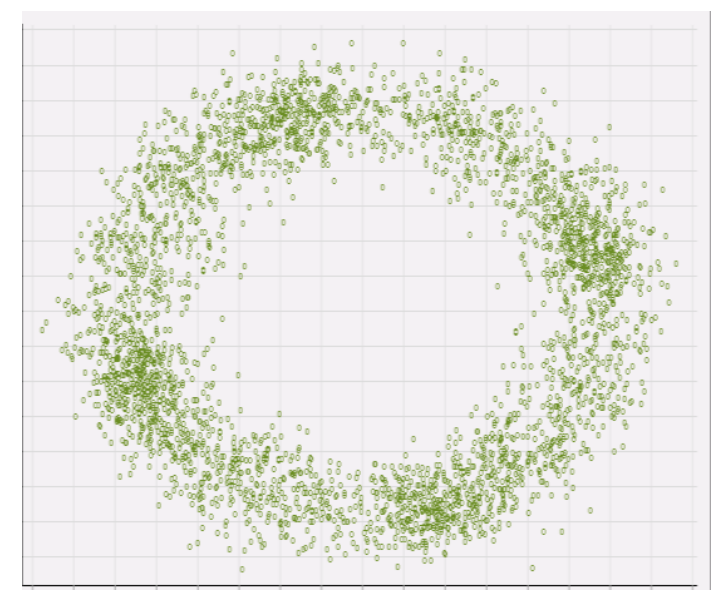

(a)

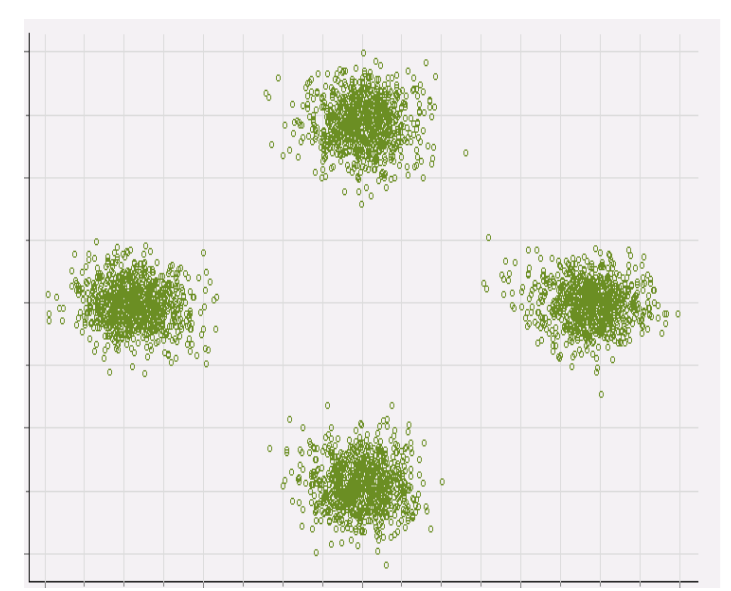

(b)

Figura 2.13: Constelações 4-QAM obtidas no VPI player 8.7. Em (a) sem equalização e em (b) com equalização [13].

Seja x um sinal a ser transmitido em um canal com resposta impulsiva h. O prefixo cíclico consiste na extensão da última parte do $n$-ésimo bloco OFDM que é copiada para o início do bloco.

É ilustrada, na Figura 2.14, a ideia do prefixo cíclico. Nesta representação, cada linha identifica um canal e o símbolo é identificado pelos blocos 0 , bloco 1 e bloco 2, no qual

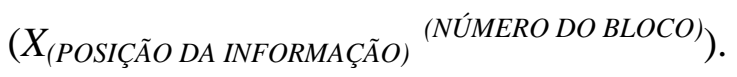

Assim, o bloco 0 é formado pelos elementos $\left\{X_{0}{ }^{0}, X_{1}{ }^{0}, X_{2}{ }^{0}\right\}$, o bloco 1 por $\left\{X_{0}{ }^{1}, X_{1}{ }^{1}, X_{2}{ }^{1}\right\}$ e o bloco 2 por $\left\{X_{0}{ }^{2}, X_{1}{ }^{2}, X_{2}{ }^{2}\right\}$, sendo que o tamanho de cada bloco é N=3. $\mathrm{Na}$ segunda linha, os blocos são deslocados de uma posição para a direita e, assim, sucessivamente. Por fim, o prefixo cíclico (CP) é um bloco de tamanho $\mathrm{N}=2$ e possui os elementos $\left\{X_{1}{ }^{0}, X_{2}{ }^{0}\right\}$ para o bloco CP $0,\left\{X_{1}{ }^{1}, X_{2}{ }^{1}\right\}$ para o bloco CP 1 e $\left\{X_{1}{ }^{2}, X_{2}{ }^{2}\right\}$ para o bloco CP 2. 


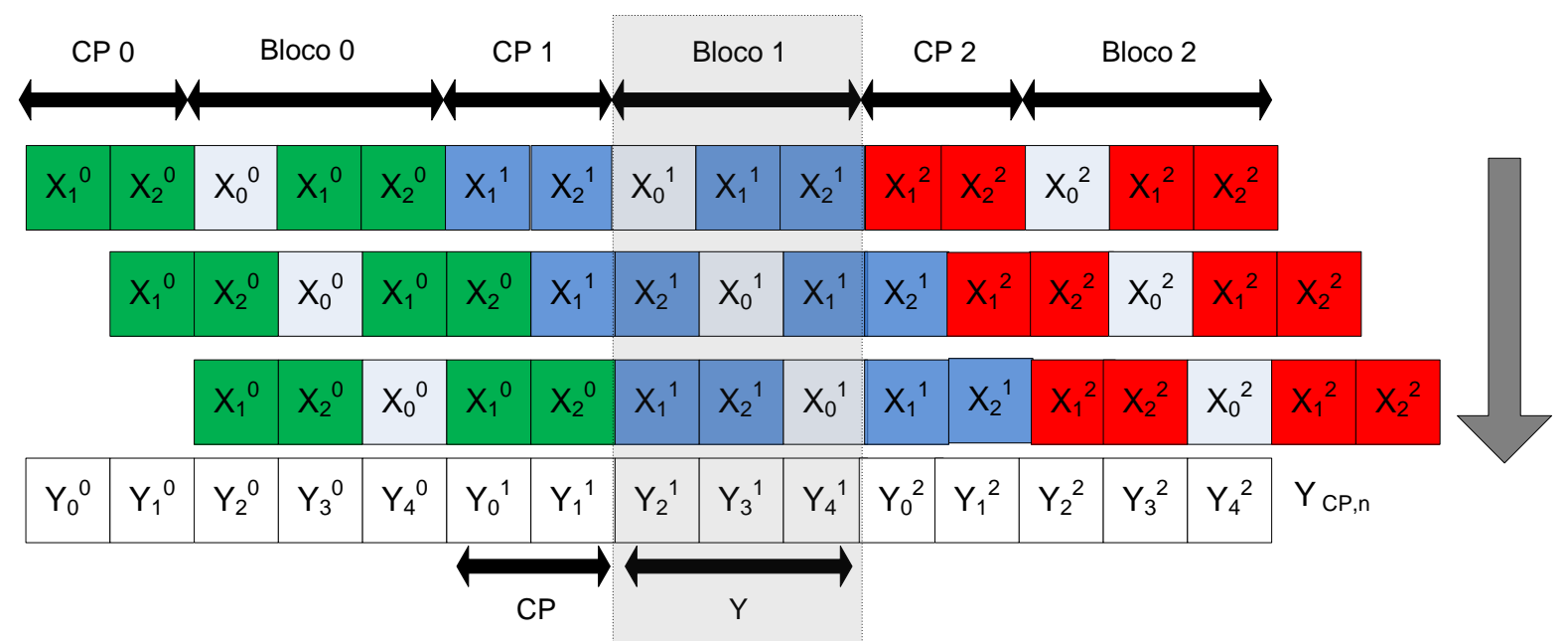

Figura 2.14: Representação do prefixo cíclico [42].

A linha $Y_{C P, n}$ contém uma janela com os elementos $Y=\left\{Y_{2}{ }^{1}, Y_{3}{ }^{1}, Y_{4}{ }^{1}\right\}$ que é afetada apenas pelos elementos $X=\left\{X_{0}{ }^{1}, X_{1}{ }^{1}, X_{2}{ }^{1}\right\}$, onde a janela $Y$ corresponde à convolução circular de $X=\left\{X_{0}{ }^{1}, X_{1}{ }^{1}, X_{2}{ }^{1}\right\}$ com o canal $H$ [42].

A convolução circular está apresentada na janela sombreada, sendo expressa por

$$
Y=H \otimes X
$$

Assim, na medida em que há convolução cíclica entre o sinal transmitido e a resposta impulsiva do canal, prefixos cíclicos são inseridos antes de cada símbolo OFDM.

Conforme afirmação feita no início desta seção, apesar do prefixo cíclico e a equalização atuarem em domínios diferentes, eles estão relacionados para a melhora significativa do sinal. 


\section{Técnicas de detecção OFDM}

Como já citado nesta dissertação, a sobreposição temporal de símbolos adjacentes caracteriza a ISI. Neste aspecto, o prefixo cíclico é um recurso muito importante da técnica OFDM no combate a este tipo de degradação. Entretanto, é apresentada, neste capítulo, uma alternativa muito conhecida para mitigar a ISI: a utilização de filtros cosseno levantado no domínio elétrico. Posteriormente, é ilustrado o processo de geração de banda lateral simples na detecção direta. São mostradas, ainda, as principais características das detecções direta e coerente.

\subsection{Filtro cosseno levantado}

Os filtros na transmissão devem, sempre que possível, atender ao critério de Harry Nyquist [43] para interferência intersimbólica nula. Harry Nyquist foi o primeiro a propor um modo de tentar anular a ISI. Se possível, vários sinais superpostos poderiam ser enviados, aproveitando ao máximo a banda passante, sem que essas superposições gerassem interferência.

Um método de controlar a ISI é a formatação adequada dos pulsos a serem transmitidos. Uma forma de pulso que produz uma ISI nula é

$$
P(t)=\frac{\operatorname{sen}(2 \pi W t)}{2 \pi W t}=\operatorname{sinc}(2 \mathrm{Wt})
$$

na qual W é a largura de banda do filtro de Nyquist e $\mathrm{P}(\mathrm{t})$ é a transformada inversa de Fourier da função retangular $\mathrm{P}(\mathrm{f})$ definida em:

$$
\begin{gathered}
P(f)=\left\{\begin{array}{l}
\frac{1}{2 W}-W<f<W \\
0,|f|>W
\end{array}\right. \\
W=\frac{R_{b}}{2}=\frac{1}{T_{b}}
\end{gathered}
$$

na qual $R_{b}$ é a taxa de bits do canal de Nyquist e $T_{b}$ a duração do bit.

É mostrada, na Figura 3.1, a forma de pulso P(t) que produz a ISI nula. A função $\mathrm{P}(\mathrm{t})$ anula-se em intervalos de tempo igualmente espaçados, múltiplos do período $T_{b}=\pi / 2$, exceto 
no centro. Portanto, os pulsos de mesma forma, espaçados por $T_{b}$ não sofrerão interferência. $\mathrm{Na}$ prática, entretanto, existem algumas dificuldades para se implementar um filtro que produza um efeito de função sinc ao pulso transmitido. Um filtro passa-baixas ideal não é fisicamente realizável. Além disso, essa forma de onda possui uma dependência crítica com a precisão da sincronização.

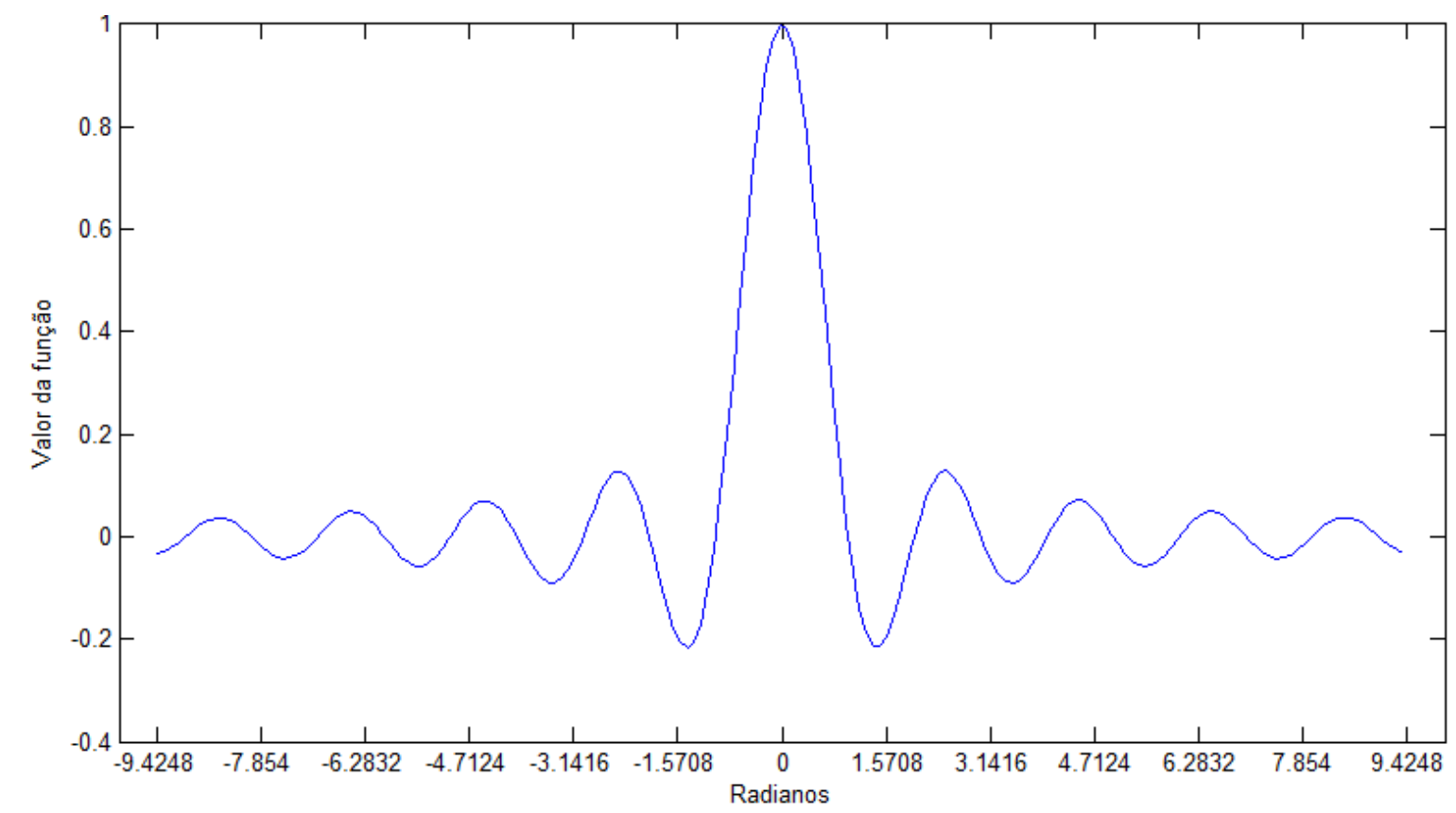

Figura 3.1: Representação da função sinc(2Wt), simulado no Matlab 2010a [22], na qual 2Wt está em radianos.

O filtro utilizado nas simulações desta dissertação é o filtro cosseno levantado. Este filtro é inserido no sistema de transmissão, logo após o componente OFDM (Figura B.1 apêndice B). O filtro cosseno levantado é capaz de atender ao requisito da resposta ao impulso, inserindo zeros uniformemente espaçados no tempo, no qual a resposta em frequência decai para zero gradualmente, ao invés de abruptamente como na função sinc (2Wt). A resposta em frequência do filtro cosseno levantado é representada em (3.4) [27].

$$
P(f)=\left\{\begin{array}{l}
\frac{1}{2 W}, 0 \leq|f|<f_{1} \\
\frac{1}{4 W}\left\{1-\operatorname{sen}\left[\frac{\pi(|f|-W}{2 W-2 f_{1}}\right]\right\}, f_{1} \leq|f|<2 W-f_{1} \\
0,|f| \geq 2 W-f_{1}
\end{array}\right.
$$

É apresentado, na Figura 3.2, o perfil da função cosseno levantado para diferentes parâmetros $\beta$. O parâmetro $\beta$ é definido a seguir. 

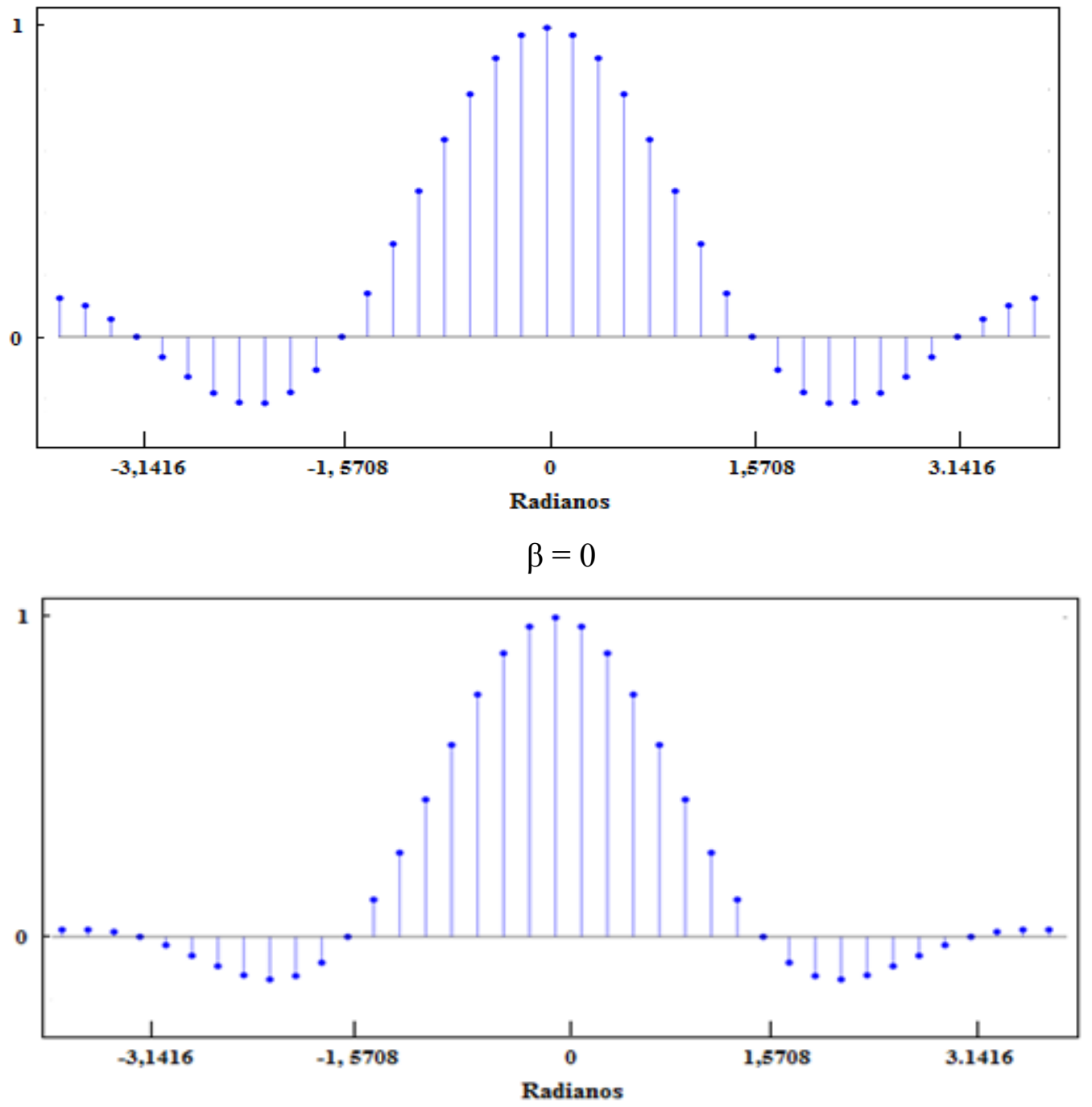

$\beta=0,5$

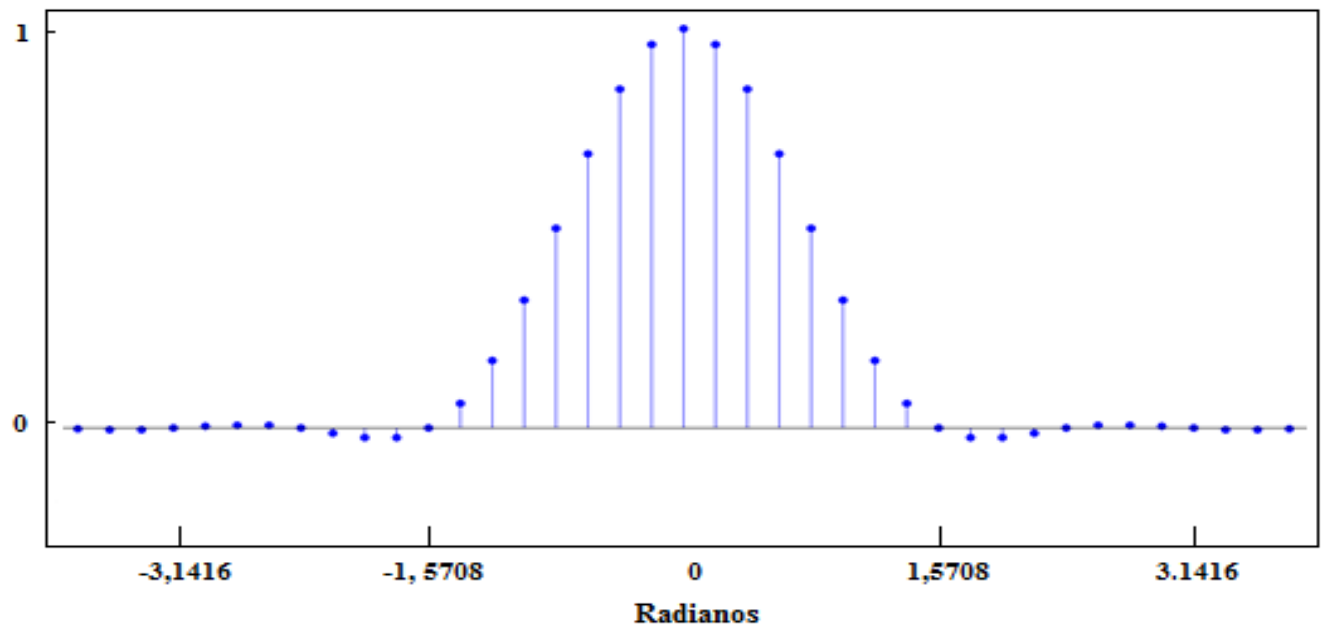

$\beta=1,0$

Figura 3.2: Perfil da função cosseno levantado para diferentes graus de suavidade, simulados no Matlab 2010a. 
$\mathrm{O}$ parâmetro de frequência $\mathrm{f}_{1}$ e a largura de banda do filtro de Nyquist $\mathrm{W}$ são relacionados por

$$
\beta=1-\frac{f_{1}}{W}
$$

O parâmetro $\beta$ é chamado de roll-off e indica o grau de suavidade da resposta em frequência.

Para $\beta=0,5$ ou $\beta=1,0$, a função $\mathrm{P}(\mathrm{f})$ é rapidamente atenuada quando comparada com o canal de Nyquist (caso ideal $\beta=0$ ).

A resposta temporal $\mathrm{p}(\mathrm{t})$ é a transformada inversa de Fourier da resposta em frequência $\mathrm{P}(\mathrm{f})$

$$
p(t)=(\sin c(2 W t))\left(\frac{\cos (2 \pi \alpha W t)}{1-16 \alpha^{2} W^{2} t^{2}}\right)
$$

A forma como (3.6) é obtida é apresentada no apêndice A.

Embora o impulso sinc seja aquele que viabiliza a máxima taxa de transmissão, com ausência de ISI, o impulso ainda apresenta sensibilidade a ISI residual devido, principalmente, ao lento decrescimento do impulso ao longo do tempo (oscilação do impulso, como mostrado na Figura 3.1). Por esse motivo, o perfil de função cosseno levantado é o mais utilizado, já que atenua os lóbulos laterais (rápido decrescimento do impulso).

\subsection{Detecção Óptica Direta OFDM (DDO-OFDM)}

$\mathrm{Na}$ detecção óptica direta o fotodetector do receptor óptico gera uma corrente elétrica proporcional à potência óptica recebida da fibra e as informações são codificadas na intensidade do sinal. Neste trabalho foram utilizados fotodetectores com estrutura PIN para a simulação. Estes fotodetectores apresentam, como principal vantagem, o menor nível de ruído quando comparado com os fotodetectores APD (avalanche photodiode).

A detecção óptica direta foi utilizada no início das pesquisas em comunicações ópticas OFDM por causa do baixo custo, ao se utilizar receptores sem circuitos adicionais de oscilação local.

O primeiro relato DDO-OFDM foi sobre o desempenho da técnica em antena de televisão comunitária (CATV - community antenna television), no qual o OFDM apresentou 
robustez ao ruído gerado pelo laser [6]. As pesquisas seguintes revelaram a viabilidade de implementação da banda lateral única (SSB-OFDM - single sideband) em DDO-OFDM com a finalidade de aumentar a eficiência espectral da arquitetura [14].

Pode-se afirmar, entretanto, que a principal desvantagem da arquitetura DDO-OFDM é a exigência de $7 \mathrm{~dB}$ a mais na OSNR para o sinal que chega ao receptor, quando comparado com o receptor coerente OFDM [44]. A detecção direta divide-se em duas categorias, de acordo com a geração do sinal OFDM:

(1) mapeada linearmente (linearly mapped), (LM-DDO-OFDM), na qual o espectro óptico OFDM é uma réplica do sinal de banda base;

(2) mapeado de forma não linear (nonlinearly mapped), (NLM-DDO-OFDM), na qual o espectro óptico OFDM não exibe uma réplica da banda base. 


\subsubsection{Detecção óptica direta linearmente mapeada}

Na Figura 3.3 são mostrados os pontos de localização dos analisadores de espectro elétrico e óptico para a obtenção dos resultados apresentados nessa seção.

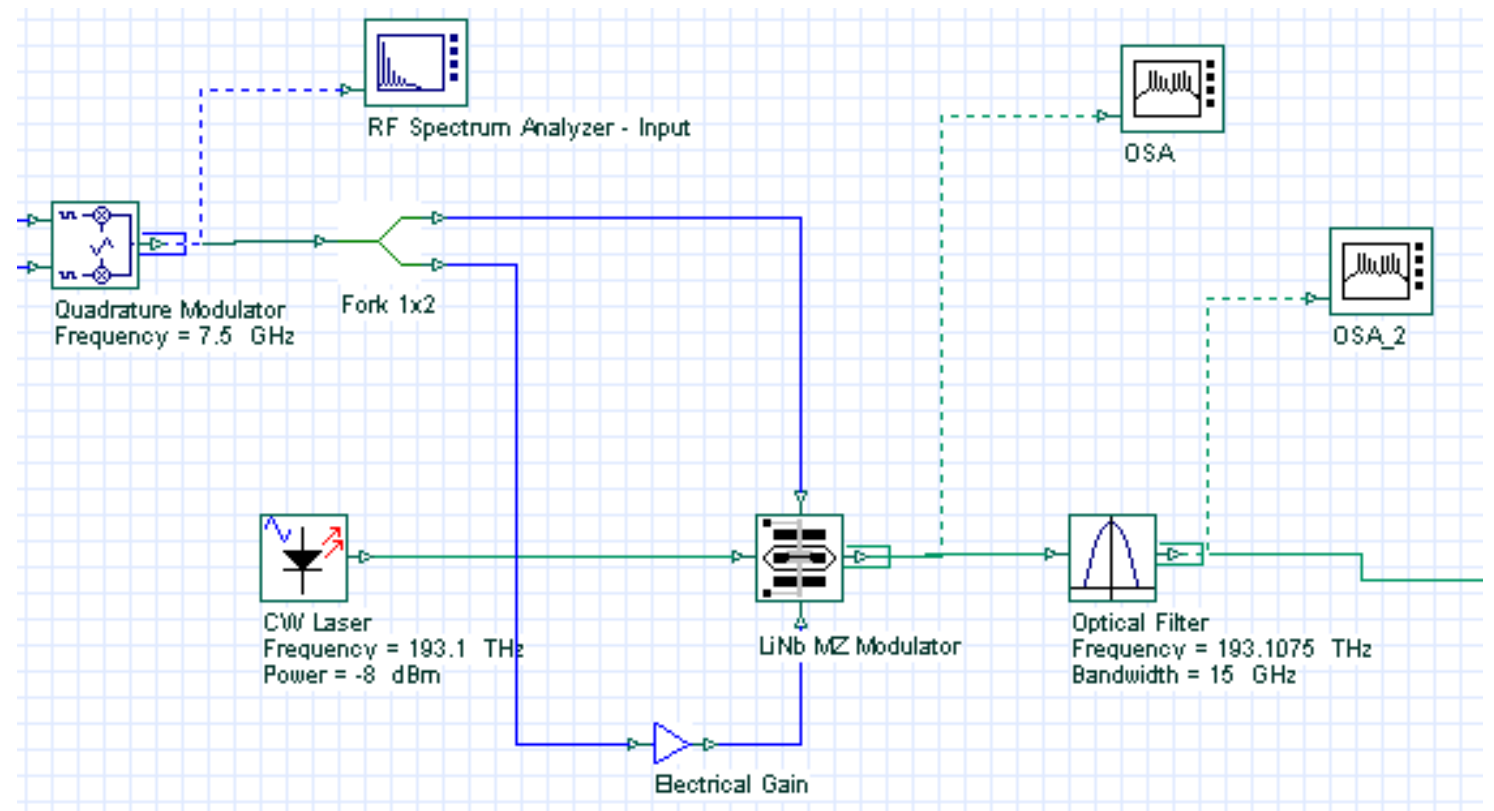

Figura 3.3: Localização dos analisadores de espectro para a obtenção dos resultados obtidos no Optisystem 9.0.

Na Figura 3.4 (a) é ilustrado o sinal elétrico de banda base do multiplexador OFDM. A banda base especifica a faixa de frequências de um determinado sinal modulante. Na Figura 3.4(b), a portadora óptica principal, na frequência de 193,1 THz, é modulada pelo sinal banda base.

O processo de modulação é realizado pelo modulador simétrico de Mach-Zehnder. 

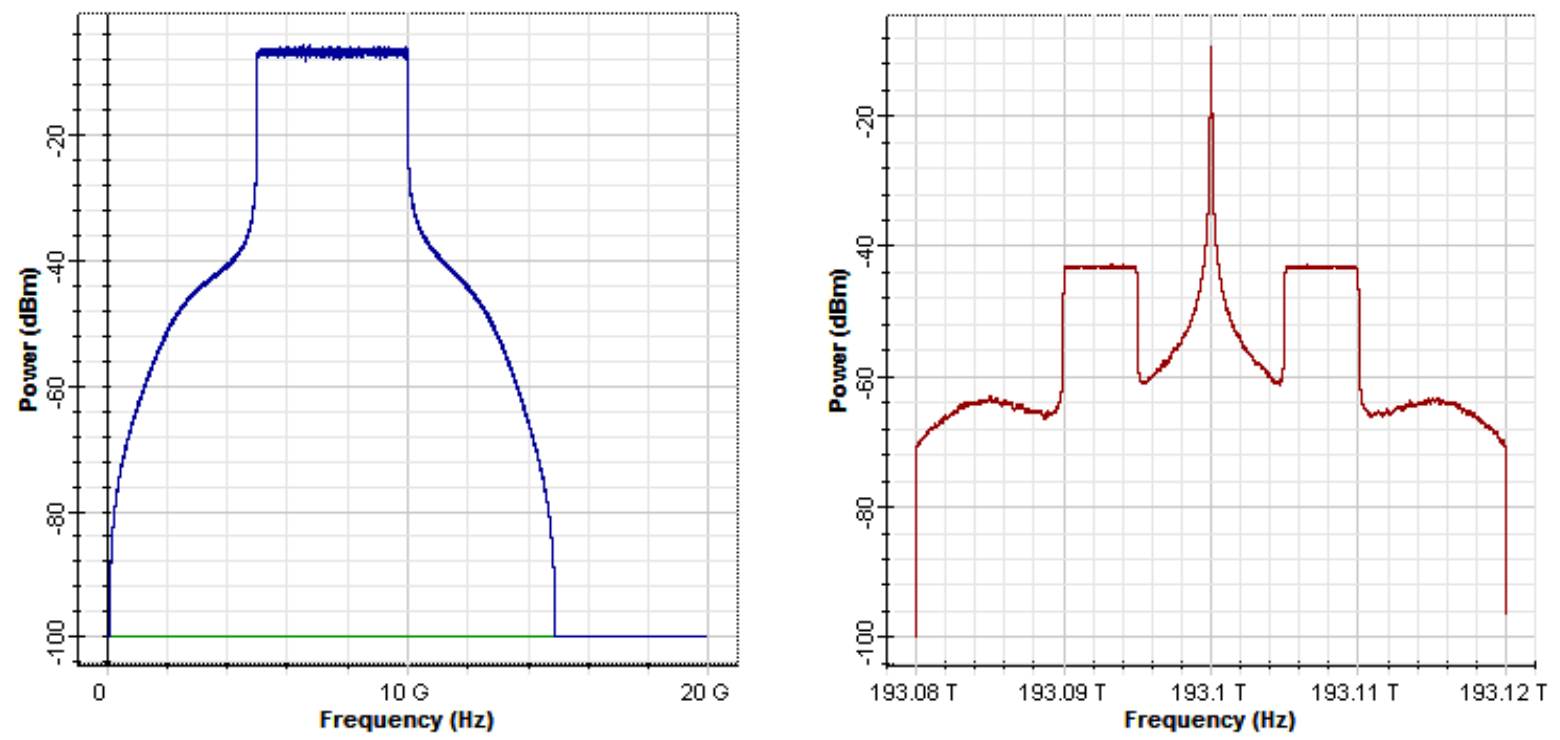

Figura 3.4: (a) Espectro da banda base (domínio elétrico) e (b) espectro do sinal (em banda lateral dupla) no domínio óptico (sem filtragem), simulados no Optisystem 9.0.

O espectro do sinal óptico, como apresentado na Figura 3.4 (b), apresenta uma grande desvantagem. Devido aos efeitos dispersivos da fibra óptica, as bandas laterais podem sofrer desvios de fases diferentes, dependendo da distância percorrida pelo sinal na fibra óptica e da frequência de modulação do sinal.

Estes desvios de fase podem originar interferências destrutivas ou construtivas. A inserção de um filtro óptico na saída do modulador Mach-Zehnder é, conceitualmente, o método mais simples para suprimir uma banda lateral [45]. Outra vantagem da supressão de uma das bandas laterais é elevar a eficiência espectral, permitindo a inserção de um número maior de canais.

A detecção de um espectro óptico na detecção direta (DDO-OFDM) pode ser descrita por [6]:

$$
s(t)=e^{j 2 \pi f t}+\alpha e^{j 2 \pi\left(f_{0}+\Delta f\right) t} s_{B}(t)
$$

no qual $s(t)$ é o sinal óptico OFDM, $f_{0}$ é a frequência da portadora óptica principal e $\Delta f$ é a banda de guarda da portadora óptica.

No processo de conversão do domínio elétrico para o óptico, $\alpha$ é o coeficiente da 
portadora óptica, $s_{B}(t)$ é o sinal de banda base (sinal OFDM no domínio elétrico), representado por

$$
S_{B}(t)=\sum_{k=1}^{N} c_{k} \cdot e^{j 2 \pi f_{k} t}
$$

Conforme definido no Capítulo 2, $c_{k}$ e $f_{k}$ são, respectivamente, a informação do símbolo OFDM e a frequência da subportadora $k_{N}$. Em (3.5), apenas a banda base é considerada. Entretanto, após se propagar pela fibra óptica com efeitos dispersivos, não lineares e ruídos, o sinal é modificado. Considerando, como exemplo, somente o efeito da dispersão cromática, conforme descrito em [6], o sinal no domínio óptico, pode ser representado por

$$
\begin{aligned}
& \left.r(t)=e^{j\left(2 \pi f f_{0} t+\phi_{D}(-\Delta f)+\phi(t)\right)}+\alpha e^{j\left(2 \pi\left(f_{0}+\Delta f\right) t+\phi(t)\right)} \cdot \sum_{k=1}^{N} c_{i k} e^{(j 2 \pi f} k t+\phi_{D}\left(f_{k}\right)\right) \\
& \phi_{D}\left(f_{k}\right)=\pi \cdot c \cdot D_{t} \cdot \frac{f_{k}^{2}}{f_{0}^{2}}
\end{aligned}
$$

na qual $r(t)$ é a potência da radiação que atinge o fotodetector, $\Phi_{D}\left(f_{k}\right)$ é o atraso da fase devido à dispersão cromática para a subportadora $k, D_{t}$ é a dispersão cromática acumulada em picossegundo por picometro (ps/pm), $f_{0}$ é a frequência central do espectro óptico OFDM e $c$ é a velocidade da luz no vácuo $(\mathrm{m} / \mathrm{s})$.

Utilizando a expressão para a fotodetecção (lei quadrática do fotodetector), a fotocorrente pode ser aproximada por

$$
\begin{aligned}
& I(t) \propto|r(t)|^{2}=1+2 \alpha \operatorname{Re}\left\{e^{j 2 \pi \Delta f t} \sum_{k=1}^{N} c_{i k} e^{\left(j 2 \pi f f_{k} t+\phi_{D}\left(f_{k}\right)-\phi_{D}(-\Delta f)\right)}\right\}+ \\
& \left|\alpha^{2}\right| \sum_{k=1}^{N} \sum_{k=1}^{N} c^{*} k_{2} c_{k_{1}} e^{\left[j 2 \pi\left(f_{k_{1}}-f_{k_{2}}\right)+\phi_{D}\left(f_{k_{1}}\right)-\phi_{D}\left(f_{k_{2}}\right)\right]}
\end{aligned}
$$

O primeiro termo é um componente linear constante, o segundo termo representa as subportadoras OFDM e o terceiro termo é um componente não linear de segunda ordem e precisa ser removido. Desta forma, o objetivo das abordagens descritas, a seguir, é reduzir a penalidade no sinal advindo do termo não linear de segunda ordem. 
A primeira técnica a ser discutida, procura reduzir a penalidade inserida pelo termo não linear. É a técnica da banda lateral simples deslocada. Esta técnica utiliza um processo de filtragem óptica para suprimir uma das bandas laterais e eliminar o termo não linear de segunda ordem. A finalidade da segunda técnica é a mesma. Entretanto, é efetuada por microcontroladores. A terceira técnica também propõe a eliminação do termo não linear de segunda ordem por meio da transmissão coerente.

1 - A banda lateral simples deslocada OFDM (OSSB-OFDM - offset single sideband $O F D M$ ) foi proposta por Lowery e Armstrong [46]. Inicialmente, o sinal elétrico OFDM em banda base é processado em um modulador de quadratura, que ajusta a fase e frequência da banda base, de acordo com a frequência da portadora óptica. Os sinais do modulador de quadratura são enviados para o modulador óptico simétrico de Mach-Zehnder, o qual gera, devido ao efeito de modulação da portadora, bandas simétricas em relação à portadora óptica, conforme mostrado na Figura 3.4 (b).

É apresentada, na Figura 3.5 (a), a portadora óptica antes do modulador óptico simétrico de Mach-Zehnder, e na Figura 3.5 (b), o espectro do sinal modulado após o modulador óptico simétrico de Mach-Zehnder com filtragem óptica.
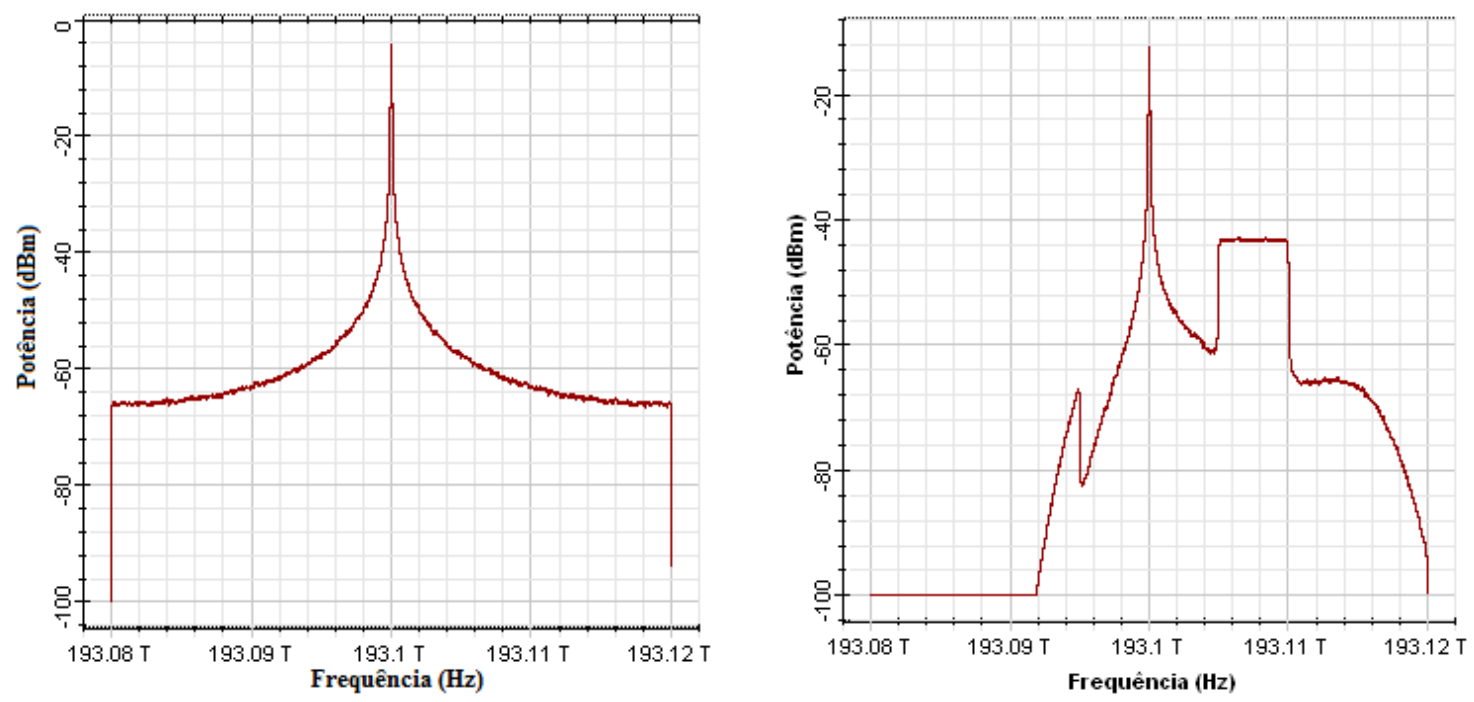

Figura 3.5: (a) Espectro antes do MZM simétrico, (b) espectro óptico na saída do filtro, localizado após o MZM simétrico. Espectros simulados no Optisystem 9.0.

Caso não ocorra o ajuste da frequência do modulador de quadratura com a região de frequências na qual o filtro atua, não ocorrerá a supressão da banda lateral. Desta forma, o ajuste correto do conjunto (modulador de quadratura/filtro óptico) é importante para a filtragem da banda lateral. A fim de compreender melhor a ideia é apresentado na Figura 3.6 
(a) um espectro com bandas laterais muito próximas, o que dificulta a filtragem da banda lateral. É mostrada na Figura 3.6 (b) uma filtragem óptica defeituosa (sem supressão da banda lateral) decorrente da falta de sincronismo entre o modulador de quadratura/filtro óptico.
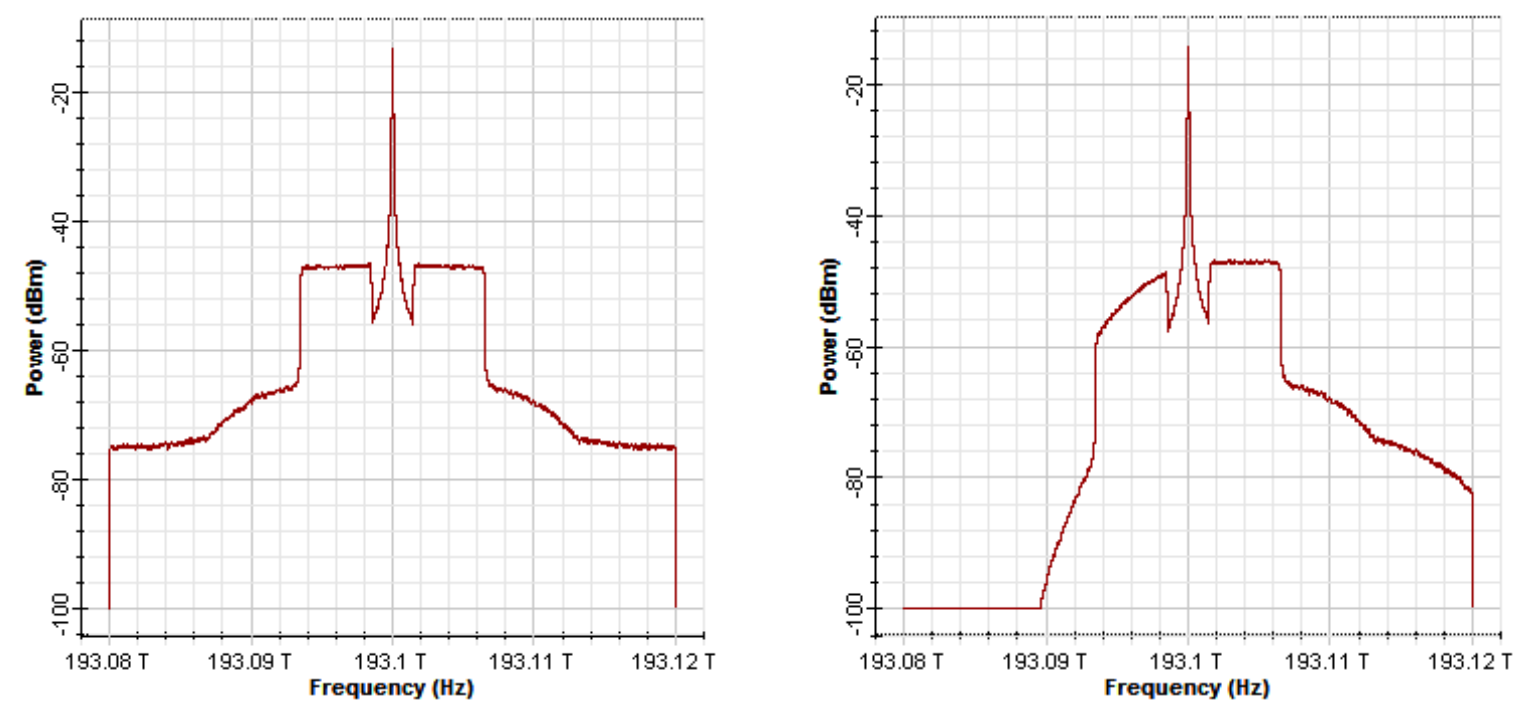

Figura 3.6: (a) Espectro com bandas laterais muito próximas dificultando a filtragem da banda lateral, (b) banda lateral sem supressão (filtragem incompleta da banda lateral).

2 - A banda base óptica lateral simples (BO-SSB-OFDM - baseband optical single sideband $O F D M$ ) exibe uma banda óptica lateral, obtida por intermédio de um processamento digital, que utiliza microcontroladores e um modulador simétrico Mach-Zehnder, de acordo com os estudos em [47]. Como a técnica não utiliza filtros ópticos para a obtenção da SSBOFDM, parte do termo não linear de segunda ordem permanece no sinal [6]. A técnica oferece, assim, baixa eficiência no tratamento da banda lateral.

3 - A técnica OFDM assistida por pulso RF (RF-TA-OFDM - radio frequency toneassisted $O F D M$ ) é capaz de realizar uma modulação coerente no transmissor, usando um pulso RF nas subportadoras, uma espécie de batimento. A referência [6] não cita características detalhadas do pulso.

Quando utilizado na arquitetura de detecção direta, a técnica apresenta boa sensibilidade na recepção, quando comparada com a técnica $B O-S S B-O F D M$, além de exibir uma menor penalidade na transmissão após $260 \mathrm{~km}$, utilizando uma fibra óptica monomodo convencional [48]. As vantagens desta técnica são a boa eficiência espectral e a razoável sensibilidade no receptor, embora requeira certa complexidade na implementação do sistema de transmissão. 
O termo não linear de segunda ordem é mitigado, de acordo com [6], pela modulação coerente no transmissor.

\subsubsection{Detecção óptica direta mapeada de forma não linear}

A diferença entre a detecção óptica direta mapeada de forma não linear e a detecção óptica direta mapeada de forma linear, respectivamente, NLM-DDO-OFDM e LM-DDOOFDM, está no seu espectro óptico. A NLM-DDO-OFDM é geralmente produzida por lasers com modulação direta. Esses modulam as portadoras ópticas pela variação da corrente de injeção. Desta forma, os lasers com modulação direta convertem o sinal elétrico neles aplicado em sinal óptico de saída.

Algumas das desvantagens da modulação direta com relação à modulação externa são o chirp $^{1}$ elevado e a dificuldade de modulação a altas frequências.

É mostrada na Figura 3.7, a comparação entre as duas classes de mapeamento.
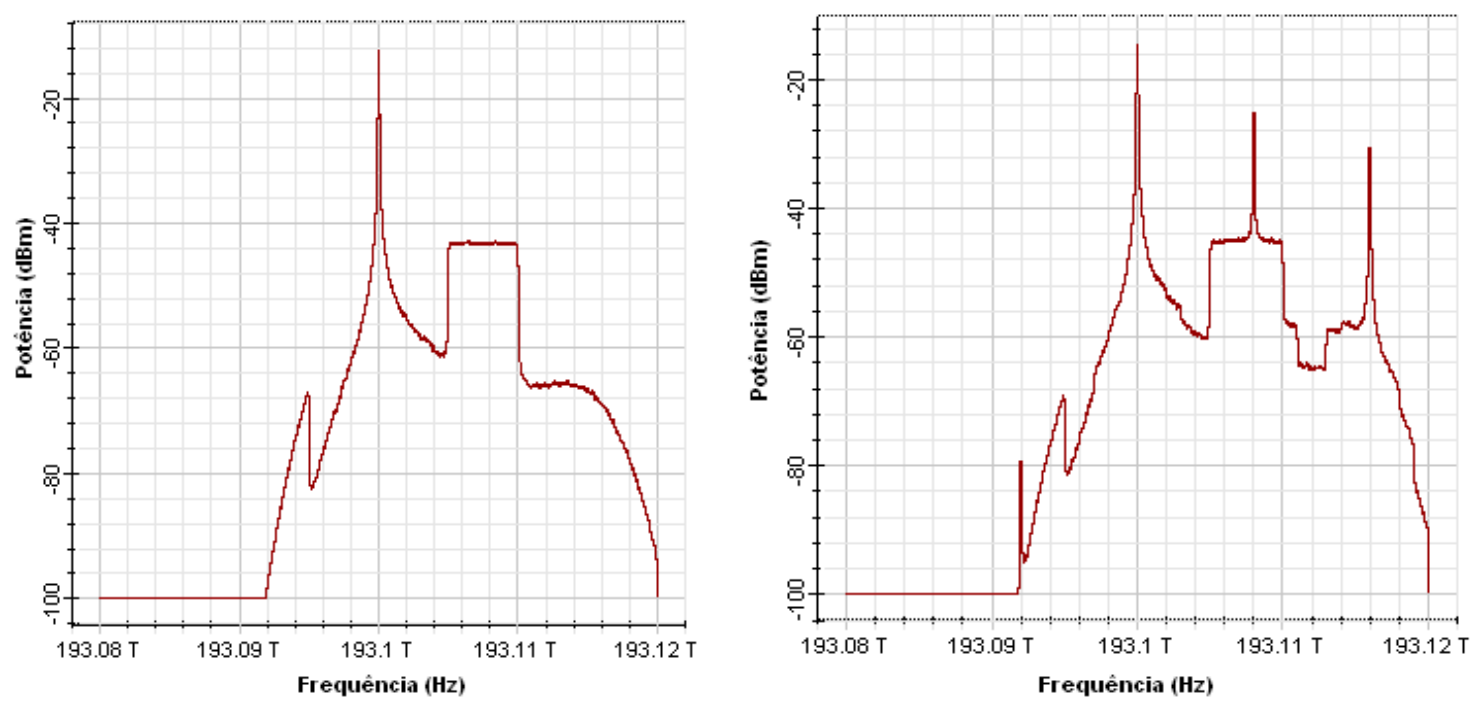

Figura 3.7: (a) Espectro óptico em LM-DDO-OFDM, (b) Espectro óptico em NLM-DDO-OFDM, simulados no Optisystem 9.0.

A classe NLM-DDO-OFDM produz um espectro de potência no domínio óptico que não estabelece uma relação linear com sua banda base. Assim, a NLM-DDO-OFDM

\footnotetext{
${ }^{1}$ Aumento da largura espectral da portadora óptica. Resulta, principalmente, devido às mudanças na corrente de injeção (gorjeio do laser).
} 
proporciona uma significativa distorção no espectro óptico, por isso, esta classe de detecção é utilizada apenas em aplicações de muito curta distância, i.e. até 4 km [6].

\subsection{Detecção Óptica Coerente OFDM (COD-OFDM)}

O mecanismo da detecção coerente (COD- coherent optical detection) é diferente da detecção direta. Em geral, a detecção coerente é classificada em heteródina ou homódina. Em ambos os casos, o receptor necessita de um oscilador óptico local. A ideia é produzir interferência entre o sinal de detecção com o gerado no oscilador óptico local. O resultado dessa interferência produzirá um sinal elétrico resultante pelo fotodetector.

A diferença entre a detecção coerente heteródina e a homódina é que na primeira, as frequências de transmissão e do oscilador local são diferentes e na segunda, são iguais [10].

A detecção óptica coerente representa o estado da arte de desempenho e sensibilidade do receptor, por possibilitar uma ótima eficiência na estimação de fase do canal, eficiência espectral e robustez à PMD e à dispersão cromática. Entretanto, ela requer maior cuidado na implementação, quando comparada com a detecção direta. Na literatura, a detecção óptica coerente com a técnica OFDM foi proposta, inicialmente, por [49] e pouco tempo depois foi formalizada a ideia de múltiplas entradas e múltiplas saídas para facilitar o controle da PMD [50]. Uma COD-OFDM foi construída sem a adição de prefixo cíclico nas subportadoras em [51] e, por intermédio desta técnica, foi confirmada a alta eficiência dos sistemas OFDM utilizando detecção coerente.

\subsubsection{Princípio de funcionamento do COD-OFDM}

A arquitetura COD-OFDM possui dois esquemas de detecção: com conversão direta, utilizado nesta dissertação, e com frequência intermediária. Ambos permitem que a detecção seja coerente homódina ou heteródina.

No esquema de conversão direta, o receptor é constituído de dois pares de fotodetectores e um circuito para ajuste de fase para minimizar a ocorrência de interferências.

É mostrada, na Figura 3.8, a arquitetura COD-OFDM com o esquema de conversão direta. 


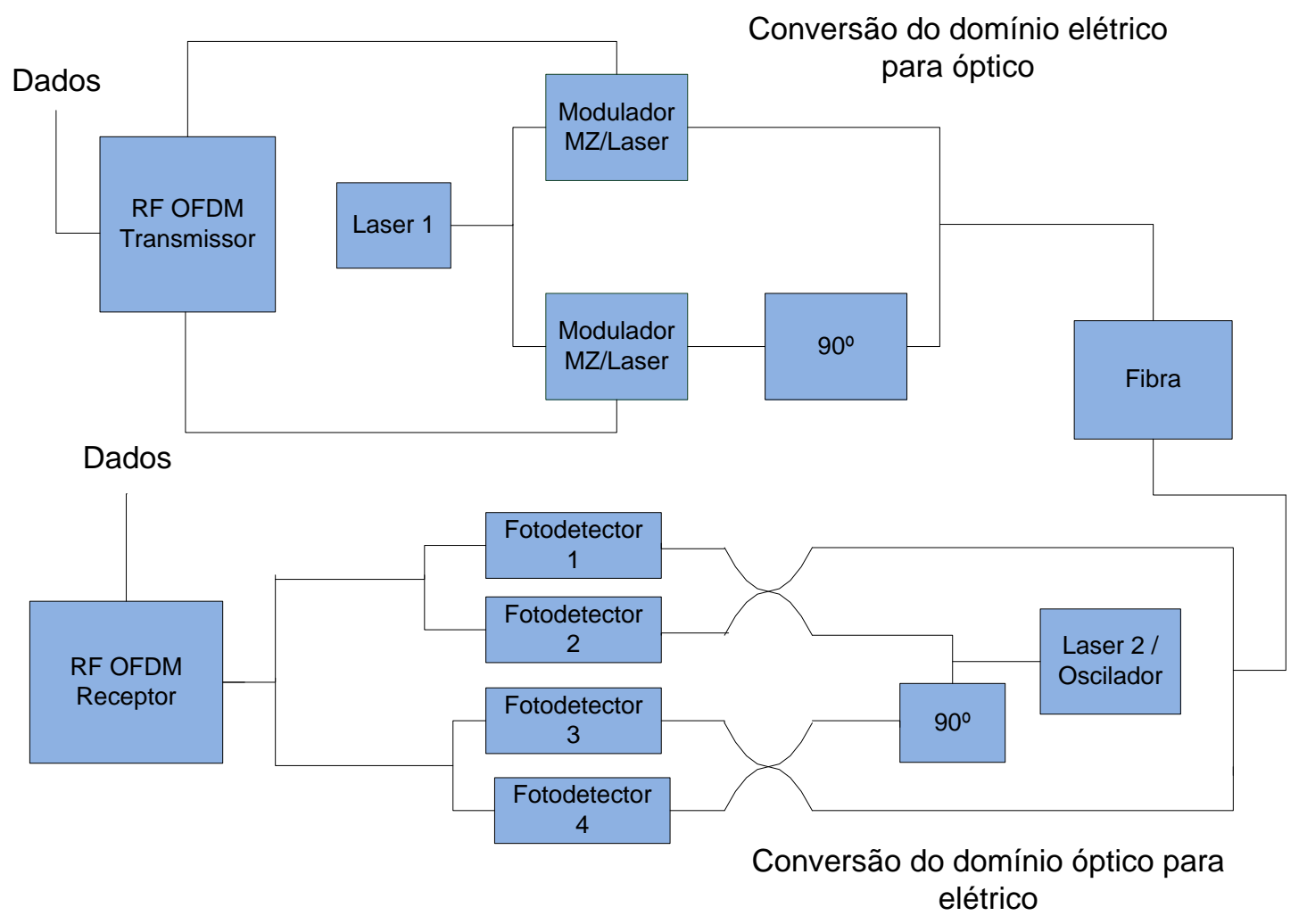

Figura 3.8: Esquema básico da arquitetura COD-OFDM com conversão direta [6].

O objetivo de utilizar dois pares de fotodetectores é suprimir o ruído e mitigar os efeitos não lineares advindos da intermodulação dos sinais OFDM [52].

São apresentados, na Figura 3.8, dois moduladores MZM que trabalham com controle de atrasos entre os sinais, com a finalidade de evitar distorções nos formatos de modulação [53].

As vantagens da detecção coerente com conversão direta, em relação à detecção direta offset SSB-OFDM, a mais difundida e utilizada nesta dissertação, são:

(1) oferecer a possibilidade de operar sem filtragem óptica na saída do modulador MZM;

(2) exigir menor OSNR na detecção [44].

$\mathrm{Na}$ arquitetura COD-OFDM, no esquema de frequência intermediária, há a necessidade de dois osciladores elétricos, sendo o primeiro no transmissor e o segundo no receptor, conforme é ilustrado na Figura 3.9. 
Nesta detecção é exigida a reconfiguração do transmissor e do receptor após qualquer alteração de parâmetros. Isso ocorre, já que esta configuração exige sincronismo, entre as fases do sinal do transmissor e do receptor. Pode-se afirmar que a COD-OFDM com frequência intermediaria é uma versão da técnica OFDM assistida por pulso RF; porém, nesta seção, operando com a técnica de detecção coerente, diferente da mencionada na seção 3.2.1, com detecção direta.

É mostrada, na Figura 3.9, a arquitetura COD-OFDM no esquema de frequência intermediária. Não foram simulados enlaces com este esquema, já que o simulador Optisystem não possui, até o momento, componentes que permitam a inserção de um oscilador local no transmissor.

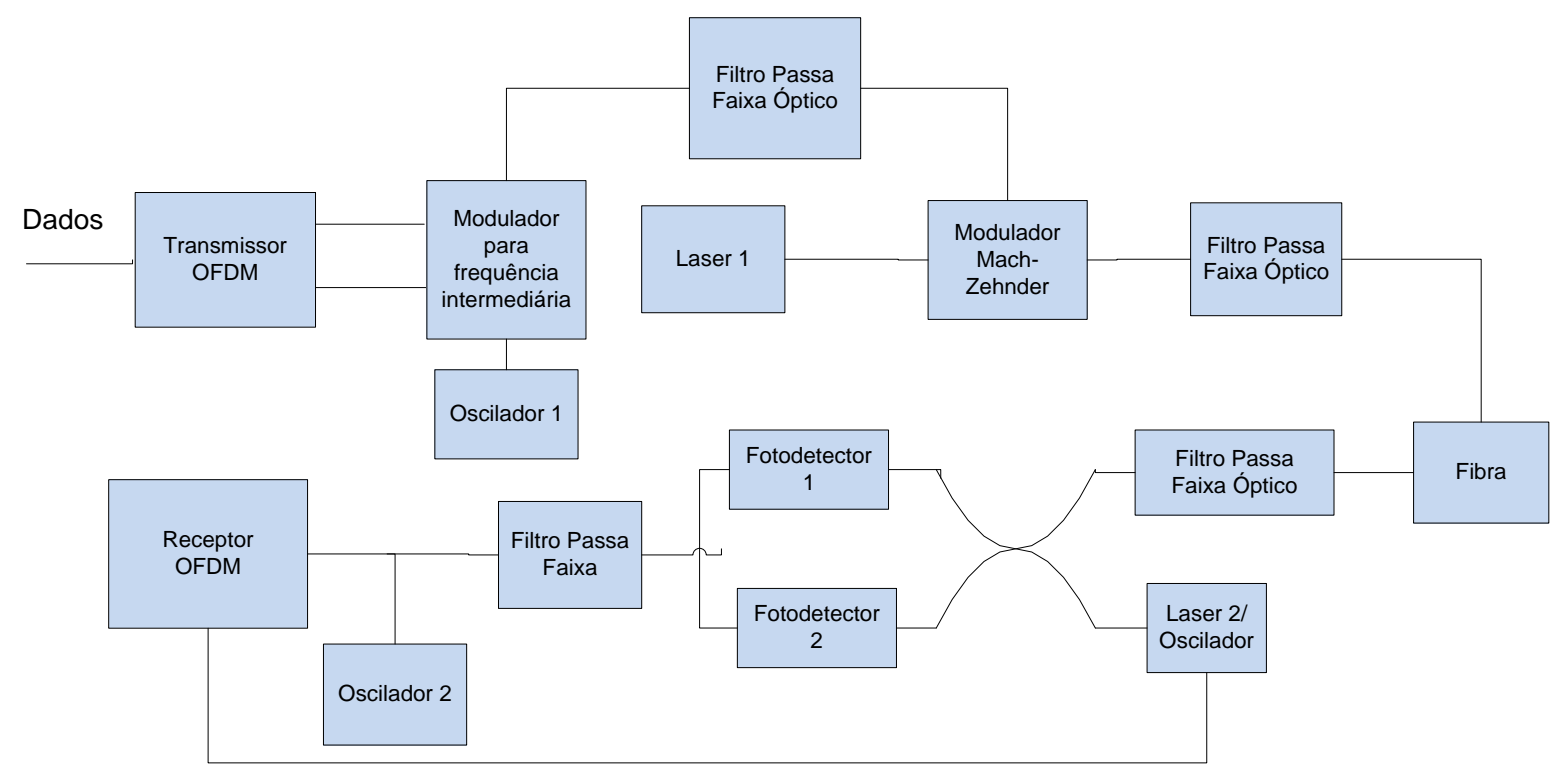

Figura 3.9: Esquema básico da arquitetura COD-OFDM com frequência intermediária [6]. 


\section{Efeitos de degradação, vantagens e desvantagens do OFDM}

Os sistemas de comunicações ópticas têm sido mundialmente utilizados desde 1980, revolucionando as redes de telecomunicações e possibilitando o extraordinário crescimento da internet. Assim, atualmente, as fibras ópticas são o suporte das redes de telecomunicações, encontrando-se tanto em redes que abrangem uma grande área geográfica, incluindo as redes intercontinentais, como em pequenas redes isoladas dentro de condomínios. Entretanto, vários efeitos de degradação podem provocar degradação do sinal transmitido por fibras.

Neste capítulo, são apresentados os efeitos dispersivos, os efeitos não lineares e os fenômenos do espalhamento inelástico, todos esses classificados como os principais efeitos de degradação do sinal em fibras ópticas.

São apresentadas, também, as vantagens e desvantagens em utilizar a técnica OFDM em comunicações ópticas.

\subsection{Principais efeitos de degradação do sinal}

São apresentados, na Figura 4.1, os principais efeitos de degradação do sinal em fibra óptica.
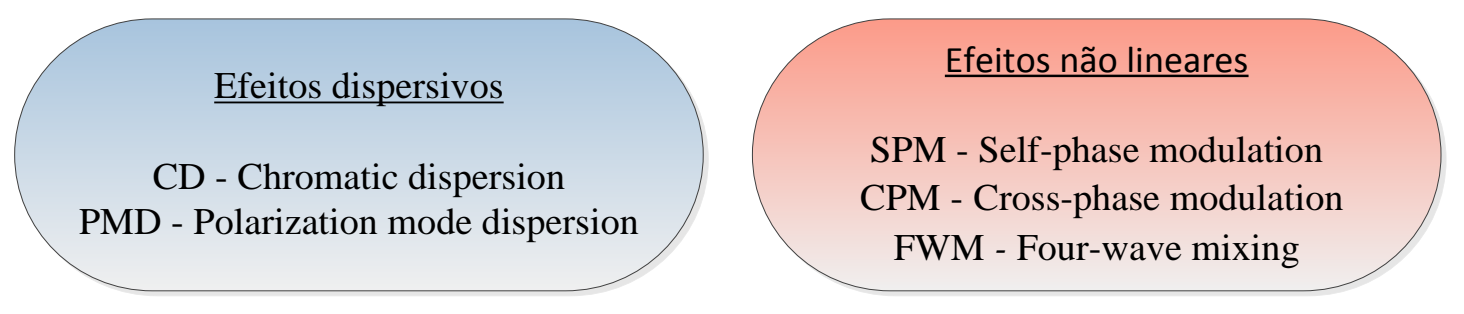

Fenômenos do espalhamento inelástico

SBS - Stimulated Brillouin-scattering

SRS - Stimulated Raman-scattering

Figura 4.1: Relação dos principais efeitos de degradação do sinal em fibras ópticas [24]. 


\subsubsection{Efeitos dispersivos}

Os efeitos dispersivos influenciam na evolução temporal dos pulsos, ocasionando alargamento e, consequentemente, provocando aumento na taxa de erro de bits. São apresentados, a seguir, os principais efeitos dispersivos em fibra óptica.

\section{a) Dispersão cromática}

Como o índice de refração depende do comprimento de onda e as fontes luminosas possuem uma largura espectral finita, ou seja, não são idealmente monocromáticas, a onda eletromagnética referente a cada comprimento de onda propaga-se com velocidade de fase diferente para cada componente espectral do sinal. Após determinada distância de propagação, as diferentes componentes espectrais estarão atrasadas entre si e o pulso sofrerá um alargamento temporal, limitando a taxa máxima de dados a ser transmitida [54]. É apresentado, na Figura 4.2, um sinal sob ação da dispersão cromática.

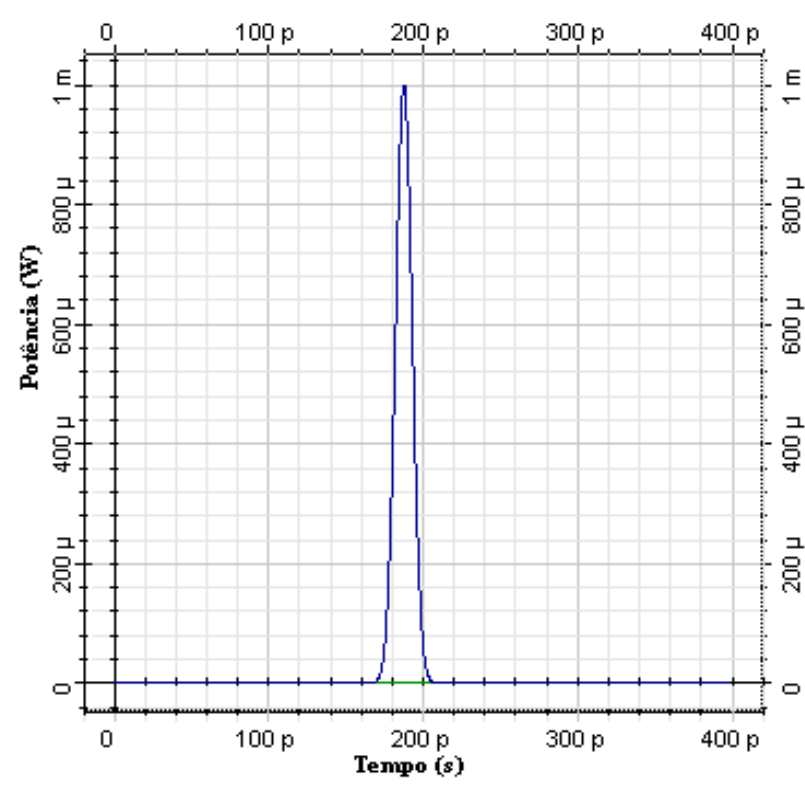

(a)

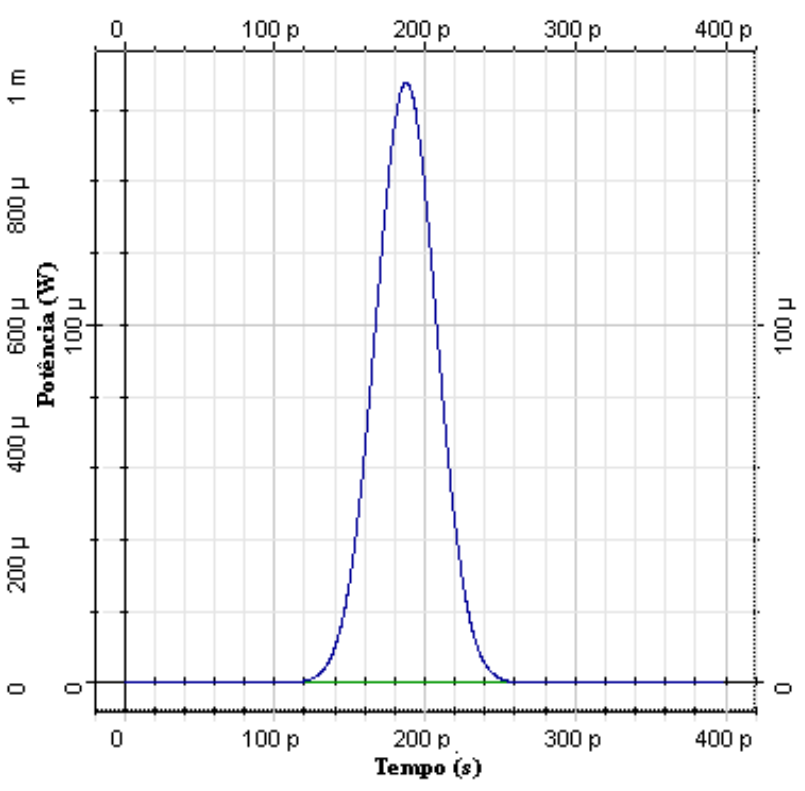

(b)

Figura 4.2: Espectro de um pulso sob ação de dispersão cromática, a) saída do transmissor, b) espectro óptico após enlace de $10 \mathrm{~km}$. Dados do pulso de entrada: pulso gaussiano, potência de pico de $0 \mathrm{dBm}$, comprimento de onda $1552 \mathrm{~nm}$. Características do enlace: parâmetros da Tabela 5.2, pág. 55, com coeficiente não linear da fibra igual a zero. Simulação no Optisystem 9.0. Layout do sistema na Figura B.5. 


\section{b) Dispersão por modo de polarização}

A dispersão dos modos de polarização (PMD - polarization mode dispersion) é causada pelas distorções assimétricas da fibra em relação a uma geometria cilíndrica perfeita. Devido à simetria circular, as fibras monomodo (SMF - single mode optical fiber) possuem dois modos de polarização degenerados. Entretanto, devido às imperfeições no processo de fabricação, estresse imposto durante o cabeamento, emendas ou variações de temperatura ocorrem assimetrias no núcleo da fibra, como pode ser visto na Figura 4.3 (b).

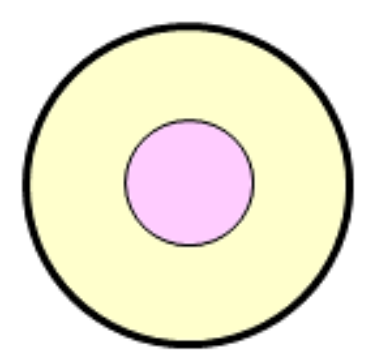

Núcleo - circulo rosa

Revestimento - região em amarelo

Casca - circulo preto

(a)

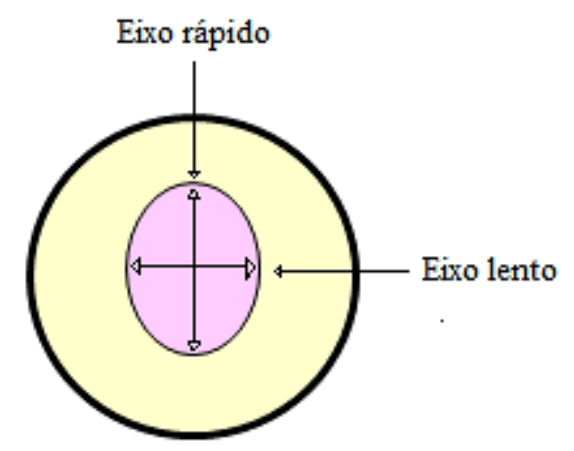

(b)

Figura 4.3: (a) Fibra ideal com simetria circular, (b) fibra real assimétrica [55].

Essa assimetria da fibra introduz diferenças no índice de refração para os dois estados de polarização (birrefringência). Por causa da birrefringência, cada modo de polarização possui velocidade de grupo diferente, dando origem à velocidade diferencial de grupo (DGD - differencial group velocity). O efeito da DGD é um alargamento dispersivo do pulso.

É apresentado, na Figura 4.4, o efeito da birrefringência em cada modo de polarização.

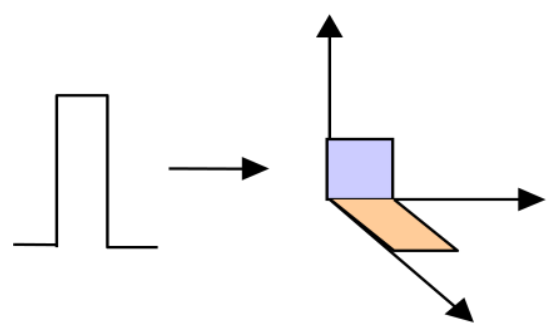

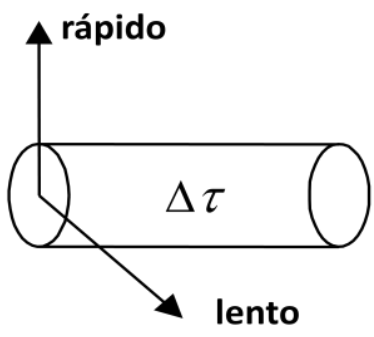

Birrefringência

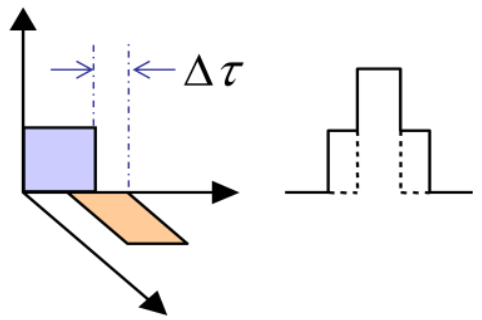

$\Delta \tau$ : Differential Group Delay (DGD)

Figura 4.4: Efeito da birrefringência em cada modo de polarização [55]. 


\subsubsection{Efeitos não lineares}

Em 1895, John Kerr observou que ao aplicar campos elétricos em meios ópticos isotrópicos, como líquidos e cristais de simetria cúbica, ocorria uma birrefringência induzida devido ao alinhamento das moléculas do meio (efeito Kerr). Em comunicações ópticas, o forte confinamento óptico faz as intensidades de luz dentro das fibras ópticas alcançar $\mathrm{GW} / \mathrm{m}^{2}$ [24]. Em tais níveis de intensidade óptica, ocorrem mudanças no índice de refração da fibra, que alteram as fases dos sinais ópticos.

São apresentados, a seguir, os efeitos de automodulação de fase, modulação de fase cruzada e mistura de quatro ondas. Todos estes efeitos são classificados como decorrentes do efeito Kerr.

\section{a) Automodulação de fase (SPM - Self-phase modulation)}

A automodulação de fase é um dos principais efeitos não lineares. O efeito é compreendido ao ser analisado três parâmetros: índice de refração do meio óptico, potência do campo eletromagnético e a sua fase. O índice de refração do meio causa um deslocamento de fase que é proporcional a intensidade do campo eletromagnético, assim, o efeito resultante é o alargamento espectral dos pulsos ópticos na fibra devido à sua própria intensidade. A automodulação de fase é responsável pelo gorjeio (chirping) dos pulsos transmitidos, já que as partes do pulso são afetadas por diferentes deslocamentos de fase. É apresentado, na Figura 4.5 (b), um pulso gaussiano sob ação da automodulação de fase [12].

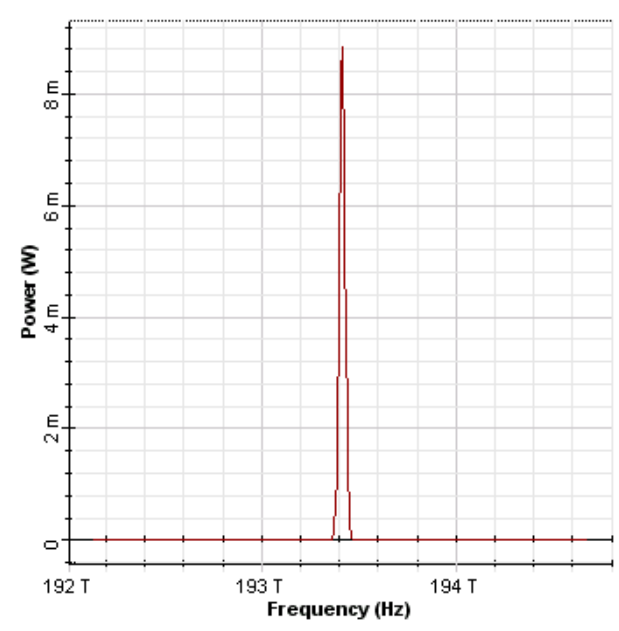

(a)

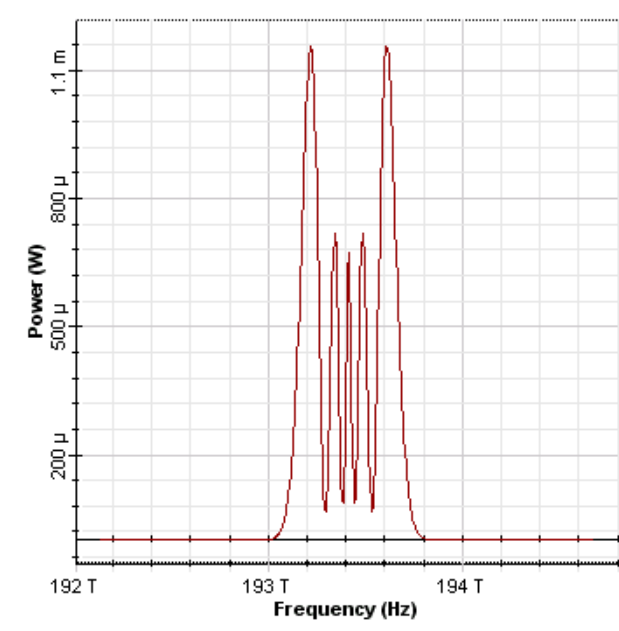

(b)

Figura 4.5: Espectro de um pulso sob a ação do SPM, a) Pulso transmitido, b) espectro óptico após enlace de $10 \mathrm{~km}$. Dados do pulso transmitido: gaussiano com 1552nm, potência do laser $30 \mathrm{dBm}$. Dados da fibra: valores da tabela 5.2, pág. 55. Simulado no Optisystem 9.0. Layout do sistema em B.6. 


\section{b) Modulação de fase cruzada (XPM - cross-phase modulation)}

A modulação de fase cruzada ocorre quando a fase de um campo eletromagnético é modulada não só pela sua própria potência, mas também pela potência do campo eletromagnético copropagante. Assim, é necessário que haja sobreposição temporal entre dois campos para que ocorra XPM. Este efeito ocorre geralmente em sistemas de múltiplos canais ou em sistemas de polarização cruzada [12].

É apresentado, na Figura 4.6, o efeito de modulação de fase cruzada.

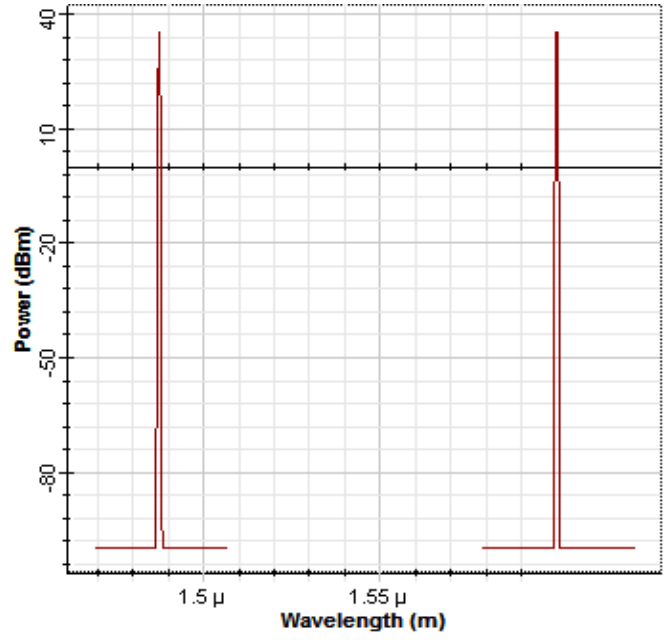

(a)

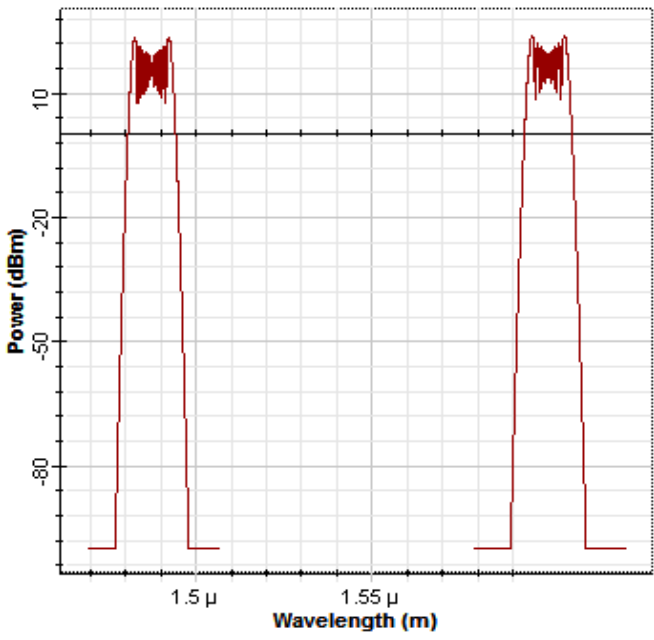

(b)

Figura 4.6: Espectro de dois pulsos sob a ação de XPM, modulação de fase cruzada, a) Dois pulsos em WDM, b) espectro óptico, após enlace de $20 \mathrm{~m}$. Dados do pulso: dois pulsos gaussianos com 62 $\mathrm{dBm}^{2}$. Dados da fibra: valores padrão da tabela 5.2, pág. 55. Simulados no Optisystem 9.0. Layout do sistema em B.7.

\section{c) Mistura de quatro ondas (FWM - four-wave mixing)}

O efeito FWM é intrínseco aos sistemas multicanais e envolve a interação entre dois ou mais sinais ópticos de frequências diferentes. Após a transmissão destes sinais na fibra, eles interagem entre si e com o meio dielétrico e geram combinações de frequências que

\footnotetext{
${ }^{2}$ Apesar de graficamente não parecer que foi utilizado $62 \mathrm{dBm}$, essa foi de fato a potência dos pulsos transmitidos.
} 
podem afetar de forma severa o desempenho da rede. A geração do efeito ocorre, entretanto, porque a fibra óptica exibe comportamento não linear ao ser submetida a sinais de alta potência (superiores a $0 \mathrm{dBm} / \mathrm{canal}$ ).

A geração de crosstalk $^{3}$, devido ao efeito da FWM, pode até reduzir a potência dos canais afetados [12].

\subsubsection{Fenômenos do espalhamento inelástico}

Os processos de interação entre o campo eletromagnético e a matéria dão origem ao espalhamento inelástico.

Existem dois espalhamentos inelásticos: o Raman e o Brillouin. Estes espalhamentos são descritos brevemente a seguir.

\section{a) Espalhamento estimulado Brillouin (SBS - Stimulated Brillouin-scattering)}

O espalhamento estimulado Brillouin ocorre quando a luz interage com os modos normais de vibração da rede de um cristal sólido (fônons). Estes modos de vibração modulam o índice de refração do meio e, assim, ocorre uma intensa reflexão da luz no meio (espalhamento). Esse espalhamento diminui a intensidade de luz que atravessa a fibra e manifesta-se de forma mais acentuada quando se utilizam lasers de alta potência, maiores que $1 \mathrm{~mW}(0 \mathrm{dBm})$.

b) Espalhamento estimulado Raman (SRS Stimulated Ramanscattering)

O espalhamento estimulado Raman ocorre quando os fótons do feixe interagem com os fônons de um cristal sólido e este contato promove a emissão de um novo fóton [56]. Os

\footnotetext{
${ }^{3}$ Interferências que um canal pode sofrer a partir de outros canais do sistema.
} 
fônons podem absorver a energia do novo fóton e emitir fótons com energia superior (antiStokes Raman) ou inferior (Stokes Raman). Desta forma, a interação pode propiciar um aumento ou infligir uma diminuição da energia que os primeiros fótons originalmente possuíam no sistema. Assim, o efeito Raman pode ser aplicado no aumento da energia dos fótons (amplificação por efeito Raman).

\subsection{Vantagens da técnica OFDM}

A técnica OFDM tem sido amplamente utilizada em redes sem fio, principalmente, por ser uma solução efetiva para os casos de interferência intersimbólica causada por um canal dispersivo [3].

A consequência da baixa interferência intersimbólica é a alta capacidade de transmissão, já que a informação a ser transmitida é dividida em várias subportadoras, moduladas em taxas de bit mais baixas. Por exemplo, uma transmissão em $100 \mathrm{~Gb} / \mathrm{s}$ pode ser realizada por 512 subportadoras de dados com taxa de 195,3 Mb/s cada, o que resulta em robustez frente a efeitos de propagação, como dispersão cromática e dispersão dos modos de polarização.

Além das vantagens tradicionalmente apontadas, destacam-se:

1) a técnica OFDM utiliza técnica de equalização adaptativa baseada em subportadoras piloto, inseridas para prevenir deslocamentos de fase nos símbolos [6];

2) o OFDM utiliza diferentes tipos de modulação em cada subportadora, que podem ser facilmente adaptadas para diferentes condições de transmissão;

3) o processamento computacional utilizando operações FFT/IFFT é mais rápido;

4) os transmissores OFDM permitem reconfiguração na taxa de dados enviada, ou seja, caso haja um aumento na demanda de dados por subportadora e, com isso, diminuição do desempenho do sistema, as subportadoras podem automaticamente diminuir a taxa, adicionar códigos corretores de erro, alterar o prefixo cíclico e ainda adicionar subportadoras piloto para melhorar o desempenho [6].

Este é o contexto de redes ópticas autorreconfiguráveis. Estas redes são capazes de realizar continuamente a monitoração de suas taxas e tomar decisões de alteração de parâmetros para manutenção da qualidade de serviço, sem nenhuma intervenção humana. 
5) eficiência energética - a reconfiguração na taxa de dados permite uma redução na exigência por equipamentos para processamento digital de sinal, os quais demandam alto consumo de energia elétrica;

6) em fibras multimodo, verifica-se a robustez do OFDM em relação ao espalhamento temporal causado pela propagação multipercurso. O espalhamento temporal pode alterar a amplitude de várias componentes do espectro de sinal transmitido. Neste caso, o OFDM permite que tal alteração ocorra de maneira uniforme, em toda a faixa de frequências do sinal, configurando o que é chamado de desvanecimento plano.

É mostrado, na Figura 4.7, um espectro em situação de desvanecimento seletivo.

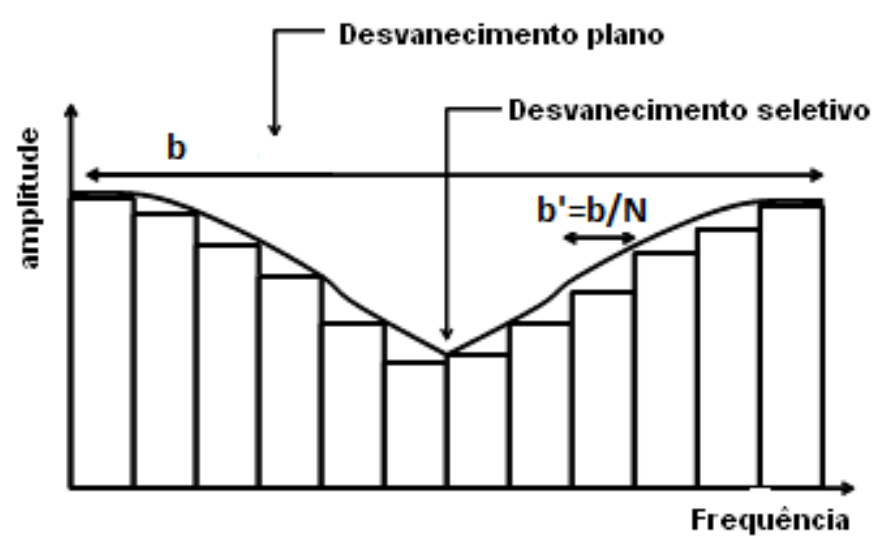

Figura 4.7: Desvanecimento plano e desvanecimento seletivo [37].

O desvanecimento causa uma oscilação na intensidade do sinal. Ele é chamado de seletivo em frequência, já que essas oscilações não são uniformes em todo espectro, sendo verificado apenas em certas frequências.

\subsection{Desvantagens da técnica OFDM}

A principal desvantagem do sistema OFDM é a alta razão entre a potência de pico e média (PAPR - peak to average power ratio), problema que causa distorção no sinal transmitido. Para entender como este problema ocorre, é importante lembrar que os amplificadores elétricos utilizados operam próximos do ponto de saturação, para garantirem ótimo rendimento. Com isso, os picos de amplitude do sinal OFDM levam o amplificador à condição de corte, distorcendo o sinal amplificado e introduzindo ceifamento. 
Estes picos de amplitude do sinal OFDM são formados quando as fases das subportadoras se combinam construtivamente. Estes sinais são complexos e podem estar modulados por diferentes subportadoras, o que torna o processo de equalização do sinal complexo [4].

É apresentado, na Figura 4.8, o problema do PAPR. Na Figura 4.8 (a), o sinal é ceifado próximo de $-10 \mathrm{dBm}$, na saída do transmissor. Na Figura 4.8 (b), é mostrado o sinal obtido na saída de um fotodetector.

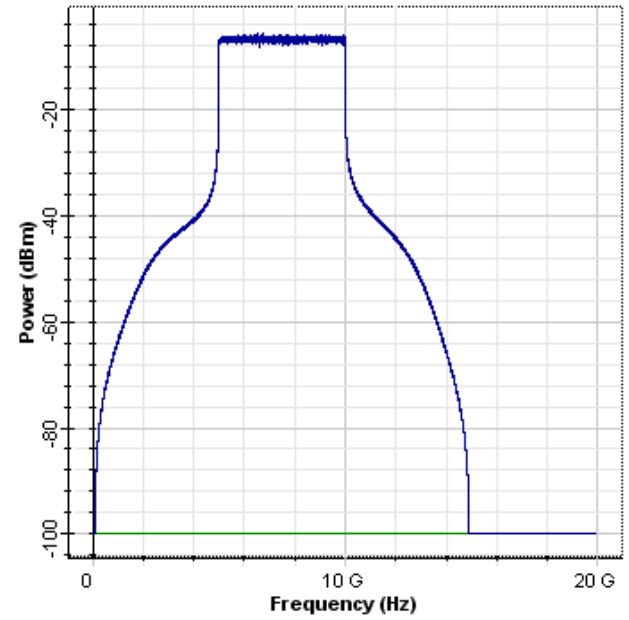

(a)

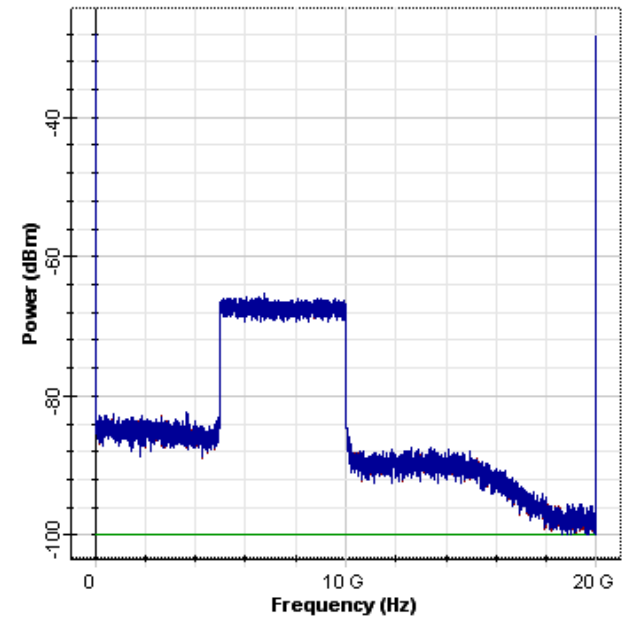

(b)

Figura 4.8: a) Espectro de potência do sinal na saída do transmissor, b) espectro de potência do sinal que chega ao receptor. Simulados no Optisystem 9.0.

Após a análise das simulações, acredita-se que parte da queda na intensidade do sinal, na Figura 4.8 (b), deve-se, também, às perdas de inserção e ruídos dos componentes do sistema. A outra parte pode ser em razão da distorção proveniente da intermodulação das subportadoras (termo não linear de segunda ordem) discutido na Seção 3.2.1.

A parte menos significativa, entretanto, pode estar relacionada ao método de ceifamento de sinal (clipping) dos amplificadores elétricos [57]. Este método consiste em limitar o sinal a certa amplitude, ou seja, atribui um valor para a amplitude do sinal quando esta ultrapassa um valor limite.

A degradação PAPR, além de provocar interferência na ortogonalidade das subportadoras, provoca diminuição na OSNR [58]. Vários métodos de redução dos efeitos do PAPR tem sido apresentada na literatura, com destaque para o water filling. Entretanto, 
quando não há informações precisas sobre as subportadoras no transmissor, a potência pode ser alocada em toda a faixa de transmissão, afetando assim a eficiência do algoritmo [42].

Outra desvantagem da técnica OFDM são os ruídos de fase do laser e do oscilador local, que podem degradar sensivelmente a recepção e rotacionar as constelações do sinal [59]. Estas rotações nas constelações dos símbolos são, frequentemente, confundidas com efeitos não lineares. 


\section{Simulações computacionais de sistemas OFDM nas arquiteturas de detecção direta e detecção coerente}

São apresentados, neste capítulo, os resultados das simulações computacionais das arquiteturas OFDM realizadas com o software Optisystem versões 9.0 e 10.0. As simulações apresentadas não foram implementadas com processador digital de sinais no receptor. Além disso, todos os enlaces foram elaborados a fim de obter a menor BER e a melhor constelação de sinais para cada arquitetura, não sendo possível estabelecer comparações diretas entre as arquiteturas. Em alguns casos, por exemplo, foram utilizados amplificadores e filtros ópticos a fim de melhorar a transmissão nos enlaces ópticos.

Todos os gráficos que exibem a BER, nesta dissertação, foram calculados com código corretor de erro (FEC-forward error correction), por intermédio de algoritmo executado no analisador de BER do simulador. Os resultados das simulações mostram que as arquiteturas implementadas podem ser indicadas para redes ópticas de acesso.

As simulações apresentadas são:

1) OFDM 4-QAM com detecção direta;

2) OFDM 4-QAM e 16-QAM com detecção coerente;

3) WDM-OFDM-PON com detecção coerente;

4) OFDM 4-QAM de dupla polarização com detecção coerente.

\subsection{OFDM 4-QAM com detecção direta}

Nesta seção são apresentados os resultados da simulação OFDM 4-QAM com detecção direta em distâncias de até $120 \mathrm{~km}$. São mostradas as constelações de sinais da arquitetura para diferentes distâncias do enlace.

\subsubsection{Simulações do OFDM 4-QAM com detecção direta}

A fim de reproduzir os trabalhos citados na Seção 1.2, pág. 4, foram organizados, em tabelas, os principais parâmetros dos sistemas de transmissão, recepção e enlace. O esquema do sistema simulado está no apêndice B, Figura B.1. 
São mostrados, na Tabela 5.1, os parâmetros de simulação utilizados no ajuste do transmissor para a arquitetura DD-OFDM (DD- direct detection).

\begin{tabular}{ll}
$\begin{array}{ll}\text { Tabela 5.1: Parâmetros de simulação DD-OFDM [15]. } \\
\text { Parâmetro }\end{array}$ & Valor/ \\
& Especificação \\
\hline Taxa de bits $(\mathrm{Gb} / \mathrm{s})$ & 10 \\
Modulação & QAM \\
Número subportadoras & 512 \\
Número de pontos DFT & 1024 \\
Número de bits por símbolo & 2 \\
Número de prefixo cíclico & 0 \\
Modulador de quadratura (GHz) & 7,5 \\
Comprimento de onda do laser (nm) & 1552,52 \\
Largura de linha do laser (MHz) & 0,15 \\
Modulador Mach-Zehnder (simétrico) & $\mathrm{LiNbO}_{3}$ \\
\hline Razão de extinção do MZM (dB) & 30 \\
\hline Responsividade do fotodiodo (A/W) & 1 \\
Corrente de escuro do fotodiodo (nA) & 10
\end{tabular}

Com a intenção de reproduzir o sistema DD-OFDM com os parâmetros de transmissão de [15], foram utilizados um booster e um pré-amplificador com ganhos de $13 \mathrm{~dB}$ e figura de ruído de $5 \mathrm{~dB}$. O amplificador óptico (booster) é inserido após o transmissor, já o préamplificador óptico é inserido antes do receptor. A principal função do booster no enlace é permitir a extensão do sinal na fibra, enquanto isso, o pré-amplificador melhora a sensibilidade no fotodetector.

O ajuste de prefixo cíclico foi realizado no modo sweep (modo de varredura do simulador, o qual permite encontrar o melhor valor para o parâmetro após diversas iterações). O modo sweep indicou o prefixo cíclico nulo como o melhor valor para a arquitetura elaborada. Por esse motivo, o prefixo cíclico mostrado na Tabela 5.1 é zero.

É mostrado, na Tabela 5.2, os parâmetros usados no enlace da simulação DD-OFDM 4-QAM. O valor e a especificação dos parâmetros foram escolhidos com base na configuração default (padrão dos componentes no simulador). 
Tabela 5.2: Características do enlace utilizado na simulação para DD-OFDM [12].

\begin{tabular}{ll} 
Parâmetro & Valor/Especificação \\
\hline Enlace monomodo $(\mathrm{km})$ & $0-120$ \\
Comprimento de onda de referência $(\mathrm{nm})$ & $1552,4 \mathrm{~nm}$ \\
Atenuação da fibra $(\mathrm{dB} / \mathrm{km})$ & 0,2 \\
Dispersão cromática da fibra $(\mathrm{ps} \times \mathrm{km} / \mathrm{nm})$ & 16,75 \\
Inclinação da dispersão $\left(\mathrm{ps} \times \mathrm{km} / \mathrm{nm}^{2}\right)$ & 0,075 \\
cromática da fibra & \\
Dispersão do modo de polarização $\left(\mathrm{ps} /(\mathrm{km})^{1 / 2}\right)$ & 0,5 \\
Área do núcleo da fibra $\left(\mu \mathrm{m}^{2}\right)$ & 80 \\
Coeficiente não linear da fibra $\left(\mathrm{m}^{2} / \mathrm{W}\right)$ & $26 \times 10^{-21}$ \\
Número de amplificadores óptico no enlace & 2 \\
Ganho dos amplificadores ópticos $(\mathrm{dB})$ & 13 \\
Figura de ruído dos amplificadores ópticos $(\mathrm{dB})$ & 5 \\
Amplificador elétrico $(\mathrm{dB})$ & 16 \\
Formato do filtro óptico & Gaussiano de segunda \\
& ordem \\
\hline Largura de banda do filtro óptico $(\mathrm{GHz})$ & 15 \\
\hline
\end{tabular}

Com a finalidade de ilustrar as vantagens do uso da amplificação no enlace é apresentado, na Figura 5.1, o diagrama básico de enlace óptico passivo e ativo.

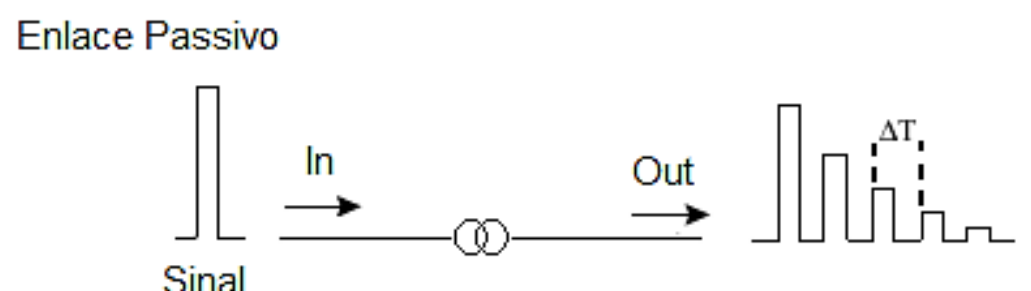

(a)

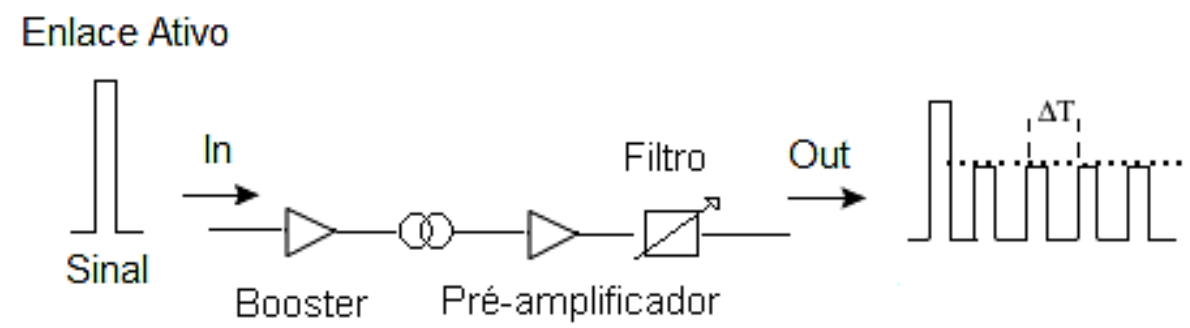

(b)

Figura 5.1: Enlaces de fibra óptica, (a) passivo e (b) ativo [60]. 
O enlace ativo, na Figura 5.1 (b), compensa grande parte das perdas de sinal, quando comparado com o enlace passivo, Figura 5.1 (a). A função do filtro óptico inserido é suprimir ruídos ASE (amplified spontaneous emission) provenientes dos amplificadores ópticos. Uma forma de investigar as limitações dos sistemas, frente aos efeitos de degradação, é realizar a interpretação das constelações. São apresentadas, na Figura 5.2, as constelações DD OFDM 4-QAM obtidas após o sinal percorrer um enlace com até 120 km de extensão.

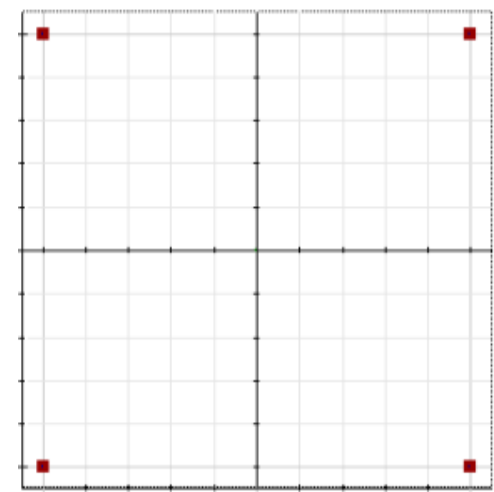

(a) Sinal elétrico QAM

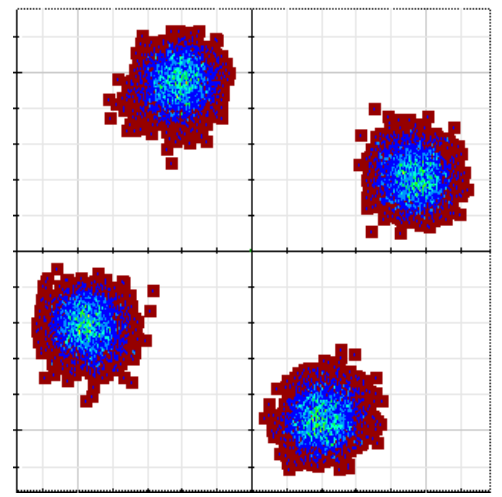

(d) $40 \mathrm{~km}$

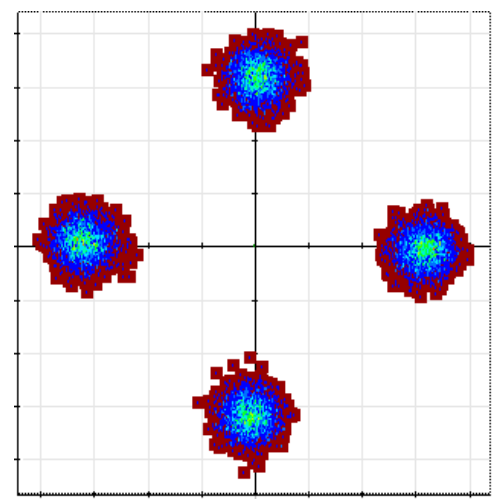

(b) back to back

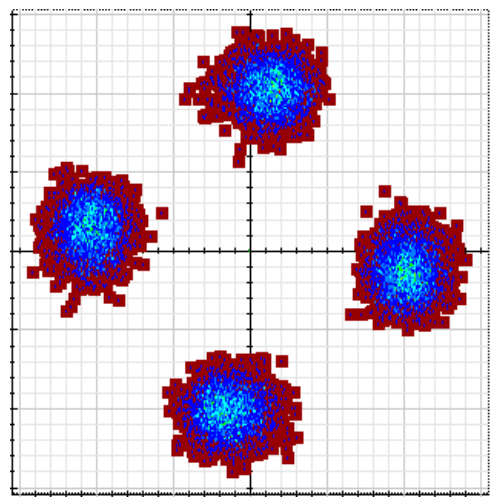

(e) $60 \mathrm{~km}$

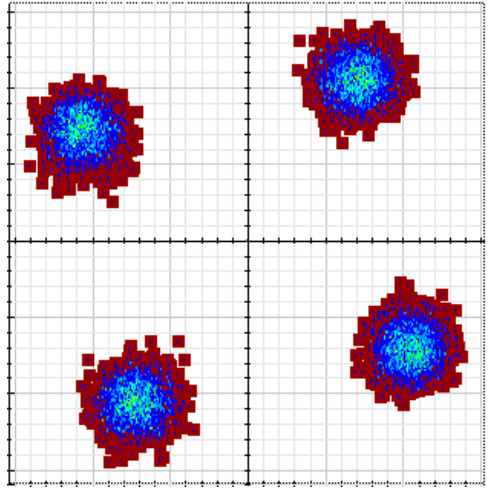

(c) $20 \mathrm{~km}$

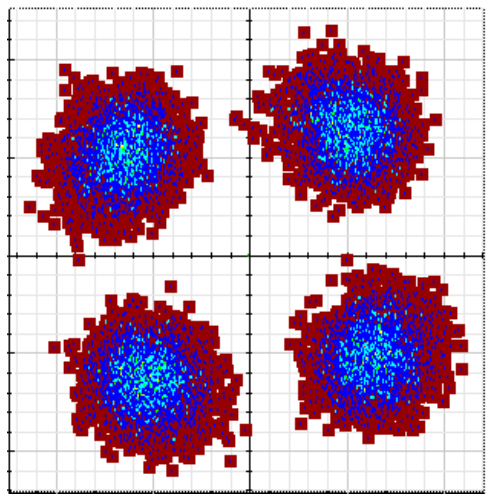

(f) $80 \mathrm{~km}$

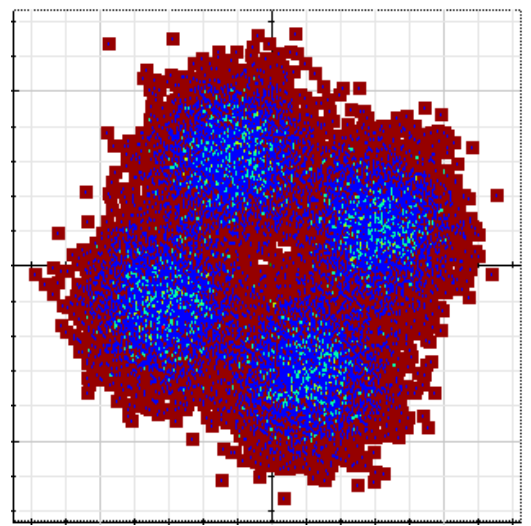

(g) $100 \mathrm{~km}$

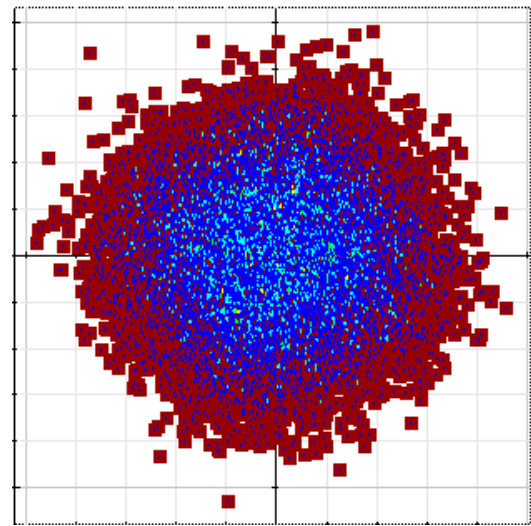

(h) $120 \mathrm{~km}$

Figura 5.2: Constelação DD-OFDM 4-QAM, após o sinal percorrer diferentes distâncias. 
A análise das constelações simuladas nos diferentes comprimentos de enlace oferece uma visão puramente qualitativa, já que estas medidas não permitem uma análise estatística dos dados, ou seja, os dados não são quantificáveis. Entretanto, as constelações são importantes na identificação de quais efeitos de degradação atuam no sistema.

O nível de potência que entra na fibra, para a simulação das constelações da Figura 5.2, é de $-3 \mathrm{dBm}$, de acordo com o medidor de potência óptica localizado após o booster.

Nas constelações exibidas, o sinal de informação do símbolo está indicado na cor vermelha e o ruído, na informação do símbolo, pela cor verde. Na cor azul estão indicados os pontos de indecisão do visualizador de constelação. Nesses pontos o visualizador não consegue diferenciar o sinal e o ruído. Essas informações podem ser encontradas no manual do simulador [12].

As constelações, da Figura 5.2, apresentam um desvio aleatório de fase que alonga os pontos da constelação de tal forma que se assemelham a semicírculos. Isto ocorre por causa dos efeitos dispersivos e não lineares da fibra óptica. Caso a fibra não esteja presente, e ainda haja este desvio aleatório de fase do sinal, o responsável, possivelmente, seja o ruído de fase do laser [24], [6]. Nas constelações do COD OFDM 4-QAM, todos os efeitos serão bem visíveis.

Observa-se, na Figura 5.2, que com o aumento do comprimento da fibra a degradação no sinal é aumentada até alcançar os 120 km, a partir desta distância não há mais nenhuma identificação da constelação.

Apesar de a detecção direta ser amplamente utilizada em diversos sistemas ópticos, os autores de [61] mencionam que a detecção coerente é o sistema de recepção mais indicado para a próxima geração de sistemas OFDM. Dessa forma, as demais simulações desta pesquisa são focadas em estudos com detecção coerente. 


\subsection{OFDM 4-QAM e 16-QAM com detecção coerente}

Nesta seção, são apresentados os resultados obtidos por meio de simulações com a técnica de detecção coerente (COD - coherent detection). Foram simuladas as arquiteturas OFDM 4-QAM e OFDM 16-QAM com distâncias de até 200 km, pois, após esta distância, o sinal se apresenta muito degradado. Foram utilizados dois amplificadores ópticos que ficaram localizados nas extremidades da fibra óptica. Após o pré-amplificador foi inserido um filtro óptico, a fim de suprimir ruídos ASE. Um gráfico da BER em função da OSNR é apresentado, no qual são mostradas diversas curvas com diferentes níveis de potência na entrada da fibra (saída do booster), variando entre $-8 \mathrm{dBm}$ e $0 \mathrm{dBm}$. São apresentadas, também, as constelações 4-QAM e 16-QAM com observações sobre as degradações de sinal.

\subsubsection{Simulações OFDM 4-QAM e 16-QAM com detecção coerente}

Diferentemente da detecção direta, na qual o sinal incidente é diretamente convertido em sinal elétrico, sem processamento prévio no domínio óptico, na detecção coerente, o sinal passa por um processamento óptico prévio. De acordo com [59], a detecção coerente pode produzir melhoria de 7,3 dB na OSNR, em relação à detecção direta.

Os resultados com detecção coerente OFDM 4-QAM são ilustrados a seguir. Os parâmetros do transmissor e receptor são mostrados na Tabela 5.3. 
Tabela 5.3: Parâmetros de simulação COD-OFDM [16].

\begin{tabular}{ll} 
Parâmetro & Valor/Especificação \\
\hline Taxa de bits (Gb/s) & 10 \\
Modulação & QAM \\
\hline Número de subportadoras & 512 \\
Número de pontos DFT & 1024 \\
Número de bit por símbolo & 2 e 4 \\
Número de prefixo cíclico ${ }^{4}$ & 0 \\
Comprimento de onda do laser (nm) & 1552,52 \\
\hline Potência do laser (dBm) & -2 \\
\hline Largura de linha do laser (MHz) & 0,15 \\
Modulador Mach-Zehnder & $\mathrm{LiNbO} 3$ \\
Razão de extinção do MZM (dB) & 60 \\
Frequência do laser do oscilador local (THz) & 193.1 \\
\hline Potência do laser do oscilador local (dBm) & $-2 \mathrm{dBm}$ \\
\hline Responsividade do fotodiodo (A/W) & 1 \\
\hline Corrente de escuro do fotodiodo (nA) & 10 \\
\hline
\end{tabular}

É citada na Tabela 5.3 uma razão de extinção para o MZM de 60 dB. Valores menores que $60 \mathrm{~dB}$ não permitiram exibir as constelações dentro do espaço de sinais. $\mathrm{O}$ ajuste do prefixo cíclico foi ajustado com a função sweep (varredura), de forma similar ao realizado nas simulações DD-OFDM.

São apresentadas, na Tabela 5.4, as características do enlace utilizado na simulação COD-OFDM.

\footnotetext{
${ }^{4}$ Simulador no modo sweep (modo de varredura para encontrar melhor valor).
} 
Tabela 5.4: Características do enlace utilizado na simulação COD-OFDM [12].

\begin{tabular}{ll} 
Parâmetro & Valor \\
\hline Comprimento do enlace monomodo $(\mathrm{km})$ & $0-200$ \\
\hline Comprimento de onda de referência $(\mathrm{nm})$ & 1552,4 \\
\hline Atenuação da fibra $(\mathrm{dB} / \mathrm{km})$ & 0,2 \\
\hline Dispersão cromática da fibra $(\mathrm{ps} \times \mathrm{km} / \mathrm{nm})$ & 16,75 \\
Inclinação da dispersão cromática $\left(\mathrm{ps} \times \mathrm{km} / \mathrm{nm}^{2}\right)$ & 0,075 \\
\hline Dispersão do modo de polarização $\left(\mathrm{ps} /(\mathrm{km})^{1 / 2}\right)$ & 0,2 \\
Área do núcleo da fibra $\left(\mu \mathrm{m}^{2}\right)$ & 80 \\
Coeficiente não linear da fibra $\left(\mathrm{m}^{2} / \mathrm{W}\right)$ & $26 \times 10^{-21}$ \\
Ganho do booster $(\mathrm{dB})$ & 13 \\
\hline Figura de ruído do booster $(\mathrm{dB})$ & 4 \\
Ganho do pré-amplificador $(\mathrm{dB})$ & 18 \\
Figura de ruído do pré-amplificador $(\mathrm{dB})$ & 4 \\
Ganho do amplificador elétrico & 20 \\
\hline Atenuador óptico $(\mathrm{dB})$ & 6 \\
\hline
\end{tabular}

Foram utilizados dois amplificadores ópticos no enlace simulado, sendo um booster e um pré-amplificador. Após o pré-amplificador foi inserido um filtro óptico, a fim de mitigar os efeitos cumulativos de ruído ASE. Esses efeitos degradam a relação sinal ruído óptica e adicionam flutuações ao sinal amplificado. É apresentada, na Figura 5.3, a BER para o COD OFDM 4-QAM em função da OSNR utilizando os parâmetros das Tabelas 5.3 e 5.4. 


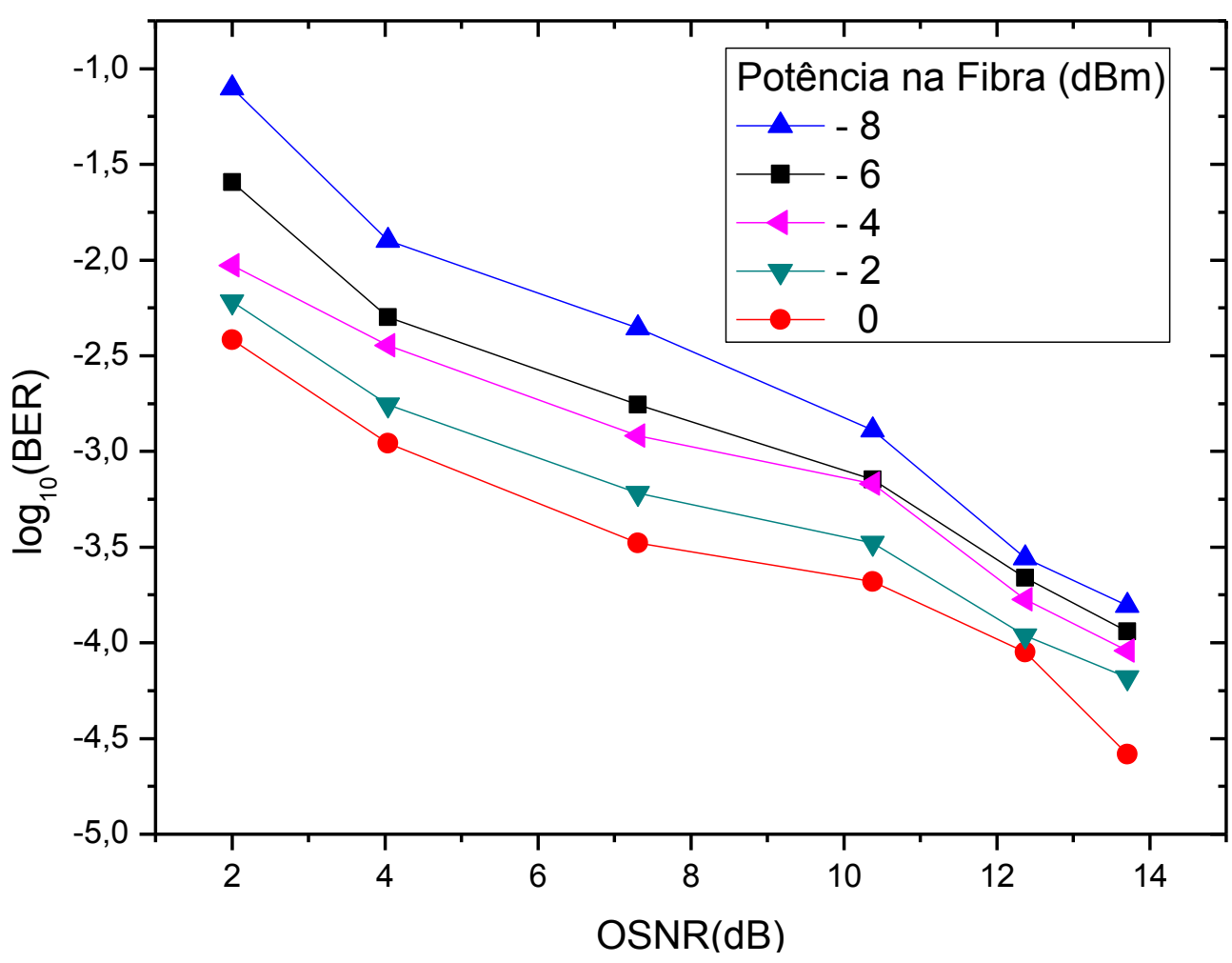

Figura 5.3: BER em função OSNR para os parâmetros das Tabelas 1 e 3.

As curvas, da Figura 5.3, foram obtidas com uma fibra monomodo de $100 \mathrm{~km}$, de acordo com os parâmetros da Tabela 5.4. Na amplificação do sinal foi utilizado um booster e um pré-amplificador, o que permitiu a obtenção de uma OSNR muito próxima ao resultado da arquitetura COD-OFDM implementada em [62]. Com o auxílio de um medidor de potência foi possível obter os parâmetros para o cálculo da OSNR.

A expressão para o cálculo da OSNR é

$$
\operatorname{OSNR}(d B)=10 \cdot \log \left(\frac{P_{\text {SINAL }}}{P_{\text {RUIDO }}}\right)
$$

na qual $P_{\text {sinal }}$ e $P_{\text {ruido }}$ são as potências em watt.

O único parâmetro que foi alterado para o cálculo da OSNR é a atenuação óptica, por meio de um atenuador óptico inserido na entrada do fotodetector.

São apresentadas, na Figura 5.4, as constelações para COD OFDM 4-QAM. A saída do sinal elétrico QAM do transmissor pode ser vista na Figura 5.4 (a). Nas Figuras 5.4 (b) a 5.4 (h), são apresentadas as constelações obtidas, processadas no receptor. Como na DD OFDM 4-QAM, o sinal está indicado na cor vermelha e o ruído na cor verde. Em azul, estão indicados os pontos de indecisão do visualizador. Foi fixada a potência de $-4 \mathrm{dBm}$ na saída do booster para a análise das constelações a seguir. 


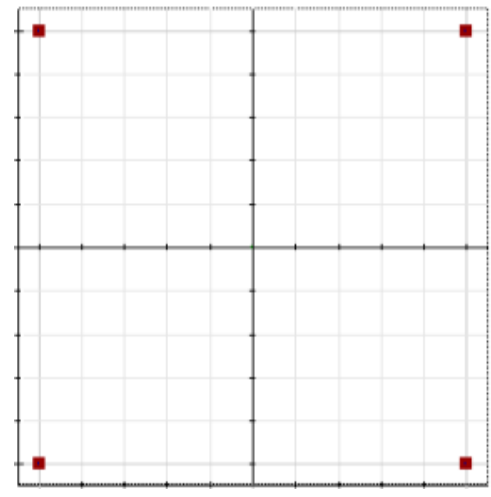

(a) Sinal elétrico QAM

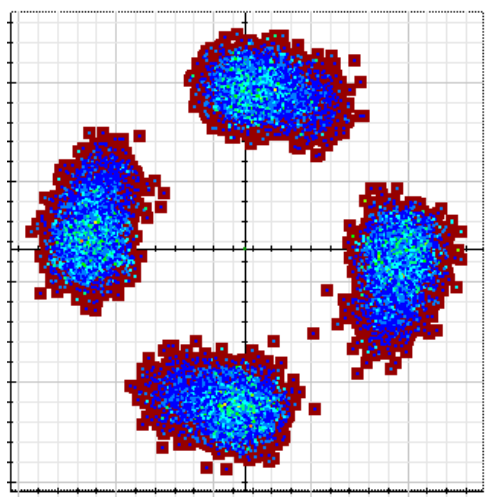

(d) $120 \mathrm{~km}$

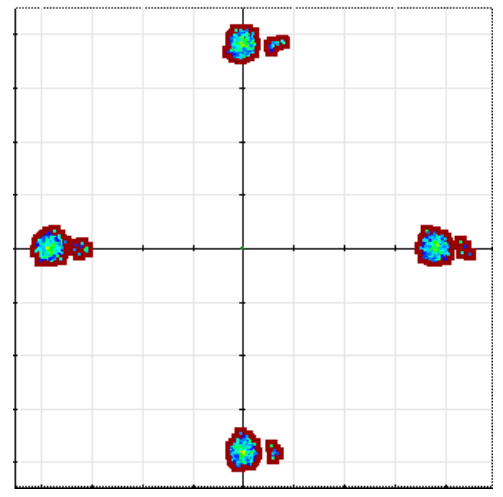

(b) back to back

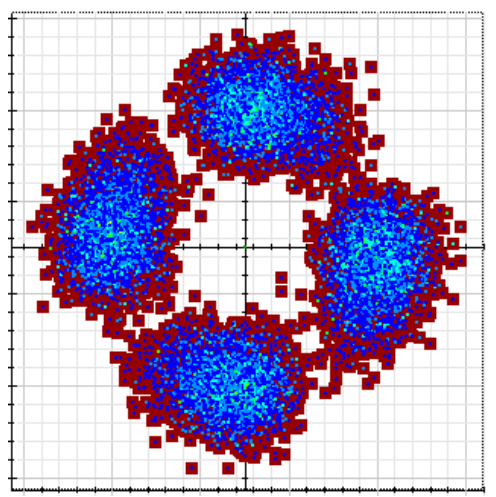

(e) $140 \mathrm{~km}$

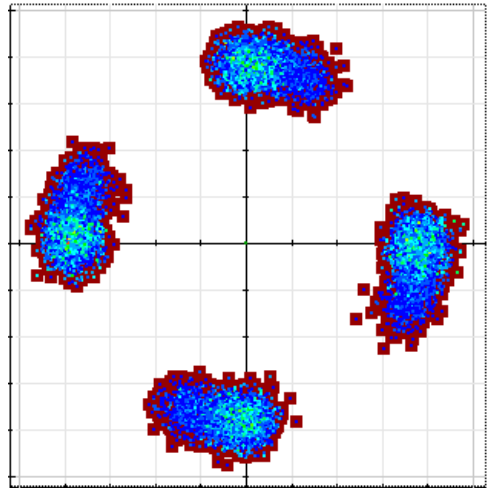

(c) $100 \mathrm{~km}$

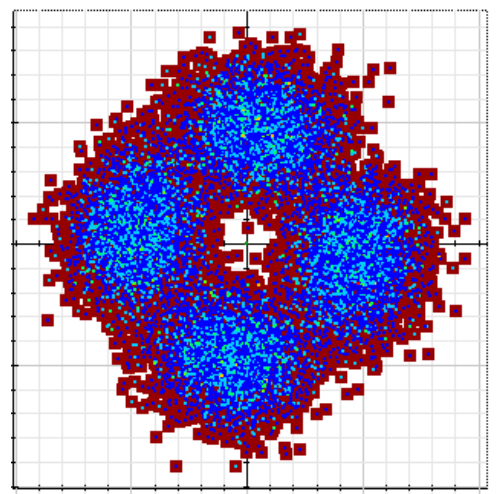

(f) $160 \mathrm{~km}$

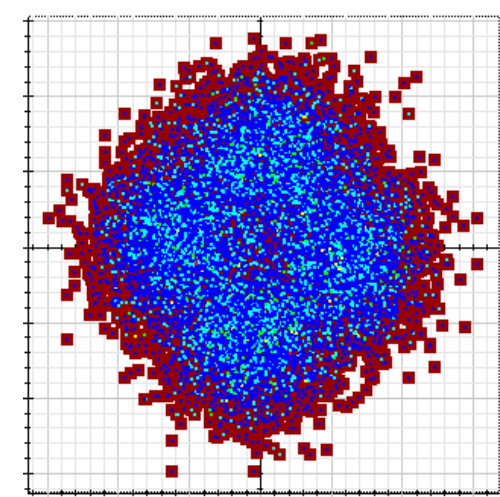

(g) $180 \mathrm{~km}$

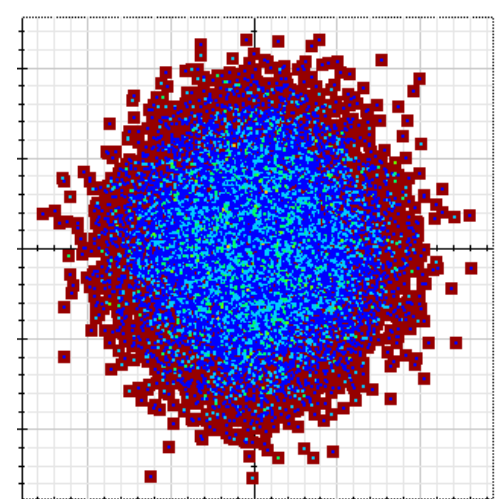

(h) $200 \mathrm{~km}$

Figura 5.4: Constelações obtidas na recepção do sistema OFDM ao longo do enlace.

Na Figura 5.4 (b), configuração back to back, a presença de ruído advindo dos sistemas eletrônicos de transmissão e recepção provoca uma nuvem no interior dos pontos originais do sinal da constelação. Esta nuvem é circular e não possui desvio aleatório de fase que é caracterizado pelo alongamento do símbolo (como se o símbolo fosse esticado), algo bem visível na Figura 5.4 (c).

O desvio aleatório de fase do símbolo é diferente da rotação dos símbolos, mostrado 
na Figura 5.4 (b). O desvio aleatório de fase ocorre na presença da fibra óptica, o qual é provocado pelos efeitos dispersivos e não lineares [24]. Quanto à rotação dos quatro símbolos no sentido anti-horário da Figura 5.6 (b), acredita-se que seja devido ao ruído de fase do laser, já que após zerar esse parâmetro no simulador, a rotação dos símbolos da constelação desaparece.

A análise qualitativa, da Figura 5.4 (c), permite afirmar que para distâncias de até 100 km o sistema apresenta degradação intermediária, quando comparado com as constelações a partir de $120 \mathrm{~km}$. Deste modo, acredita-se que a arquitetura simulada possa ser aplicada nas redes ópticas de acesso, já que a constelação (análise qualitativa) e a BER em função da OSNR (análise quantitativa) se mostraram pouco degradadas em distâncias de até $100 \mathrm{~km}$.

Resumindo, acredita-se que:

1) o inchaço (nuvem) da constelação seja em grande parte devido ao ruído dos sistemas eletrônicos de transmissão e recepção;

2) o desvio aleatório de fase (alongamento do símbolo) - ocorre na presença de fibra óptica (por cauda dos efeitos de propagação);

3) a rotação dos símbolos - associado ao ruído de fase do laser [63].

A fim de apresentar uma justificativa visual para as ideias apresentadas, foram simuladas as constelações da Figura 5.4, porém agora, eliminando os efeitos de propagação (dispersivos, não lineares e de espalhamento) e o ruído de fase do laser. Estas constelações são apresentadas na Figura 5.5. 


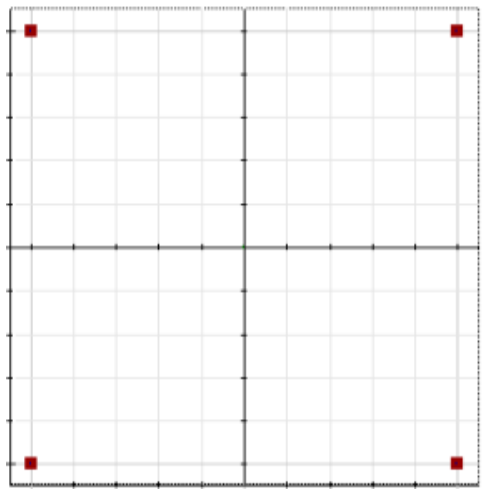

(a) Sinal elétrico QAM

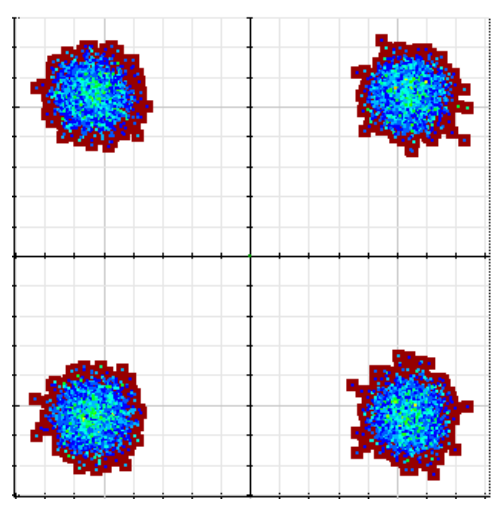

(d) $120 \mathrm{~km}$

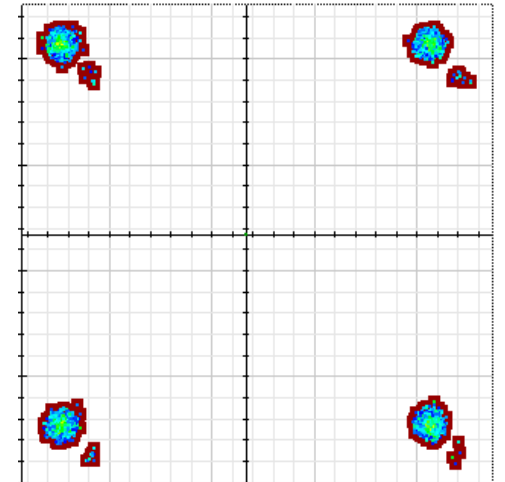

(b) back to back

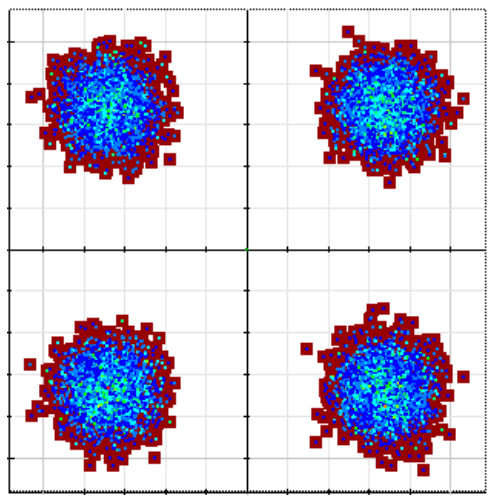

(e) $140 \mathrm{~km}$

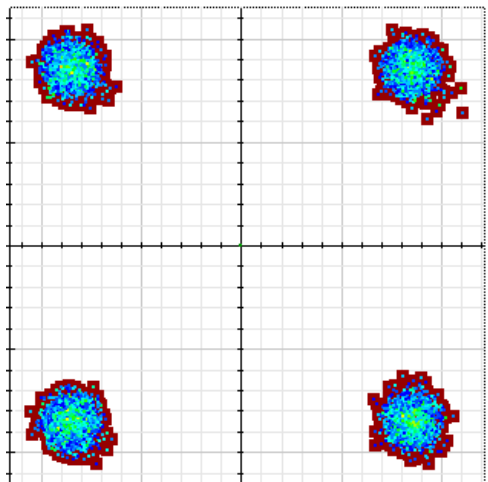

(c) $100 \mathrm{~km}$

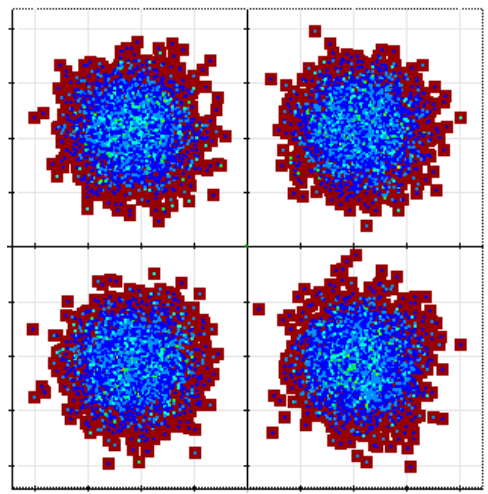

(f) $160 \mathrm{~km}$

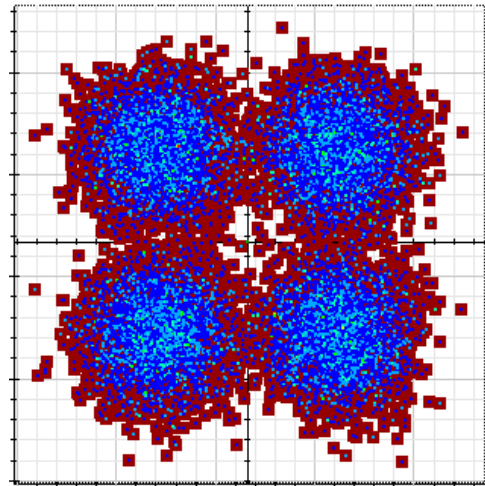

(g) $180 \mathrm{~km}$

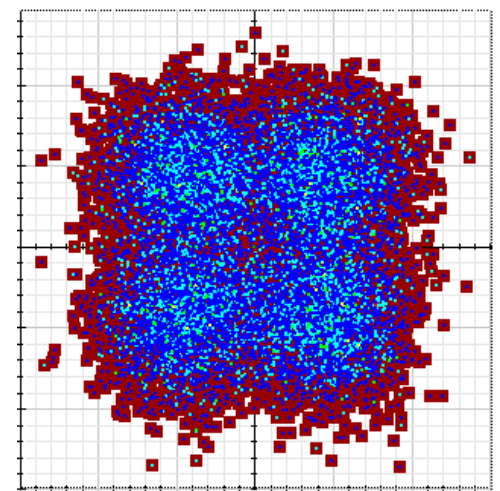

(h) $200 \mathrm{~km}$

Figura 5.5: Constelações obtidas na recepção do sistema OFDM, ao longo do enlace com efeitos de propagação e ruído de fase do laser nulo.

Nota-se a ausência do desvio aleatório de fase e a rotação dos símbolos, efeitos esses, presentes nas constelações da Figura 5.4.

São mostradas, na Figura 5.6, as constelações para o COD OFDM 16-QAM, utilizando o mesmo enlace da COD OFDM 4-QAM com os efeitos de propagação. 


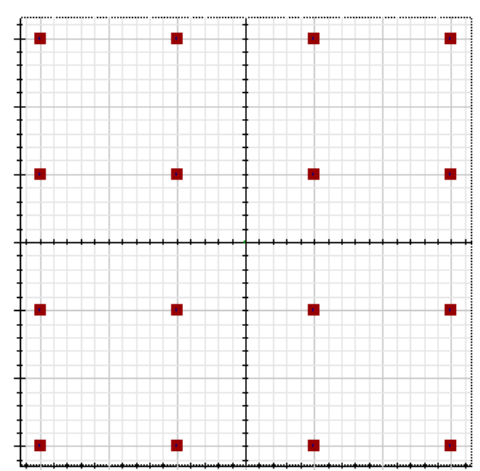

(a) Saída do transmissor

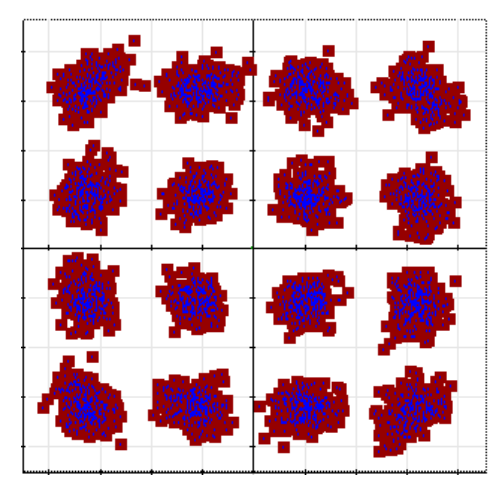

(d) $120 \mathrm{~km}$

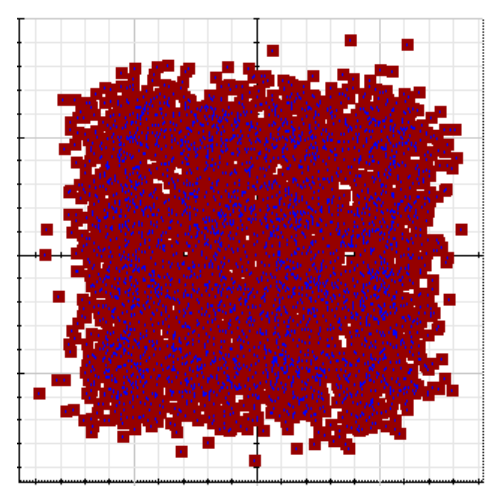

(g) $170 \mathrm{~km}$

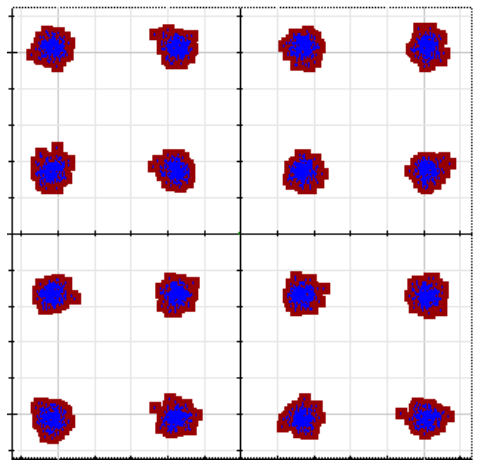

(b) back to back

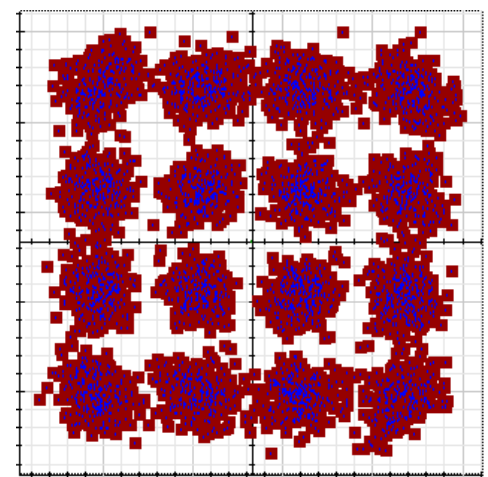

(e) $140 \mathrm{~km}$

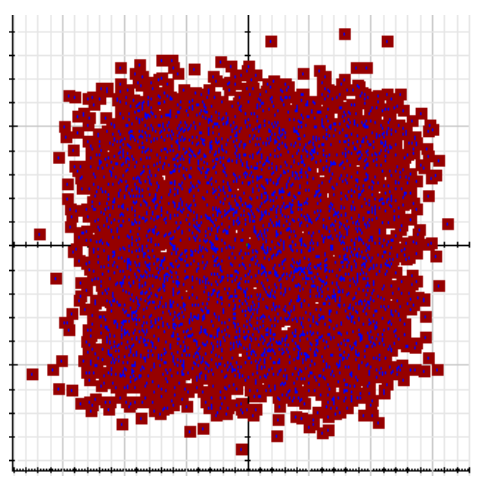

(h) $180 \mathrm{~km}$

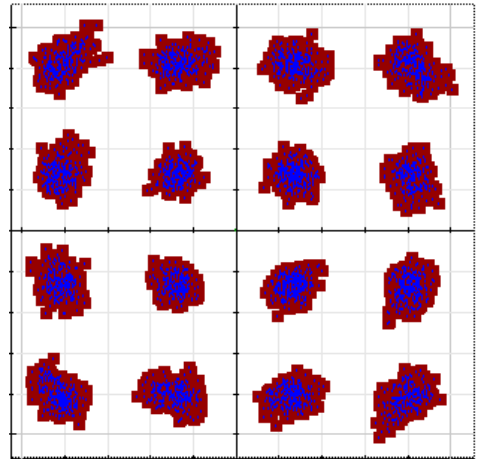

(c) $100 \mathrm{~km}$

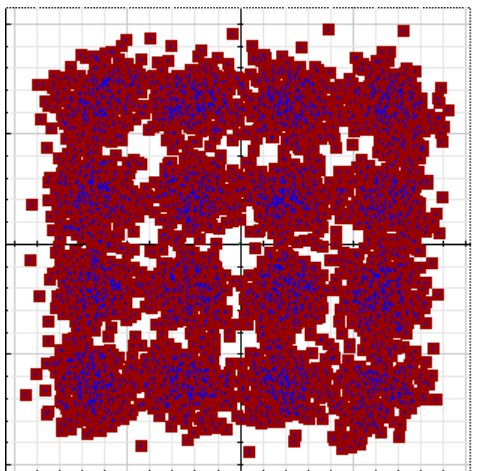

(f) $150 \mathrm{~km}$

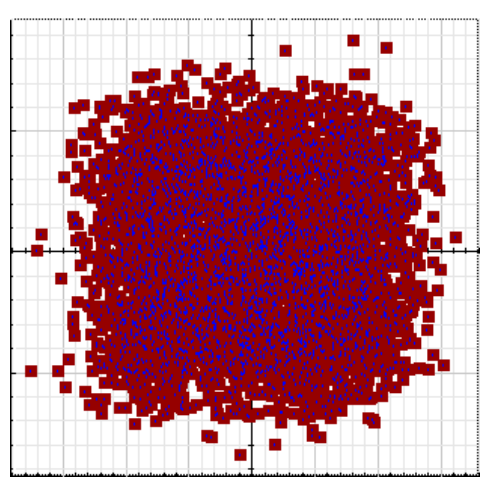

(i) $200 \mathrm{~km}$

Figura 5.6: Constelações da arquitetura COD OFDM 16-QAM.

A partir de uma análise puramente qualitativa da Figura 5.6, pode-se observar uma constelação com efeitos de propagação mais acentuados do que na Figura 5.4, para a mesma distância. Em [24], por meio de uma análise gráfica, pode-se observar que um sinal com modulação 16-QAM apresenta símbolos mais próximos quando comparados com um sinal 4QAM sob as mesmas condições de enlace, transmissão e recepção. Ou seja, para uma mesma relação sinal-ruído, a probabilidade de ocorrência de erro para um sinal 16-QAM é maior do que para um sinal 4-QAM. 


\subsection{WDM-OFDM-PON com detecção coerente}

Nesta seção, são apresentados os resultados obtidos com as simulações da arquitetura WDM-OFDM-PON. A arquitetura é implementada sem a inserção no enlace de elementos ativos, como amplificadores ópticos. Nesta condição, a distância máxima alcançada com uma taxa total de transmissão de $48 \mathrm{~Gb} / \mathrm{s}$ foi de $80 \mathrm{~km}$. O gráfico da BER em função do comprimento do enlace e os gráficos das constelações da simulação são discutidos.

\subsubsection{Importância e simulações da arquitetura WDM-OFDM-PON com detecção coerente}

Ao contrário das redes de longa distância nas quais o custo mais elevado com infraestrutura pode ser tolerado, ao ser absorvido pelo volume de serviço, as aplicações de redes de acesso necessitam de aplicações de baixo custo, a fim de se tornarem viáveis.

Neste contexto, surgem estudos em WDM-OFDM-PON que visam grande eficiência de energia, diminuição dos custos, alocação dinâmica de subportadora e diminuição de efeitos dispersivos, este último, devido à inserção de várias subportadoras com menores taxas [64], [65].

A eficiência de energia, como mostra [64], ocorre por causa do desligamento automático de módulos OFDM, em horários de baixa demanda de tráfego. Este fator promove diminuição dos custos de manutenção do sistema.

A seguir, são apresentados os resultados para as simulações WDM-OFDM-PON. A arquitetura WDM-OFDM-PON é simulada com taxa de transmissão de $48 \mathrm{~Gb} / \mathrm{s}$, dividida em 4 canais WDM com $12 \mathrm{~Gb} / \mathrm{s}$ cada. Foi escolhida a taxa de $12 \mathrm{~Gb} / \mathrm{s}$ por canal para a simulação, já que as simulações mostraram que o aumento dessa taxa degradava significativamente o sinal.

Nas simulações desta arquitetura não foram utilizados filtros e amplificadores ópticos no enlace, caracterizando, assim, o enlace de uma rede óptica passiva. A detecção utilizada foi a coerente, por causa das vantagens já mencionadas. São apresentados, na Tabela 5.5, os parâmetros do transmissor e receptor para a arquitetura WDM-OFDM-PON. 
Tabela 5.5: Parâmetros de simulação WDM-OFDM-PON [18].

\begin{tabular}{lc}
\multicolumn{1}{c}{ Parâmetro } & Valor/Especificação \\
\hline Taxa de bits (Gb/s) & 48 \\
\hline Modulação & QAM \\
Número de subportadoras & 512 \\
Número de pontos DFT & 1024 \\
Número de bit por símbolo & 2 \\
Número de prefixo cíclico ${ }^{5}$ & 64 \\
Frequência dos lasers do transmissor (THz) & $193,05-193,1$ \\
& $193,15-193,2$ \\
\hline Potência do laser do transmissor (dBm) & -12 a -6 \\
Frequência do laser do oscilador local (THz) & 193,1 \\
Potência do laser do oscilador local (dBm) & -2 \\
\hline Largura de linha do laser do transmissor (MHz) & 0,15 \\
\hline Largura de linha do laser do oscilador local (MHz) & 0,15 \\
Modulador Mach-Zehnder & LiNbO 3 \\
\hline Razão de extinção do MZM (dB) ${ }^{6}$ & 60 \\
Responsividade do fotodiodo (A/W) & 1 \\
Corrente de escuro do fotodiodo (nA) & 10 \\
\hline
\end{tabular}

Na Tabela 5.6, são apresentadas as características do enlace de rede.

\footnotetext{
${ }^{5}$ De forma similar às outras simulações, o prefixo cíclico foi obtido a partir da função sweep.

${ }^{6}$ Valores menores que $60 \mathrm{~dB}$ não permitiram exibir as constelações dentro do espaço de sinais.
} 
Tabela 5.6: Características do enlace utilizado na simulação WDM-OFDM-PON [12].

\begin{tabular}{ll} 
Parâmetro & Valor \\
\hline Comprimento do enlace monomodo $(\mathrm{km})$ & 0 a 180 \\
Comprimento de onda de referência $(\mathrm{nm})$ & 1552,4 \\
Atenuação da fibra $(\mathrm{dB} / \mathrm{km})$ & 0,2 \\
Dispersão cromática da fibra $(\mathrm{ps} \times \mathrm{km} / \mathrm{nm})$ & 16,75 \\
Inclinação da dispersão cromática $\left(\mathrm{ps} \times \mathrm{km} / \mathrm{nm}^{2}\right)$ & 0,075 \\
Dispersão do modo de polarização $\left(\mathrm{ps} /(\mathrm{km})^{1 / 2}\right)$ & 0,2 \\
Área do núcleo da fibra $\left(\mu \mathrm{m}^{2}\right)$ & 80 \\
Coeficiente não linear da fibra $\left(\mathrm{m}^{2} / \mathrm{W}\right)$ & $26 \times 10^{-21}$ \\
\hline
\end{tabular}

São apresentadas, na Figura 5.7, as constelações da arquitetura com distância de até 180 km, conforme os parâmetros das Tabelas 5.5 e 5.6. Os resultados foram obtidos a partir do canal 1. Neste canal, a detecção é coerente homódina (Secção 3.3). A potência óptica medida na entrada da fibra, para a exibição das constelações a seguir, é de $-6 \mathrm{dBm}$. 


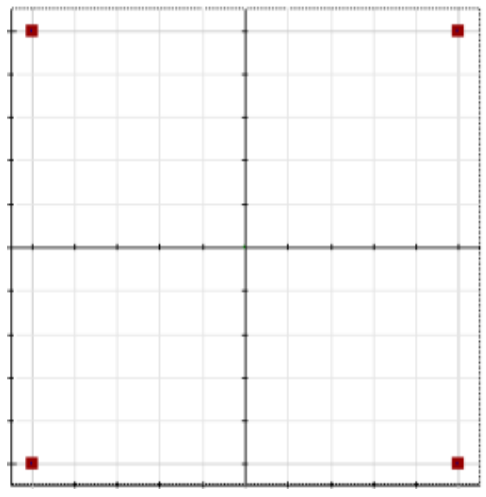

(a) Sinal elétrico QAM

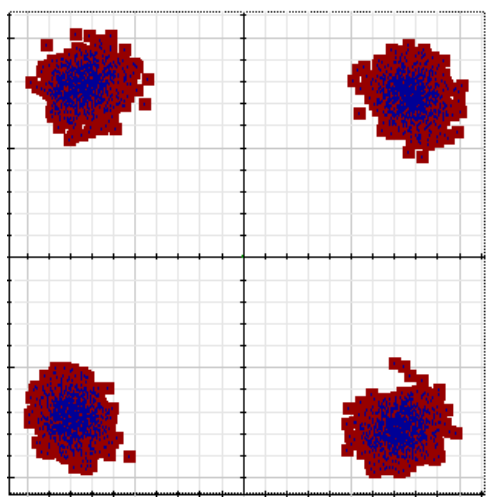

(d) $40 \mathrm{~km}$

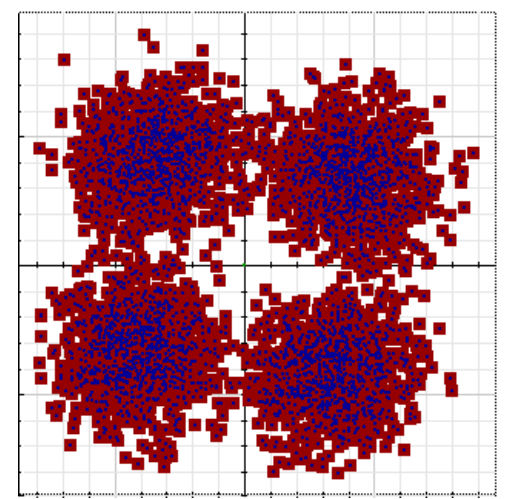

(g) $100 \mathrm{~km}$

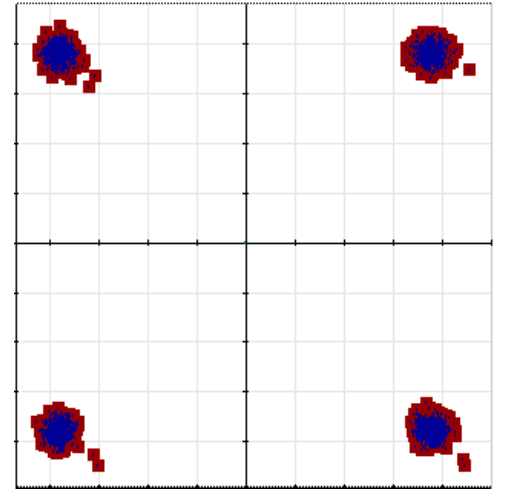

(b) back to back

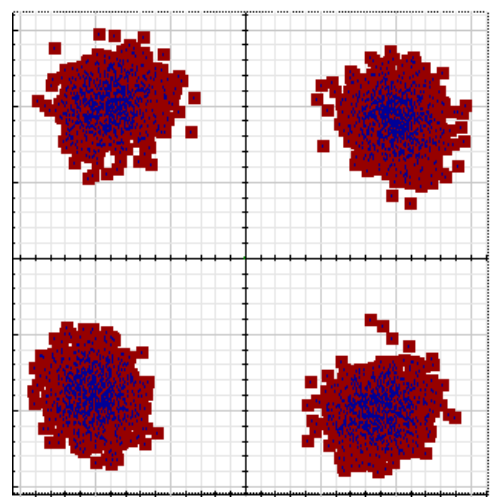

(e) $60 \mathrm{~km}$

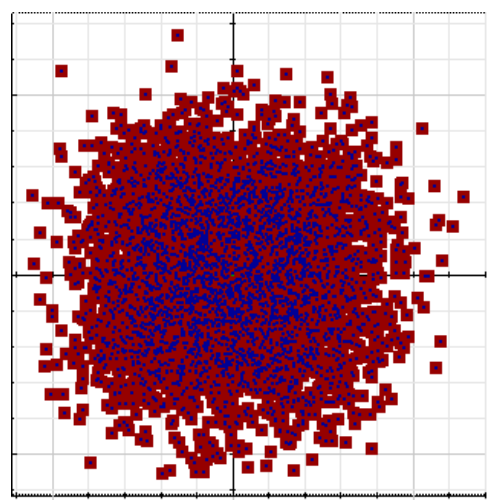

(h) $140 \mathrm{~km}$

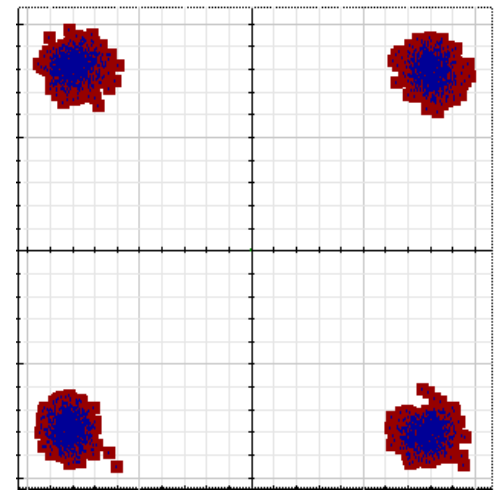

(c) $20 \mathrm{~km}$

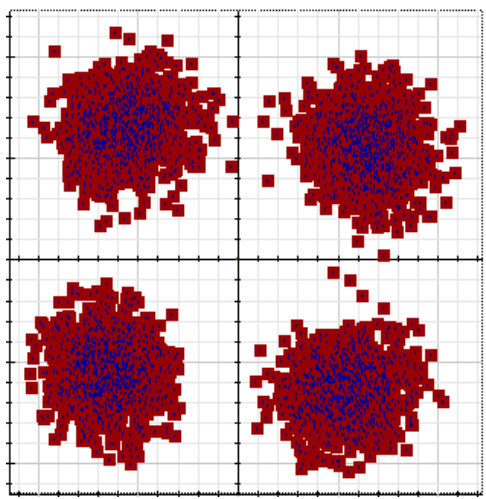

(f) $80 \mathrm{~km}$

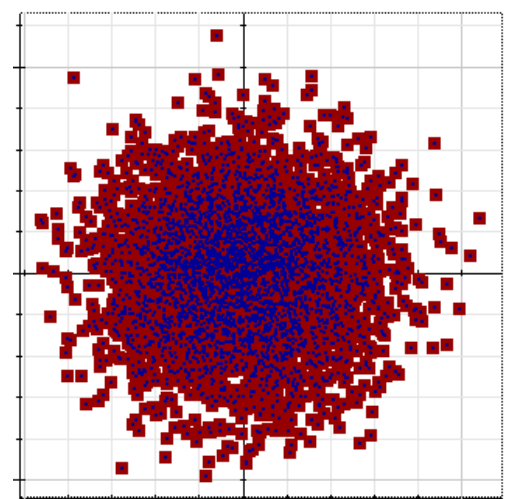

(i) $180 \mathrm{~km}$

Figura 5.7: Constelação do canal 1 da arquitetura WDM-OFDM-PON.

É mostrada, na Figura 5.7, intensa presença de efeitos de degradação, a partir da constelação de $80 \mathrm{~km}$, efeito devido, provavelmente, à inserção da arquitetura WDM com espaçamento de 0,4 $\mathrm{nm}$ entre os canais. Este espaçamento pode provocar o aparecimento de ruído de diafonia (crosstalk), na recepção, originado a partir da interferência entre os canais. A modulação de fase cruzada (XPM) e a mistura de quatro ondas (FWM), conforme 
apresentadas na Seção 4.1.2, provocam efeitos não lineares em sistemas ópticos com subcanais, como é o caso do WDM, assim, parte da degradação do sinal pode ser referida a esses efeitos.

Entretanto, o resultado da arquitetura é satisfatório, pois houve aumento da taxa total de transmissão, utilizando uma rede óptica passiva (sem filtros e amplificadores ópticos).

Conforme apresentado na Figura 5.7, sinais produzidos pelas arquiteturas WDMOFDM-PON exibem constelações com sinais menos dispersos em distâncias de até $40 \mathrm{~km}$, de acordo com [18], [17]. A simulação mostra ainda que a arquitetura WDM-OFDM-PON pode ser utilizada em redes ópticas de acesso, já que as taxas de transmissão estão em torno de 10 $\mathrm{Gb} / \mathrm{s}$ por canal [9].

É mostrado, na Figura 5.8, o gráfico BER em função do comprimento do enlace.

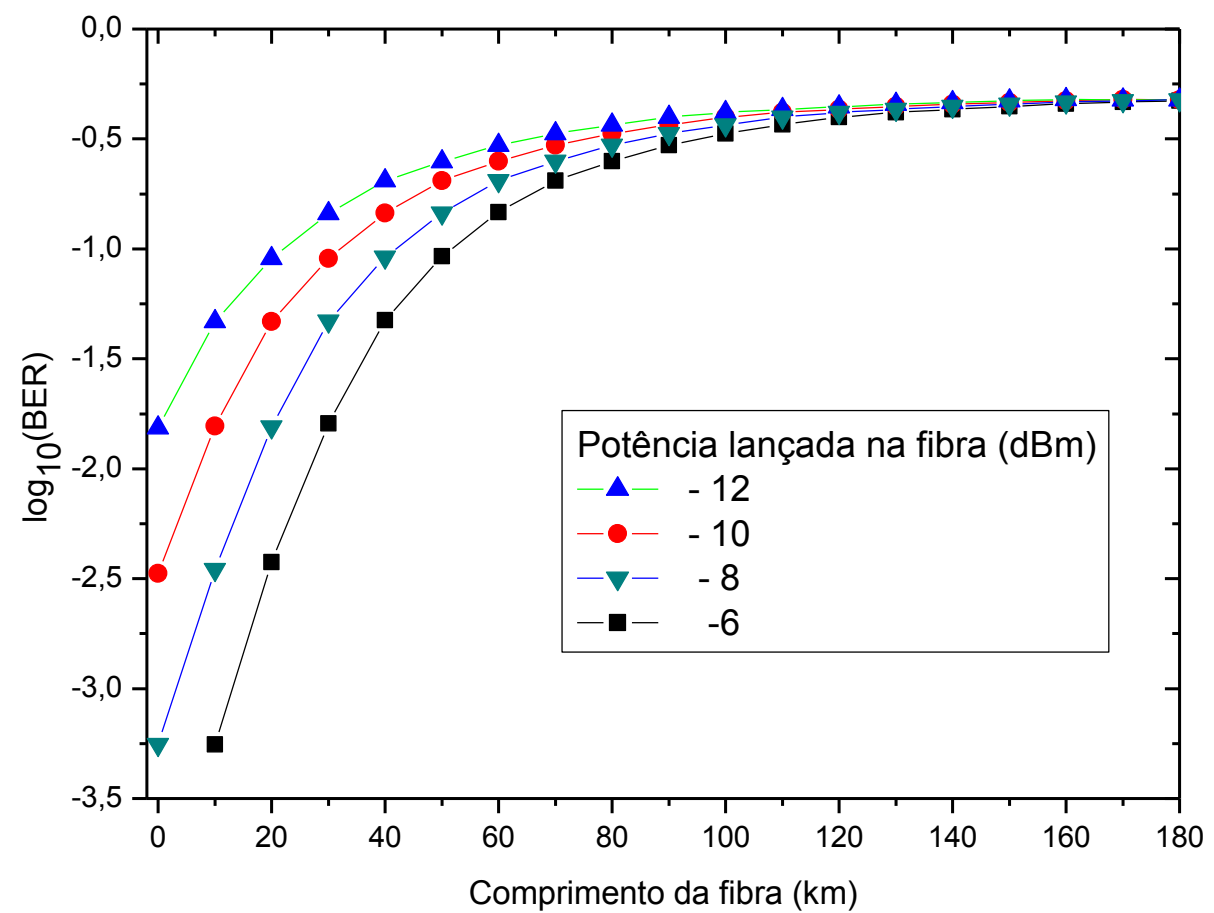

Figura 5.8: BER em função do comprimento do enlace para a arquitetura WDM-OFDM-PON com os parâmetros das Tabelas 5.5 e 5.6.

É mostrado, na Figura 5.8, que a partir do comprimento de $80 \mathrm{~km}$, a BER apresenta-se elevada, de acordo com a análise qualitativa da Figura 5.7. A elevada penalidade na taxa de bits transmitidos, como já mencionado, poderia ser melhorada com um processador digital de sinais no receptor. 


\subsection{OFDM 4-QAM de dupla polarização com detecção coerente}

Nesta seção são apresentados os resultados obtidos com as simulações da arquitetura OFDM 4-QAM de dupla polarização com detecção coerente.

A polarização dupla é uma técnica que consiste em separar e combinar as polarizações do laser com um divisor de feixe polarizador, polarization beam combiner/splitter (PBCS), possibilitando um aumento na eficiência espectral da arquitetura [19]. A arquitetura OFDM 4QAM, de dupla polarização com detecção coerente, é implementada no contexto de rede óptica passiva. Em distâncias de até $20 \mathrm{~km}$ de fibra, os resultados são satisfatórios, de acordo os gráficos mostrados a seguir. O gráfico da BER em função do comprimento do enlace e os gráficos das constelações são discutidos.

\subsubsection{Características e simulações da arquitetura OFDM 4-QAM de dupla polarização com detecção coerente}

A polarização dupla (DP- dual polarization), em conjunto com a técnica OFDM, produz elevada eficiência espectral, como discutido em [66]. A utilização de dupla polarização em sistemas de comunicação foi e continua sendo muito empregada nas comunicações móveis ao utilizar um conjunto de transmissores e receptores que permitem aumentar a capacidade do canal, em ordem direta ao número utilizado.

É apresentada, nesta seção, uma arquitetura de dupla polarização OFDM 4-QAM com detecção coerente que alcança capacidade de transmissão de $100 \mathrm{~Gb} / \mathrm{s}$, ou seja, 10 vezes maior que a capacidade da arquitetura COD OFDM 4-QAM, sem dupla polarização, já analisada nesta dissertação. Apesar do resultado satisfatório, existem desvantagens na utilização da técnica de dupla polarização, que são:

1) a polarização pode variar ao longo da fibra devido à birrefringência aleatória;

2) os dispositivos ópticos do sistema devem manter a polarização do sinal em um grau comparável ao da fibra.

Os tipos de efeitos químicos e físicos que afetam a propagação da luz polarizada podem ser: efeito fotoelástico, efeito Faraday e efeito Kerr. Em todos estes casos, alguma influência externa (força mecânica, campo magnético ou campo elétrico) é exercida sobre o 
meio óptico. Entretanto, quando controladas, permitem que um sistema de comunicação óptica apresente resultado satisfatório na capacidade de transmissão, como mostrado em [20].

As principais vantagens da técnica de dupla polarização são:

1) inserção de dois sistemas de transmissão por meio de um único canal;

2) capacidade de compensar a PMD quando o transmissor e receptor estão bem sincronizados;

O processo de separação da polarização é realizado um por divisor de feixe polarizador, que é colocado na saída do laser, como pode ser visto na Figura B.4, apêndice B. Com as polarizações ortogonais da luz, cada uma das componentes é modulada pela técnica 4QAM.

É apresentado, na Figura 5.9, a transmissão de dois sinais 4-QAM, com componentes de polarização X e Y.

(a)
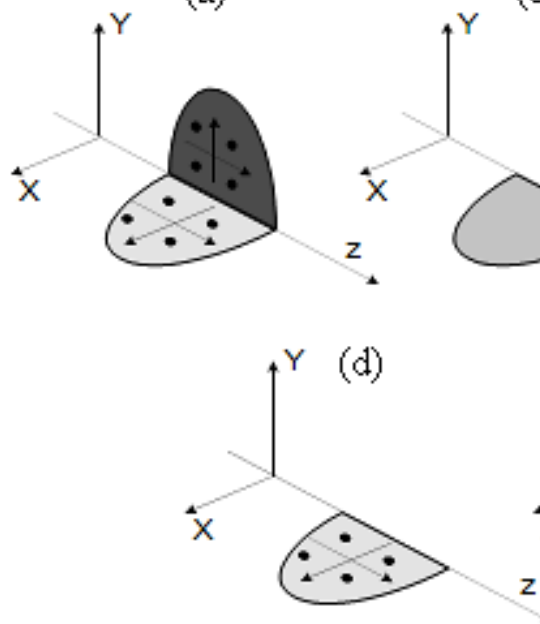

(b)
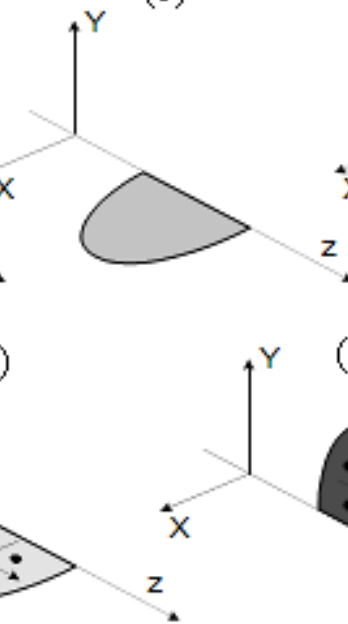

(c)
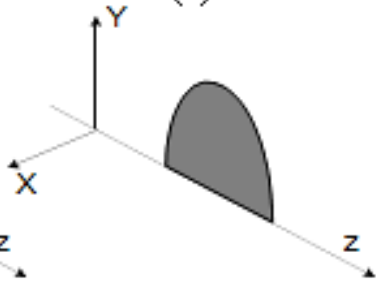

(e)

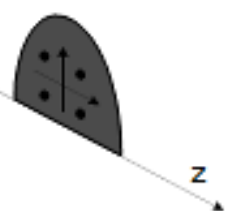

Figura 5.9: Representação de uma transmissão de polarizações ortogonais, multiplexadas e moduladas pelas técnicas OFDM-4QAM. Em (a) sinal elétrico transmitido, (b) mistura de polarização com resultante em X, (c) mistura de polarização com resultante em Y, (d) e (e) componentes de polarização sem mistura, obtidas no processo de demultiplexação [67].

Entretanto, em decorrência dos efeitos de degradação em fibras ópticas, o estado de polarização do sinal não se mantém fixo. Após a recombinação das polarizações, para os sinais serem enviados na fibra, cada componente de polarização passa a ser uma mistura das informações enviadas em cada polarização, como apresentado na Figura 5.9 (b, c).

No receptor coerente, a mistura das polarizações do sinal detectado é separada, gerando sinais independentes, com componentes de polarizações ortogonais, $\mathrm{X}$ e $\mathrm{Y}$, como mostrado nas Figuras 5.9 (d) a 5.9 (e). 
A seguir, são apresentados os resultados para a dupla polarização na configuração OFDM 4-QAM com detecção coerente. Cada polarização opera com 512 subportadoras de dados e cada uma com taxa de $97,65 \mathrm{Mb} / \mathrm{s}$, o que resulta em $50 \mathrm{~Gb} / \mathrm{s}$. A transmissão em taxas menores pelas subportadoras é um recurso da técnica OFDM para mitigar efeitos dispersivos. Como são utilizados dois sistemas de transmissão (Figura B.4, apêndice B), um para cada polarização, a taxa total de transmissão é de $100 \mathrm{~Gb} / \mathrm{s}$. Na Tabela 5.7 são apresentados os parâmetros da simulação DP-OFDM.

Tabela 5.7: Parâmetros da simulação DP-OFDM [20].

\begin{tabular}{|c|c|}
\hline Parâmetro & Valor \\
\hline Taxa de bits $(\mathrm{Gb} / \mathrm{s})$ & 100 \\
\hline Modulação & QAM \\
\hline Número de subportadoras & 512 \\
\hline Número de pontos DFT & 1024 \\
\hline Número de bit por símbolo & 2 \\
\hline Número de prefixo cíclico ${ }^{7}$ & 0 \\
\hline Frequência do laser do transmissor $(\mathrm{THz})$ & 193,1 \\
\hline Potência do laser do transmissor $(\mathrm{dBm})$ & -12 a 0 \\
\hline Frequência do laser do oscilador local (THz) & 193,1 \\
\hline Potência do laser do oscilador local (dBm) & -2 \\
\hline Largura de linha do laser do transmissor (MHz) & 0,15 \\
\hline Largura de linha do laser do oscilador local (MHz) & 0,15 \\
\hline Modulador Mach-Zehnder & $\mathrm{LiNbO}_{3}$ \\
\hline Razão de extinção do MZM $(\mathrm{dB})^{8}$ & 60 \\
\hline Responsividade do fotodiodo (A/W) & 1 \\
\hline Corrente de escuro do fotodiodo (nA) & 10 \\
\hline
\end{tabular}

\footnotetext{
${ }^{7}$ Prefixo cíclico ajustado pelo modo sweep do simulador.

${ }^{8}$ Valores menores que $60 \mathrm{~dB}$ não permitiram exibir as constelações dentro do espaço de sinais.
} 
Na Tabela 5.8 são apresentadas as características do enlace.

Tabela 5.8: Características do enlace utilizado na simulação [12].

\begin{tabular}{ll} 
Parâmetro & Valor \\
\hline Comprimento do enlace monomodo $(\mathrm{km})$ & 0 a 180 \\
Comprimento de onda de referência $(\mathrm{nm})$ & 1552,4 \\
Atenuação da fibra $(\mathrm{dB} / \mathrm{km})$ & 0,2 \\
Dispersão cromática da fibra $(\mathrm{ps} \times \mathrm{km} / \mathrm{nm})$ & 16,75 \\
Inclinação da dispersão cromática $\left(\mathrm{ps} \times \mathrm{km} / \mathrm{nm}^{2}\right)$ & 0,075 \\
Área do núcleo da fibra $\left(\mu \mathrm{m}^{2}\right)$ & 80 \\
Coeficiente não linear da fibra $\left(\mathrm{m}^{2} / \mathrm{W}\right)$ & $26 \times 10^{-21}$ \\
\hline
\end{tabular}

São mostradas, na Figura 5.10, as curvas de BER versus o comprimento do enlace. Observa-se, a partir da Figura 5.10, que em distâncias superiores a 15 km, a taxa de erro de bits é elevada quando comparada a taxa de erro em distâncias inferiores a $15 \mathrm{~km}$. Desta forma, a arquitetura com os parâmetros simulados é indicada para redes de curta distância, como as redes ópticas de acesso.

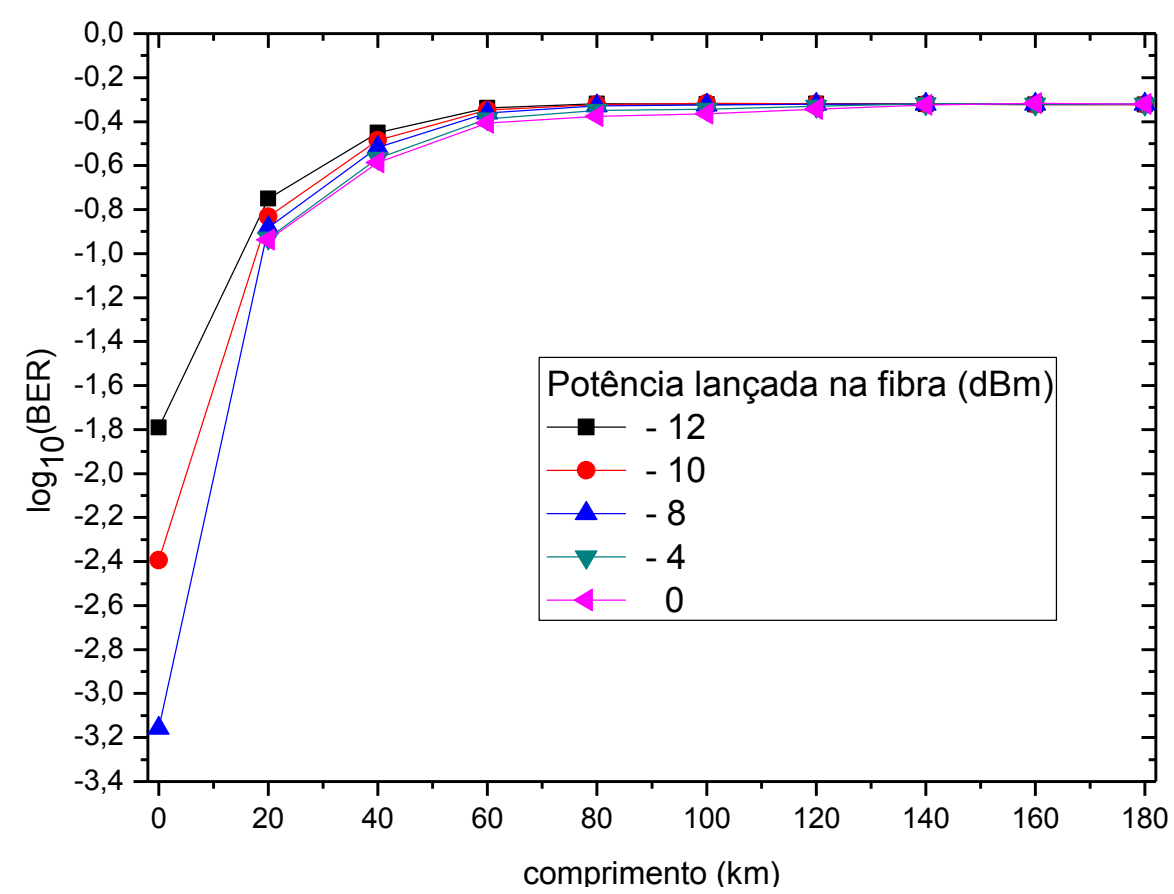

Figura 5.10: BER em função do comprimento do enlace para a arquitetura de OFDM 4-QAM de dupla polarização com detecção coerente, com os parâmetros da Tabela 5.7 e da Tabela 5.8. 
Na Figura 5.11 são mostradas as constelações da arquitetura. Estas constelações apresentam menor ruído quando comparadas com as mostradas na Figura 5.4. O desvio aleatório de fase do símbolo pode ser observado na Figura 5.11 (b), na qual existe um alongamento do símbolo (como se o símbolo fosse esticado).

Como nas constelações anteriores, o sinal está indicado na cor vermelha e o ruído na cor verde. Em azul estão indicados os pontos de indecisão do visualizador. Foi fixada a potência de $-10 \mathrm{dBm}$ na entrada da fibra para a análise das constelações a seguir.

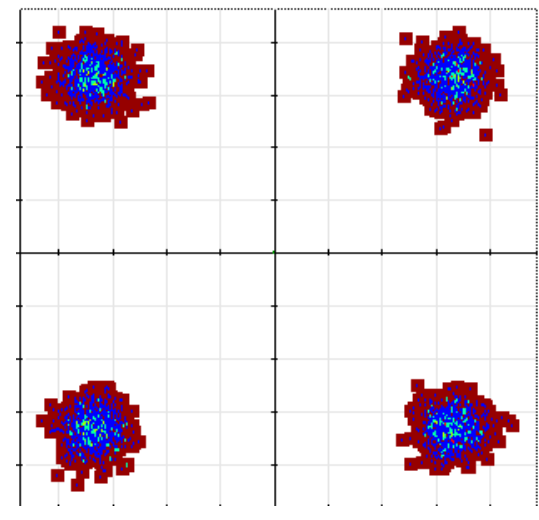

(a) back to back

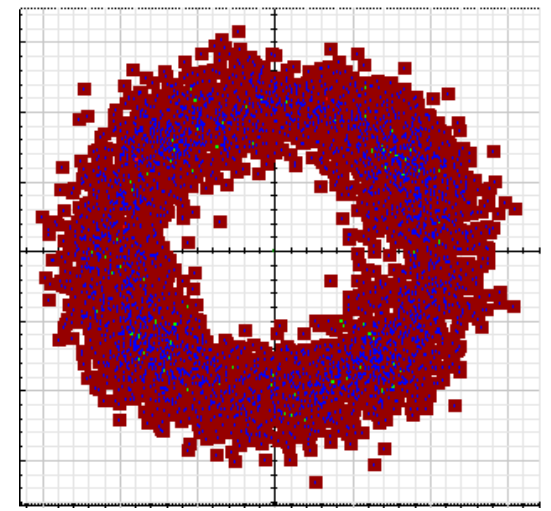

(c) $80 \mathrm{~km}$

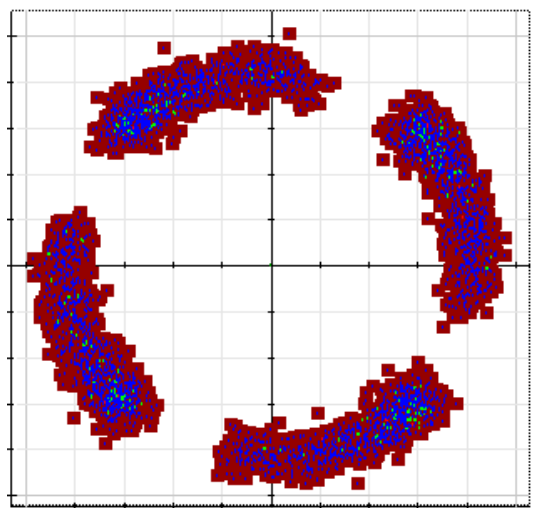

(b) $15 \mathrm{~km}$

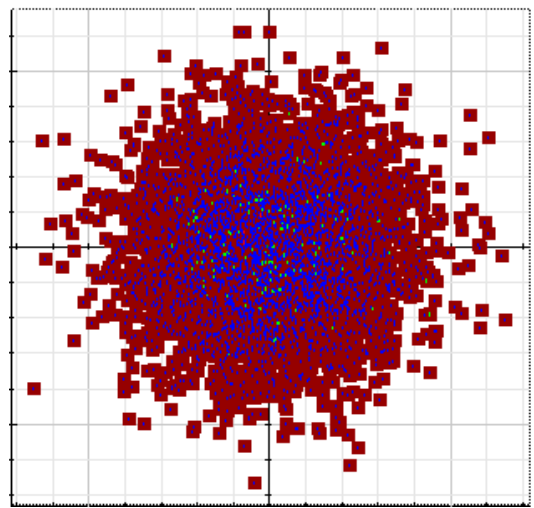

(d) $180 \mathrm{~km}$

Figura 5.11: Constelações em: (a) Constelação back to back, (b) enlace com 15 km, (c) $80 \mathrm{~km}$ e (d) $180 \mathrm{~km}$.

Dois algoritmos de processamento digital de sinal que tratam os efeitos de degradação da dupla polarização, na literatura, são os algoritmos LMS (least mean square) e o DD-LMS (direct decision LMS). Estes algoritmos potencializam o processo de equalização da constelação. O LMS é um algoritmo supervisionado, ou seja, necessita de uma sequência de treinamento para a interpretação correta da constelação de sinais. O DD-LMS é um algoritmo autodidata (Seção 2.9) [67]. 


\section{Conclusões}

Neste capítulo são relacionadas as conclusões deste trabalho. É apresentado o problema estudado, a abordagem para a solução, os resultados das simulações computacionais e a proposta para trabalhos futuros.

\subsection{Problema}

O crescimento exponencial no número de usuários que utilizam os sistemas de comunicações ópticas tem exigido das redes o aumento, cada vez mais acentuado, das taxas de transmissão. Este aumento é consequência das aplicações que exigem elevada largura de banda, como, streaming, videoconferência e compartilhamento de dados.

\subsection{Abordagem}

Para garantir a qualidade de serviços, técnicas de multiplexagem espectral e modulação avançada (OFDM-QAM) são utilizadas em comunicações ópticas como uma forma promissora de aumentar a eficiência espectral, frente aos diversos efeitos de degradação do sinal em fibra óptica, sem alterar a infraestrutura já implantada..

A abordagem deste trabalho foi realizada por meio do software comercial Optisystem. O software é uma ferramenta de simulação de sistemas de comunicação óptica que possui vasta biblioteca de componentes e recursos, o que permitiu a produção e reprodução de diversos resultados.

Assim, foram implementadas quatro arquiteturas OFDM-QAM, uma com detecção direta e três com detecção coerente, sendo todas elas inspiradas em trabalhos experimentais disponíveis na literatura. A contribuição do trabalho foi propor métricas para alcançar máxima taxa de transmissão, diminuindo os custos e a complexidade do projeto sem uso de processamento digital de sinais no receptor e a simulação de enlaces ópticos passivos em duas arquiteturas simuladas. 


\subsection{Resultados}

Neste trabalho foram utilizadas duas figuras de mérito para avaliar o desempenho das redes de comunicações ópticas: a taxa de erro de bit e a constelação de sinais. Os resultados foram apresentados em gráficos e figuras, sugerindo para qual topologia de rede óptica a arquitetura simulada é mais indicada.

\subsubsection{OFDM 4-QAM com detecção direta}

De acordo com as simulações desta pesquisa, essa arquitetura não é indicada para redes ópticas passivas, já que foi necessário o uso de amplificadores e filtros ópticos. Em distâncias superiores a $60 \mathrm{~km}$, a constelação se apresenta bem degradada. Para aumentar o desempenho da arquitetura é necessário o uso de amplificadores de linha.

\subsubsection{OFDM 4-QAM e 16-QAM com detecção coerente}

A arquitetura apresentou melhor desempenho, principalmente, devido ao controle de fase do sinal na recepção. Os amplificadores ópticos foram inseridos nas extremidades do enlace, ou seja, foram utilizados como booster e pré-amplificador, assim como na DDOFDM. Dessa forma, a análise dos resultados permitiu concluir que em distâncias de $100 \mathrm{~km}$ o sinal apresentava-se pouco degradado, assim, a arquitetura pode ser indicada para redes ópticas de acesso com alcance estendido, caso sejam utilizados parâmetros da simulação semelhantes aos utilizados neste trabalho.

\subsubsection{WDM-OFDM-PON com detecção coerente}

A arquitetura foi implementada no contexto de rede óptica passiva (não possui elementos ativos). Apesar desta condição, a arquitetura apresentou capacidade de transmissão com taxa total de $48 \mathrm{~Gb} / \mathrm{s}$, revelando-se mais eficiente que a arquitetura anterior. 
O sinal ultrapassou os $40 \mathrm{~km}$ de distância na fibra com valores de BER bem próximos aos encontrados na literatura. Concluímos que a técnica WDM pode ser implementada com a técnica OFDM permitindo, assim, alocação dinâmica de subportadora por causa da inserção da técnica OFDM. Em razão da distância, das taxas de transmissão envolvidas e por ser uma rede óptica passiva, concluímos que ela é uma forte candidata para redes ópticas de acesso.

\subsubsection{OFDM 4-QAM de dupla polarização com detecção coerente}

A arquitetura foi capaz de transmitir $100 \mathrm{~Gb} / \mathrm{s}$ em distância de até $15 \mathrm{~km}$. Após os 15 $\mathrm{km}$, o sinal apresenta forte degradação (impacto de diversos efeitos, principalmente, os dispersivos). A arquitetura foi implementada no contexto de rede óptica passiva, e utiliza apenas um divisor de polarização para transmitir os sinais polarizados. Por fim, concluímos que a arquitetura pode ser aplicada em redes ópticas de acesso.

\subsection{Propostas para Trabalhos Futuros}

As seguintes temáticas podem ser abordadas por pesquisas futuras:

1) inclusão de algoritmos para processador digital de sinal para avaliação dos sistemas com receptores de detecção direta e detecção coerente em OFDM;

2) estudar a viabilidade de aumentar a capacidade de bits por símbolo através de técnicas de modulação avançada;

3) estudar formatos de modulação e de multiplexação por meio de kits de hardware reconfigurável, os quais, incluem os FPGA (field programmable gate array), arranjo de portas programáveis em campo. Estes kits didáticos têm sido utilizados para validar resultados obtidos em softwares comerciais como Matlab e Optisystem.

4) estudar alguns projetos de processamento digital de sinais produzidos em Matlab e convertidas em linguagens de descrição de hardware reconhecidas pela indústria: VHDL ou Verilog [67]. 


\section{Referências}

[1] KAO, K.C.; HOCKHAM, G.A (1986) Dielectric-fibre surface waveguides for optical frequencies. Optoelectronics, IEE Proceedings, vol.133, n.3, pp.191-198.

[2] SEIMETZ, M. (2009). High-order modulation for optical fiber transmission. Berlin: Springer.

[3] ARMSTRONG, J. (2009). OFDM for optical communications. Journal of Lightware Technology, Washington, v. 27, n. 3, p. 198-204.

[4] VITI, R. M. (2010). Desempenho de Código Turbo Quaternário em Sistemas de Multiplexação por Divisão de Frequências Ortogonais. Dissertação (Mestrado), Faculdade de Engenharia Elétrica e de Computação, Universidade Estadual de Campinas, 2010.

[5] LUCENA, A. M. P. (2006). Estudos sobre sistemas de comunicação com sinais nãoortogonais superpostos em frequência. $134 \mathrm{f}$. Tese (Doutorado em Engenharia de Teleinformática), Universidade Federal do Ceará, 2006.

[6] SHIEH, W.; DJORDJEVIC, I. (2009). OFDM for optical communications. Amsterdam: ELSEVIER.

[7] CVIJETIC, N. (2012). OFDM for next-generation optical access networks. Journal of Lightwave Technology, Washington, v. 30, n. 4, p. 384-398.

[8] TANENBAUM, A. S. (2003). Computer networks. 4. ed. Amsterdam: Prentice Hall.

[9] Silva, G. E. V. (2010). Estudo de topologias para redes WDM-PON. Dissertação (Mestrado) - Escola de Engenharia de São Carlos, Universidade de São Carlos. 2010.

[10] COELHO, M. V. M. (2009). Simulador de receptor óptico digital de modulação de intensidade e detecção directa. Dissertação (Mestrado em Engenharia Electrotécnica e de Computadores), Universidade Técnica de Lisboa, 2009.

[11] ZANATTA FILHO, D.; FÉTY, L.; TERRÉ, M. (2007). Water-filling for cyclic prefixed single carrier transmission and MMSE receiver. In: EUROPEAN WIRELESS CONFERENCE, 13, Paris. Proceedings... Paris: SEE, 2007. p. 181-185.

[12] OPTIWAVE: design software for photonics. Disponível em: <http://www.optiwave.com/> Acesso em: 02 set. 2011.

[13] VPI Photonics. Disponível em: <http://www.vpiphotonics.com/>. Acesso em: 02 set. 2011. 
[14] XU, Z.; HUI, R.; O'SULLIVAN, M. (2009). Dual-band OOFDM system based on tandem single-sideband modulation transmitter. Optics Express, Washington, v. 17, n. 16, p. 13479-13486.

[15] BENLACHTAR, Y. et al. (2008). Experimental investigation of SPM in long-haul direct-detection OFDM systems. Optics Express, Washington, v. 16, n. 20, p. 15477-15482.

[16] JANSEN, S. L. et al. (2008). Coherent optical 25.8-Gb/s OFDM transmission over 4160km SSMF. Journal of Lightwave Technology, Washington, v. 26, n. 1, p. 6-15.

[17] CVIJETIC, N. et al. (2012). Terabit optical access networks based on WDM-OFDMAPON. Journal of Lightwave Technology, Washington, v. 30, n. 4, p. 493-503.

[18] Ming-Fang Huang. et al. (2009). Lightwave centralized WDM-OFDM-PON network employing cost-effective directly modulated laser. In: OPTICAL FIBER COMMUNICATION CONFERENCE, San Diego. Proceedings... New York: IEEE.

[19] QIAN, D. et al. (2010). 108 Gb/s OFDMA-PON With Polarization Multiplexing and Direct Detection. Journal of Lightwave Technology, Washington, v. 28, n. 4, p. 484-493.

[20] ROBERTS, K. et al. (2009). Performance of dual-polarization QPSK for optical transport systems. Journal of Lightwave Technology, Washington, v. 27, n. 16, p. 3546-3559.

[21] IP, E.; JI, P.; MATEO, E.; H. YUE-KAI; L. XU; D. QIAN; N. BAI; T.WANG; (2012). $100 \mathrm{G}$ and Beyond Transmission Technologies for Evolving Optical Networks and Relevant Physical-Layer Issues. Proceedings of the IEEE, vol.100, no.5, pp.1065-1078.

[22] MATHWORKS. Disponível em: <http://www.mathworks.com/>. Acesso em: 15 jun. 2012.

[23] RUSCHEL, O. T. (1996). Princípios da comunicação digital. EDIPUCRS.

[24] ESSIAMBRE, R. J. et al. (2010). Capacity limits of optical fiber networks. Journal of Lightwave Technology, Washington, v. 28, n. 4, p. 662-701.

[25] B. A. FOROUZAN (2004). Comunicação de dados e redes de computadores $-3^{\circ}$ Edição, Bookman.

[26] SILVEIRA, C. R. (2009). Estudo de formatos especiais de modulação digital para comunicações ópticas. Dissertação (Mestrado) - Escola de Engenharia de São Carlos, Universidade de São Carlos, 2009. 
[27] SIMON, H. (2000). Communication System. 4. ed. New York: John Wiley.

[28] GOMES, G. G. R. (1997). Modulação codificada por blocos para constelação MQAM não quadradas. Dissertação (Mestrado) - Faculdade de Engenharia Elétrica e de Computação, Universidade Estadual de Campinas, 1997.

[29] SALZ, J.; WEINSTEIN, S. B. (1969). Fourier transform communication system. In: ACM SYMPOSIUM ON PROBLEMS IN THE OPTIMIZATION OF DATA COMMUNICATIONS SYSTEMS, New York. Proceedings... New York: ACM, 1969. p. 99-128.

[30] CIMINI Jr., L. J. (1985). Analysis and simulation of a digital mobile channel using orthogonal frequency division multiplexing. IEEE Transactions on Communications, Amsterdam, v. 33, n. 7, p. 665-675.

[31] LASSALLE, R.; ALARD, M. (1987). Principles of modulation and channel coding for digital broadcasting for mobile receivers. EBU Technical Review, Geneva, n. 224, p. 168190.

[32] TELATAR, E. (1999). Capacity of Multi-Antenna Gaussian Channels. European Transactions on Telecommunications, New York, v. 10, n. 6, p. 585-595.

[33] FOSCHINI, G. J.; GANS, M. J. (1998). On limits of wireless communications in a fading environment when using multiple antennas. Wireless Personal Communications, New York, v. 6, p. 311-335.

[34] KOFFMAN, I.; ROMAN, V. (2002). Broadband wireless access solutions based on OFDM access in IEEE 802.16. IEEE Communications Magazine, Amsterdam, v. 40, n. 4, p. 96-103.

[35] SCHWARTZ, M. (2008). The origins of carrier multiplexing: Major George Owen Squier and AT\&T. IEEE Communications Magazine, New York, v. 46, n. 5, p 20-24.

[36] TOMOYUKI, K; R, OKABE; R, LUDWIG; R, ELSCHNER; C, SCHUBERT; and W, SHIGEKI (2011). Multi-stage optical FDM of 12-channel 10-Gb/s data with 20-GHz exact channel spacing using fiber cross-phase modulation with optical subcarrier signals. Opt. Express 19, B295-B300.

[37] Dutra, R. B. (2010). Avaliação do desempenho da modulação OFDM em canais HF para rádios cognitivos. Dissertação (Mestrado) - Universidade Federal do Rio de Janeiro. 
[38] MENDES, L. L. (2007). Modelos matemáticos para a estimação do desempenho de sistemas de multiplexação por divisão em frequências ortogonais. Tese (Doutorado) Faculdade de Engenharia Elétrica e de Computação, Universidade estadual de Campinas.

[39] DONIAK M. H. (2006). Estudo da transformada de Walsh-Hadamard aplicada à transmissão OFDM. Dissertação (Mestrado), Universidade Federal de Santa Catarina.

[40] Cardoso, F. A. C. M.; Lopes, E.M.; Arantes, D. S. (2008) Algoritmo concorrente com decisão suave para equalização em sistemas OFDM no domínio da frequência, $\mathbf{2 6}^{\circ}$ Simpósio Brasileiro de Telecomunicações - SBrT.

[41] J.M. Filho. Algoritmos eficientes para equalização autodidata de sinais QAM (2011). Tese (doutorado). Escola Politécnica da Universidade de São Paulo.

[42] DE PAULA, A. S. (2010). Um estudo comparativo entre os sistemas OFDM e SCCP. Dissertação (Mestrado em Engenharia Elétrica) - Escola Politécnica, Universidade de São Paulo, 2010.

[43] H. P. HSU, (2003). Comunicação analógica e digital, coleção Schaum, $2^{\circ}$ edição.

[44] HONG, Y.; VITERBO, E.; LOWERY, A. (2011). Improving the sensitivity of directdetection optical OFDM systems by pairing of the optical subcarriers. In: EUROPEAN CONFERENCE AND EXPOSITION ON OPTICAL COMMUNICATIONS, 37, Geneva. Proceedings... New York: IEEE, 2011. p 1-3.

[45] R. T. F. Gomes (2008). Transmissão de Sinais com Etiqueta Óptica em Redes Ópticas Comutadas. Dissertação (mestrado), Instituto Superior Técnico de Lisboa.

[46] LOWERY, A. J.; DU, L.; ARMSTRONG, J. (2006). Orthogonal frequency division multiplexing for adaptive dispersion compensation in long haul WDM systems. In: OPTICAL FIBER COMMUNICATION CONFERENCE, Anaheim. Proceedings... New York: IEEE, 2006.

[47] HEWITT, D.F. (2007). Orthogonal frequency division multiplexing using baseband optical single sideband for simpler adaptive dispersion compensation. In: OPTICAL FIBER COMMUNICATION CONFERENCE, Anaheim. Proceedings... New York: IEEE, 2007.

[48] PENG, W-R. et al. (2008). Experimental Demonstration of a Coherently Modulated and Directly Detected Optical OFDM System Using an RF-Tone Insertion. In: OPTICAL FIBER 
COMMUNICATION CONFERENCE, San Diego. Proceedings... New York: IEEE, 2008. Paper OMU2.

[49] SHIEH, W.; ATHAUDAGE, C. (2006). Coherent optical orthogonal frequency division multiplexing. Electronics Letters, Amsterdam, v. 42, n. 10, p. 587-589.

[50] SHIEH, W. et al. (2007). Theoretical and experimental study on PMD-supported transmission using polarization diversity in coherent optical OFDM systems. Optics Express, Washington, v. 15, n. 16, p. 9936-9947.

[51] YAMADA, E. et al. (2008). Novel no-guard interval PDM CO-OFDM transmission in 4.1 Tb/s (50 88.8-Gb/s) DWDM link over $800 \mathrm{~km}$ SMF including 50-GHz spaced ROADM nodes. In: OPTICAL FIBER COMMUNICATION CONFERENCE, San Diego. Proceedings... New York: IEEE, 2008.

[52] TANG, Y.; CHEN, W.; SHIEH, W. (2008). Study of Nonlinearity and Dynamic Range of Coherent Optical OFDM Receivers. In: OPTICAL FIBER COMMUNICATION CONFERENCE, San Diego. Proceedings... New York: IEEE, 2008.

[53] SIMÕES, F. D. (2008). Estudo do impacto do gorjeio (chirp) de transiente sobre o desempenho de sistemas de transmissão óptica com pulsos NRZ. $160 \mathrm{f}$. Tese (Doutorado) - escola de Engenharia de São Carlos, Universidade de São Paulo, 2008.

[54] WINZER, P. J.; ESSIAMBRE, R. J. (2006). Advanced optical modulation formats. Proceedings of the IEEE, New York, v. 94, n. 5, p. 952-985.

[55] KALE, K. V.; MEHROTRA, S. C.; MANZA, R. R. (2008). Advances in computer vision and information technology. New Delhi: I K International.

[56] P. C. Dainese Jr (2006). Espalhamento Brillouin em fibras de cristal fotônico. tese (doutorado), Instituto de Física Gleb Wataghin, Universidade Estadual de Campinas.

[57] G.M, Mendes (2010). Controle da razão entre a potência de pico e a potência média (PAPR) no enlace direto WiMax. Dissertação (mestrado). Universidade de Brasília.

[58] WULICH, D. (2005). Definition of efficient PAPR in OFDM. IEEE Communications Letters, New York, v. 9, n. 9, p. 832-834. 
[59] HUSSIN, S.; PUNTSRI, K.; NOE, R. (2011). Performance analysis of optical OFDM systems. In: INTERNATIONAL CONGRESS ULTRA MODERN TELECOMMUNICATIONS, 3., Paderborn. Proceedings... New York: IEEE, 2011.

[60] C. Mazzali (1997). Geração e amplificação de sinais ópticos para sistemas de comunicação de alta capacidade. Tese (doutorado), Universidade Estadual de Campinas.

[61] WONG, E. (2012). Next-Generation Broadband Access Networks and Technologies. Journal of Lightwave Technology, Washington, v. 30, n. 4, p. 597-608.

[62] CHUNG, H. S.; CHANG, S. H.; KIM, K. (2011). Companding transform based SPM compensation in coherent optical OFDM transmission. Optics Express, Washington, v. 19, n. 26, p. B702-B709

[63] S. Hussin, K. Puntsri and R. Noe, (2011). Performance analysis of optical OFDM systems. $3^{\text {rd }}$ Intern. Congress on Ultra Modern Telecommunications and Control System and Workshops ICUMT, Budapest, Hungria, pp. 1-5.

[64] HU, X. et al. (2012). Energy-efficient WDM-OFDM-PON employing shared OFDM modulation modules in optical line terminal. Optics Express, Washington, v. 20, n. 7, p. 8071-8077.

[65] QIAN, D. et al. (2010). 41.25 Gb/s Real-Time OFDM receiver for variable rate WDMOFDMA-PON transmission. In: OPTICAL FIBER COMMUNICATION CONFERENCE, San Diego. Proceedings... New York: IEEE, 2010. Paper PDPD9.

[66] Huang, Y. et al. (2009). Dual-Polarization 2x2 IFFT/FFT Optical Signal Processing for 100-Gb/s QPSK-PDM All-Optical OFDM. In: OPTICAL FIBER COMMUNICATION CONFERENCE, San Diego. Proceedings... New York: IEEE, 2009. Paper OTuM4.

[67] Cadernos CPqD Tecnologia (2011). Edição Especial: Comunicações Ópticas, vol.7, n.2,jul./dez. 


\section{Apêndice A}

É apresentada a seguir a dedução da resposta temporal p(t), (3.6).

$\mathrm{P}(\mathrm{f})$ é uma função real par e sua transforma inversa de Fourier é

$$
p(t)=2 \int_{0}^{\infty} P(f) \cos (2 \pi f t) d f=
$$

$\mathrm{P}(\mathrm{f})$ definida na expressão (3.4) pode ser escrita como

$$
P(f)=\left\{\begin{array}{l}
\frac{1}{2 W}, 0<|f|<f_{1} \\
\frac{1}{4 W}\left\{1+\cos \left[\frac{\pi\left(|f|-f_{1}\right.}{2 W-2 f_{1}}\right]\right\}, f_{1}<f<2 W-f_{1} \\
0,\left|f>2 W-f_{1}\right|
\end{array}\right.
$$

Substituindo (A.2) em (A.1)

$$
\begin{gathered}
p(t)=\frac{1}{W} \int_{0}^{f_{1}} \cos (2 \pi f t) d f+\frac{1}{2 B} \int_{f_{1}}^{2 w-f_{1}}\left[1+\cos \left(\frac{\pi\left(f-f_{1}\right)}{2 W \alpha}\right)\right] \cos (2 \pi f t) d f \\
{\left[\frac{(\sin (2 \pi f t)}{2 \pi W t}\right]+\left[\frac{\sin (2 \pi f t)}{4 \pi W t}\right]_{0}^{2 w-f_{1}}+\frac{1}{4} W\left[\frac{\sin \left(2 \pi f t+\frac{\pi\left(f-f_{1}\right)}{2 W \alpha}\right.}{2 \pi W t}\right]_{f_{1}}^{2 W-f_{1}}+\frac{1}{4 W}\left[\frac{\frac{\sin \left(2 \pi f t-\pi\left(f-f_{1}\right)\right.}{2 W \alpha}}{2 \pi t-(\pi / 2) W \alpha}\right]_{f_{1}}^{2 W-f_{1}}=} \\
=\frac{\sin \left(2 \pi f_{1} t\right)}{4 \pi W t}+\frac{\sin \left(2 \pi t\left(2 W-f_{1}\right)\right)}{4 \pi W t}-\frac{1}{4 W} \frac{\sin \left(2 \pi f_{1} t\right)+\sin \left[2 \pi t\left(2 W-f_{1}\right)\right]}{2 \pi t-(\pi / 2) W \alpha}+\frac{\sin \left(2 \pi f_{1} t\right)+\sin \left[2 \pi t\left(2 W-f_{1}\right)\right]}{2 \pi t-(\pi / 2) W \alpha}= \\
=\frac{1}{W}\left[\sin \left(2 \pi f_{1} t\right)+\sin \left[2 \pi t\left(2 W-f_{1}\right)\right]\left[\frac{1}{4 \pi t}-\frac{\pi t}{(2 \pi t)^{2}-(\pi / 2 W \alpha)^{2}}\right]=\right. \\
=\frac{1}{W}[\sin (2 \pi W t) \cos (2 \pi \alpha W t)]\left[\frac{-\left[(\pi / 2 W \alpha)^{2}\right.}{4 \pi t\left[(2 \pi t)^{2}-(\pi / 2 W \alpha)^{2}\right.}\right]=
\end{gathered}
$$


Apêndice A 86

$=\sin c(2 w t) \cos (2 \pi \alpha W t)\left[\frac{1}{1-16 \alpha^{2} W^{2} t^{2}}\right]$ 


\section{Apêndice B}

Neste apêndice são exibidas as paletas utilizadas no software Optisystem para a configuração das quatro arquiteturas OFDM simuladas nesta dissertação. São apresentadas, também, as paletas para a implementação dos sistemas não lineares simulados. Na Figura B.1 é apresentada a paleta da arquitetura OFDM 4-QAM com detecção direta. Na Figura B.2, é apresentada a paleta da arquitetura OFDM com (4-QAM e 16-QAM) com detecção coerente. Na Figura B.3, é apresentada a arquitetura WDM-OFDM-PON com detecção coerente. Os quatro sistemas de conversão da parte elétrica para a óptica do sinal da arquitetura WDMOFDM-PON estão localizados nos blocos OFDM channel e o processo de conversão é similar ao da Figura B.2.

Na Figura B.4 é apresentada a paleta da arquitetura OFDM 4-QAM de dupla polarização com detecção coerente. Em B.3 e B.4 o enlace óptico é passivo. Nas Figuras B5, B.6 e B.7 são apresentadas, respectivamente, as paletas dos sistemas que produzem os efeitos de dispersão cromática, automodulação de fase e modulação de fase cruzada de forma isolada. 


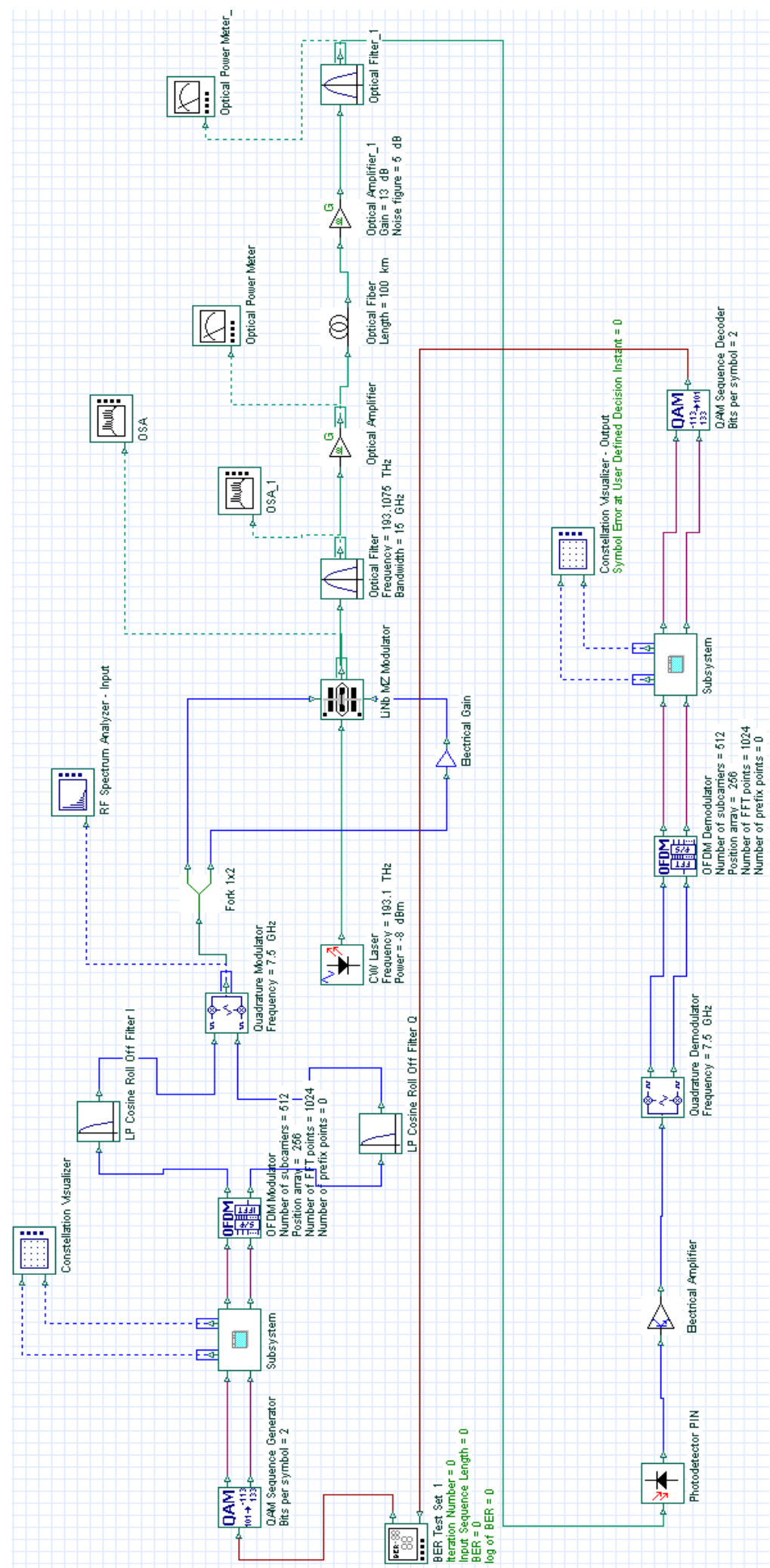

Figura B.1: Layout da arquitetura OFDM 4-QAM com detecção direta, simulado no Optisystem 9.0 [30]. 


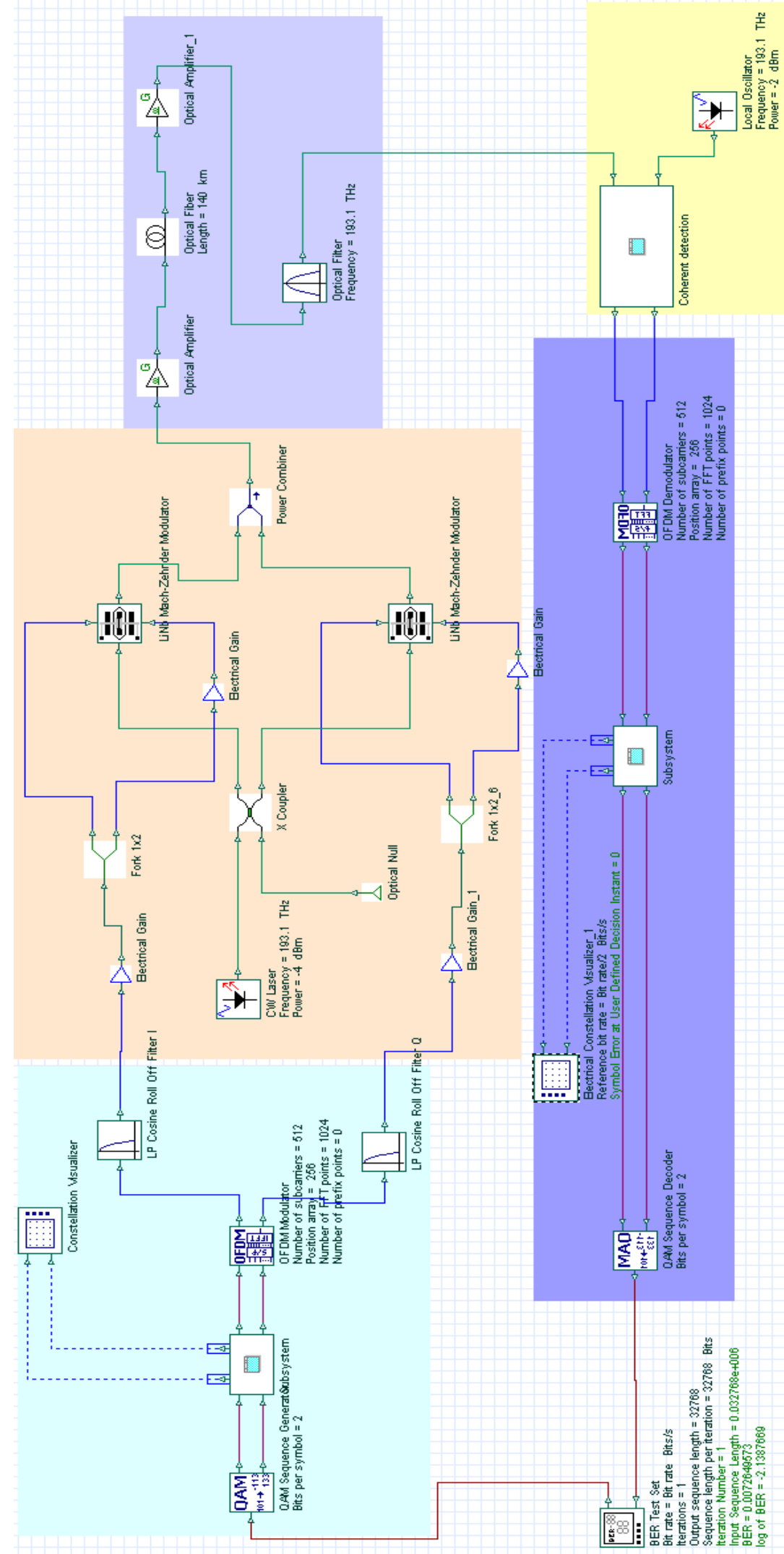

Figura B.2: Layout do sistema OFDM 4-QAM com detecção coerente, simulado no Optisystem 9.0 [30]. 


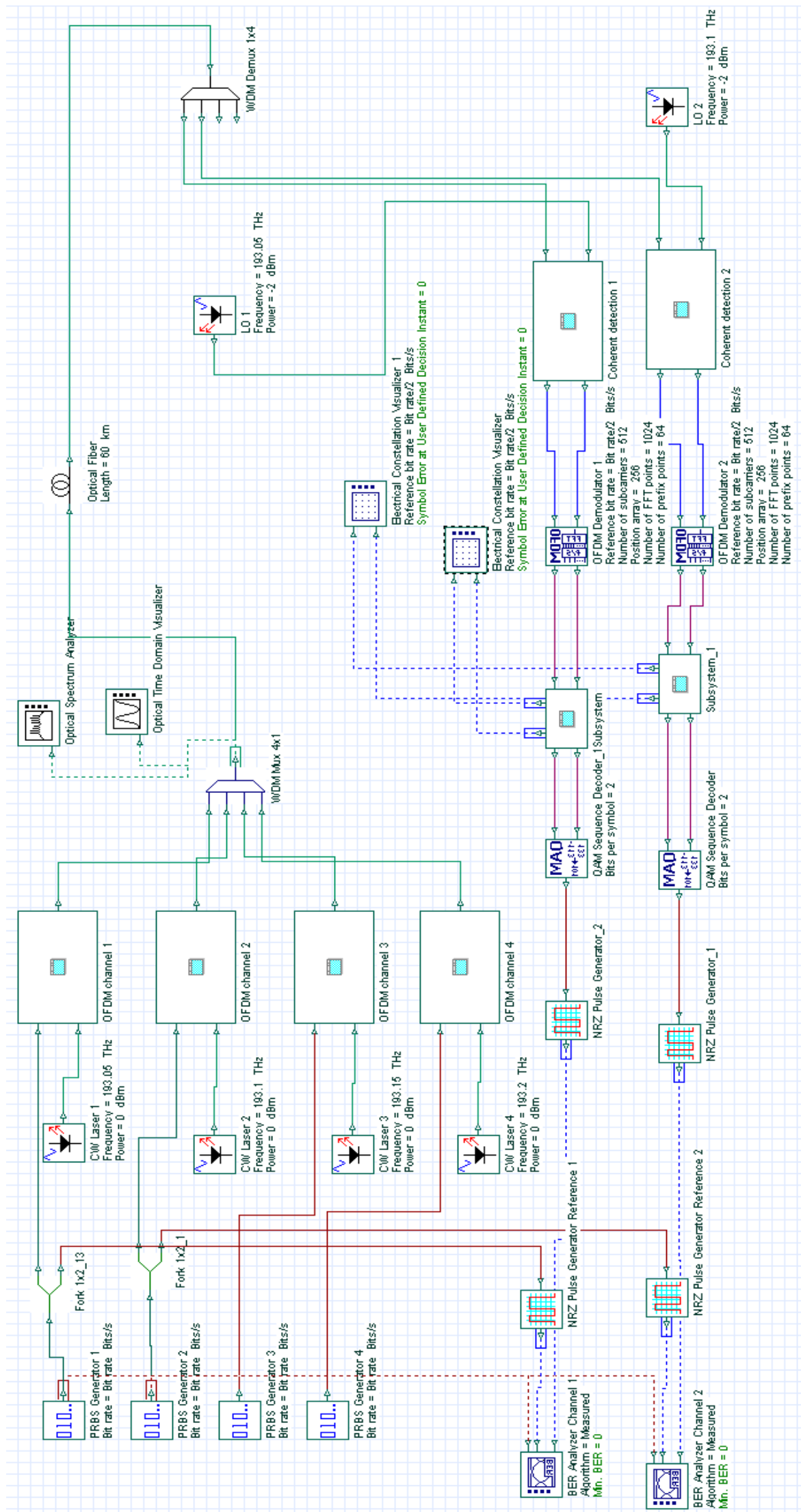

Figura B.3: Layout do sistema WDM-OFDM-PON com detecção coerente, no Optisystem 10.0 [30]. 


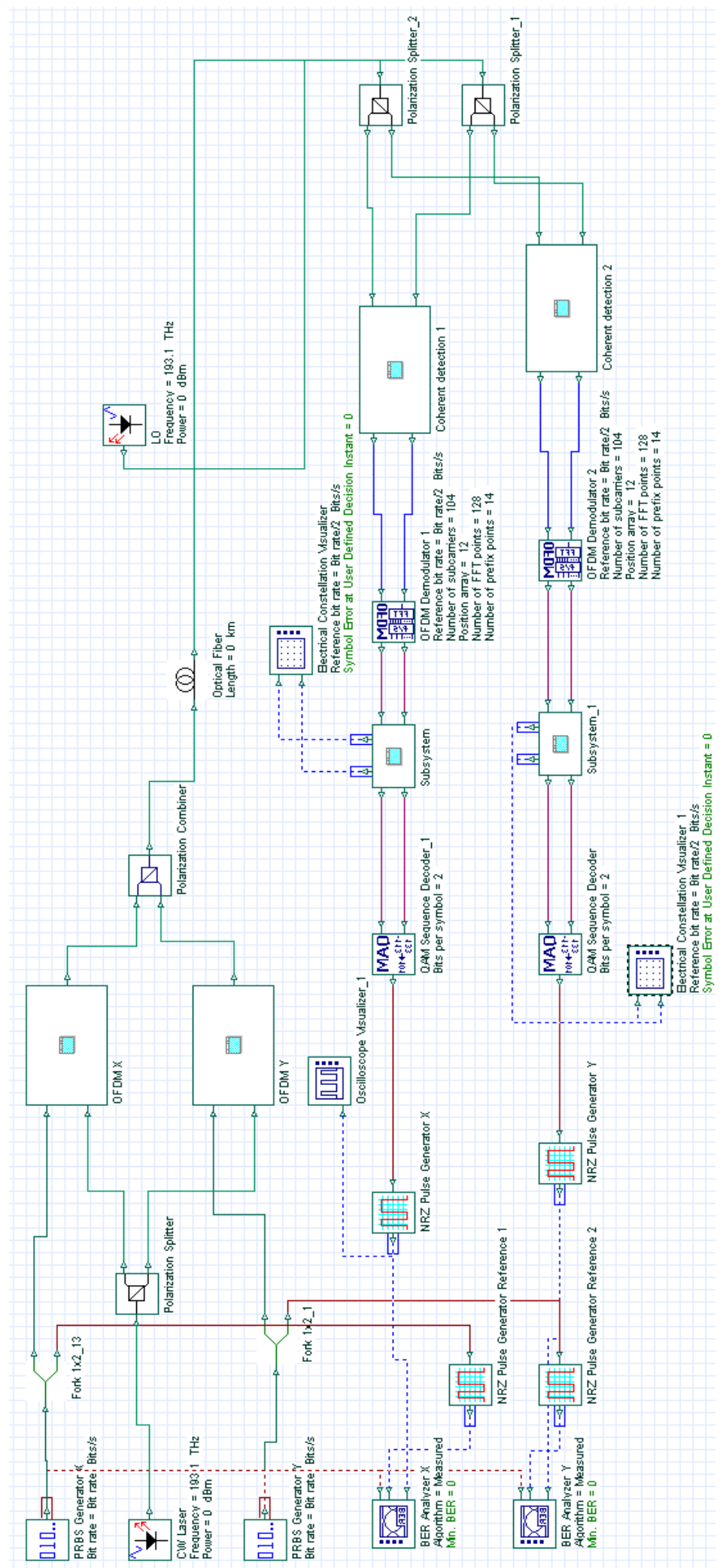

Figura B.4: Layout do sistema $100 \mathrm{~Gb} / \mathrm{s}$ COD-OFDM com dupla polarização, simulado no Optisystem $10.0[30]$. 


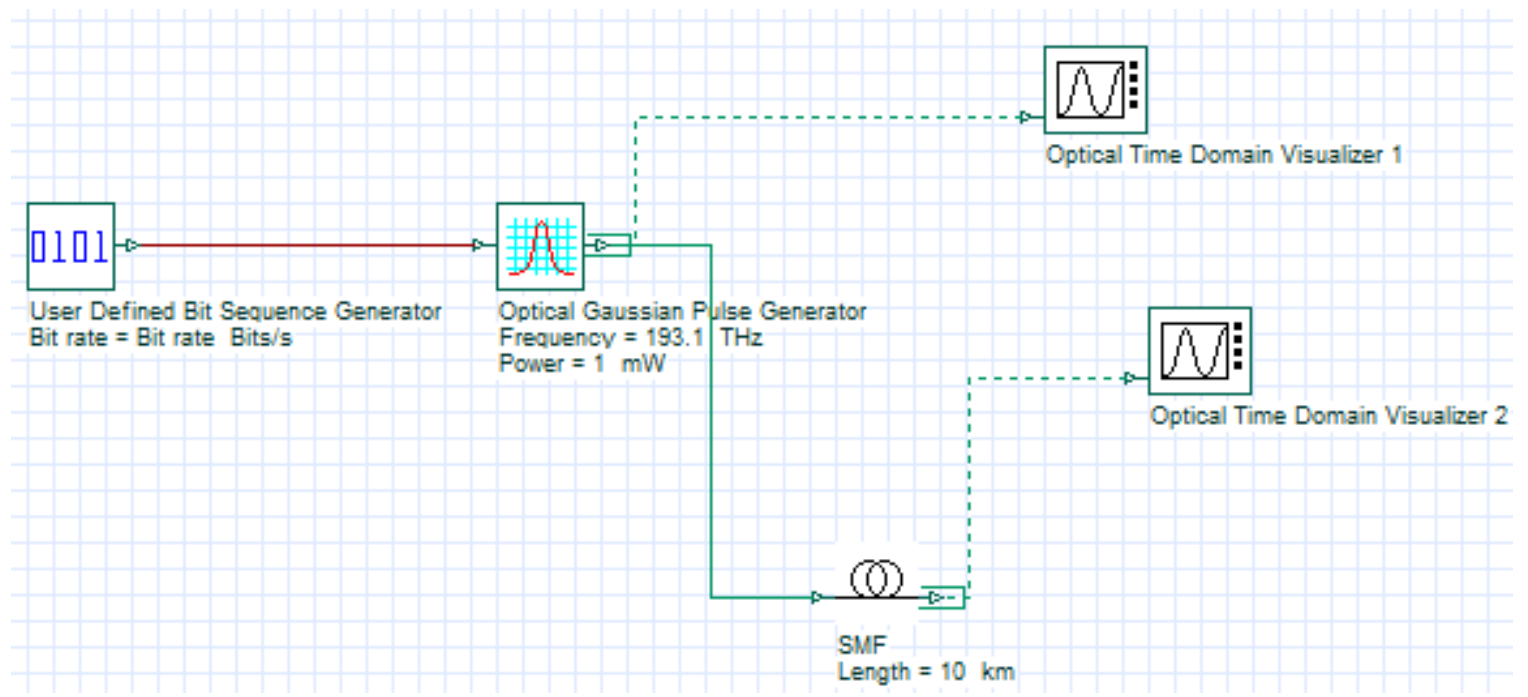

Figura B.5: Layout do sistema para o efeito de dispersão cromática.

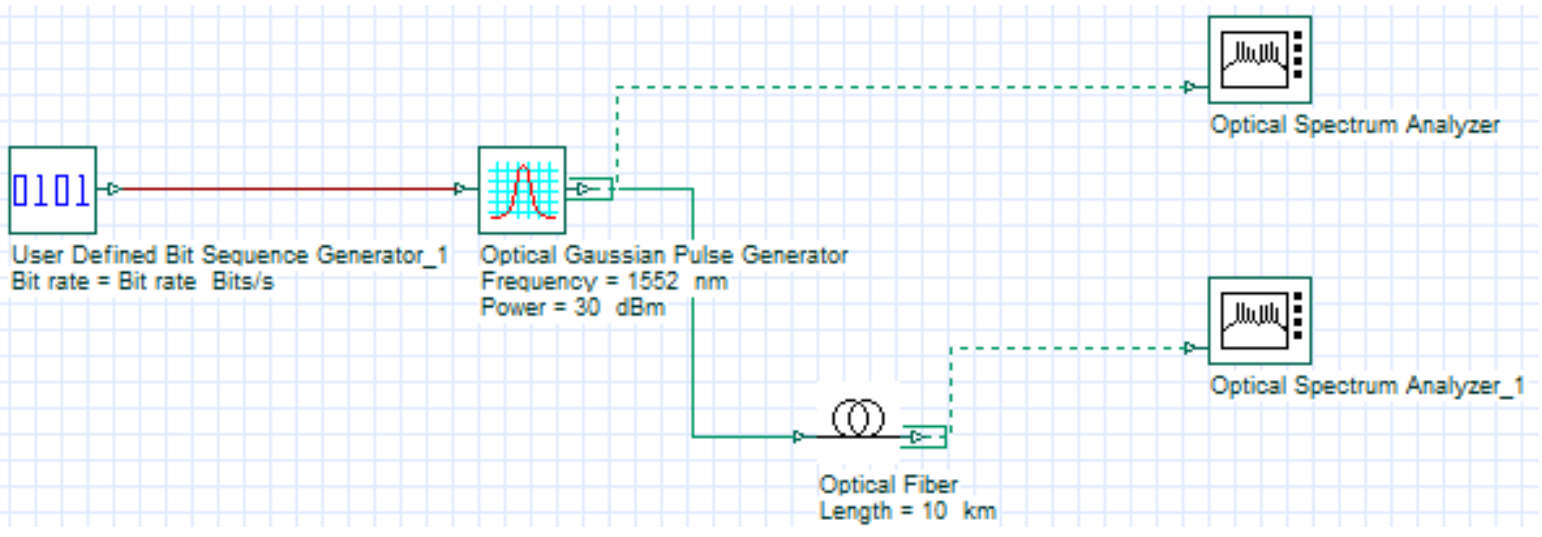

Figura B.6: Layout do sistema para o efeito de automodulação de fase. 


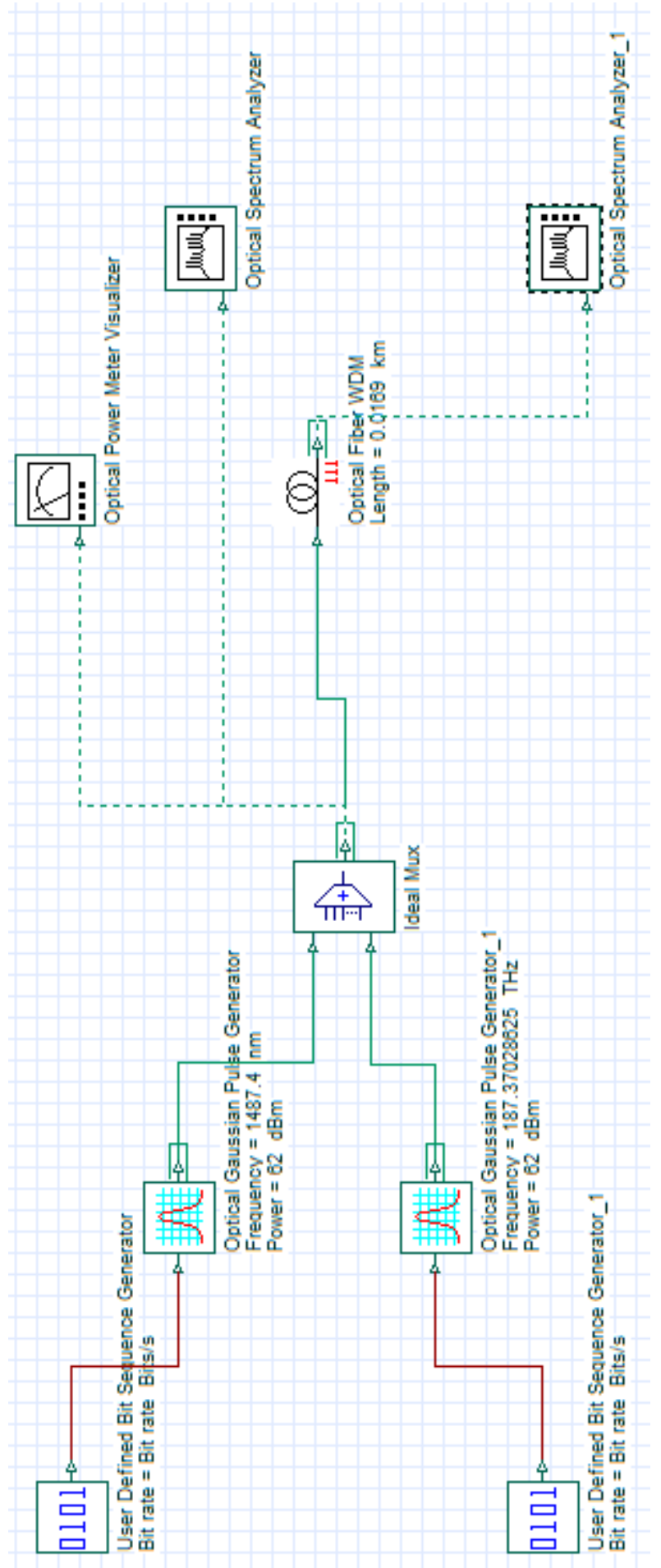

Figura B.7: Layout do sistema para o efeito de modulação de fase cruzada. 